Prepared in cooperation with the Bureau of Land Management

Climate Change Vulnerability Assessment for the California Coastal National Monument: Trinidad and Point Arena-Stornetta Units

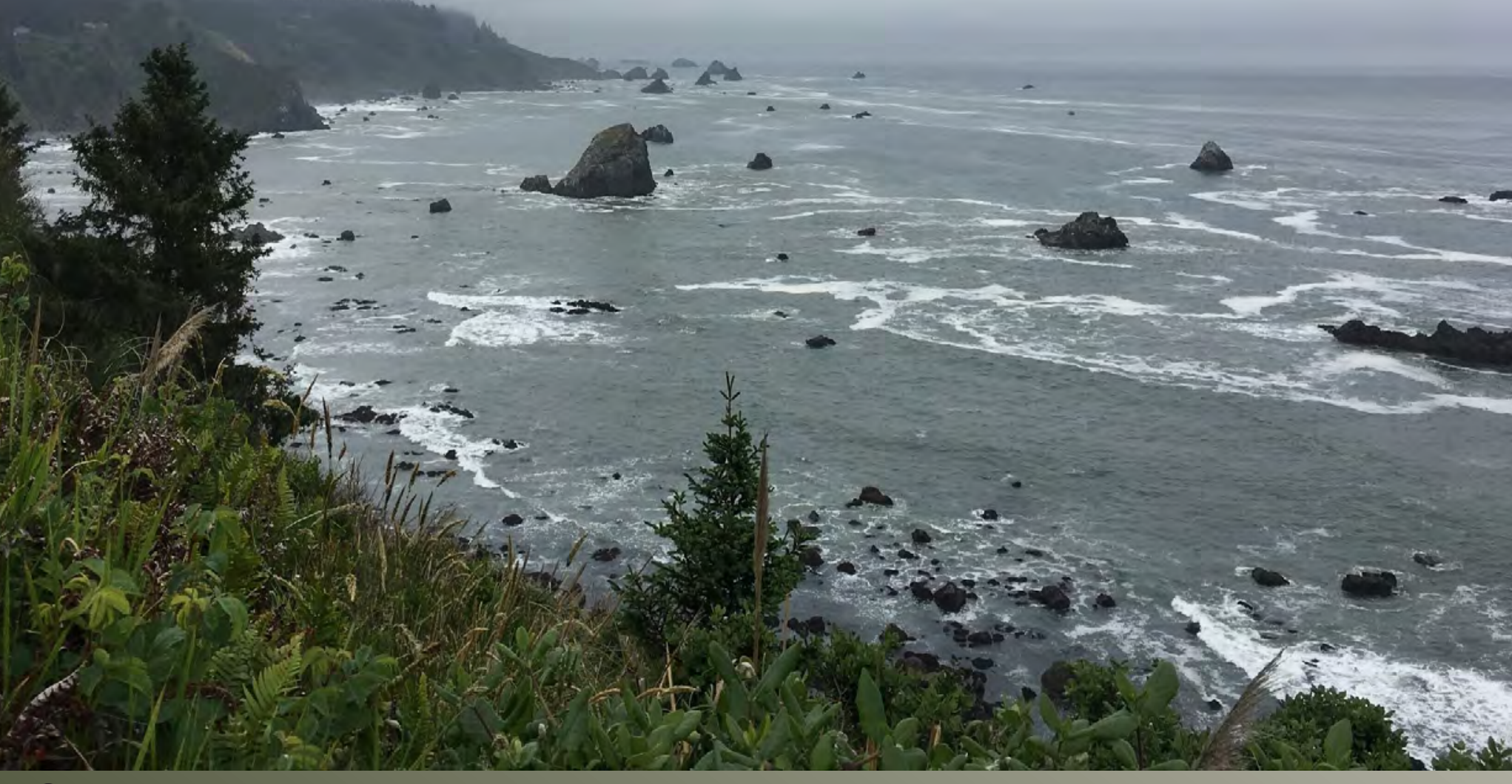

Open-File Report 2021-1050 
Cover: Trinidad-Stornetta Unit offshore rocks. Photograph taken by Karen Thorne, U.S. Geological Survey, June 2017. 


\section{Climate Change Vulnerability Assessment for the California Coastal National Monument: Trinidad and Point Arena-Stornetta Units}

By Karen M. Thorne, Chase M. Freeman, Kevin Buffington, and

Susan E.W. De La Cruz

Prepared in cooperation with the Bureau of Land Management

Open-File Report 2021-1050 


\section{U.S. Geological Survey, Reston, Virginia: 2021}

For more information on the USGS - the Federal source for science about the Earth, its natural and living resources, natural hazards, and the environment—visit https://www.usgs.gov or call 1-888-ASK-USGS.

For an overview of USGS information products, including maps, imagery, and publications, visit https://store.usgs.gov/.

Any use of trade, firm, or product names is for descriptive purposes only and does not imply endorsement by the U.S. Government.

Although this information product, for the most part, is in the public domain, it also may contain copyrighted materials as noted in the text. Permission to reproduce copyrighted items must be secured from the copyright owner.

Suggested citation:

Thorne, K.M., Freeman, C.M., Buffington, K., and De La Cruz, S.E.W., 2021, Climate change vulnerability assessment for the California coastal national monument—-Trinidad and Point Arena-Stornetta units: U.S. Geological Survey Open-File Report 2021-1050, 64 p., https://doi.org/10.3133/ofr20211050.

ISSN 2331-1258 (online) 


\section{Acknowledgments}

The project described in this report was supported by funding from the Bureau of Land Management. Support also was provided by the U.S. Geological Survey, Western Ecological Research Center. We would like to thank managers from the Bureau of Land Management, California State Parks, Trinidad Coastal Land Trust, and other stakeholders for granting us permissions for this study. We express thanks to field technicians K. Backe, and A. McCarthy who assisted with field work and data summary. Peer review was provided by J. Weigand and W. Standley. We would like to thank T. Graham for creating Figure 1 and S. Murphy for providing information on bird surveys and locations within the study areas. 



\section{Contents}

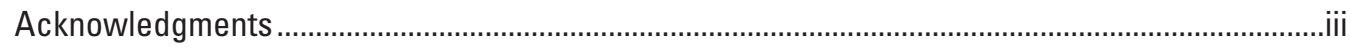

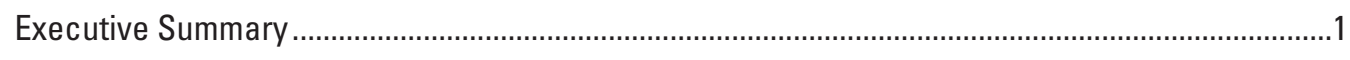

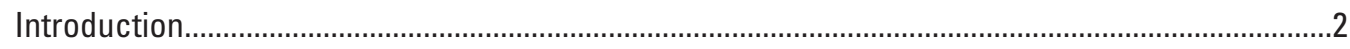

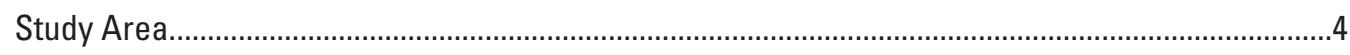

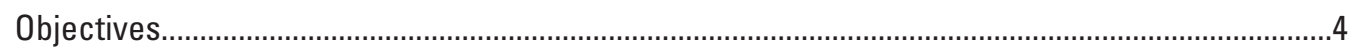

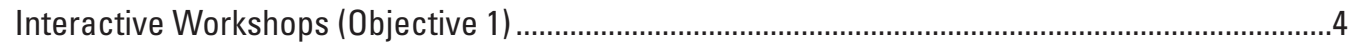

Climate Change Vulnerability Assessment (Objective 2) ................................................................

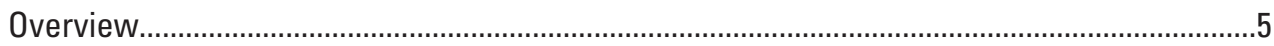

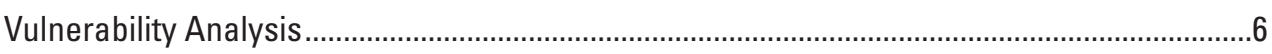

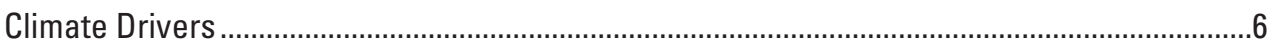

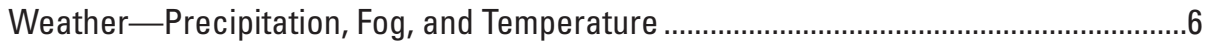

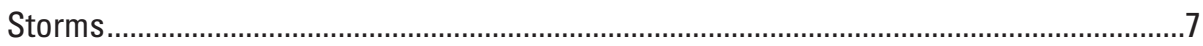

Ocean Conditions - Temperature, $\mathrm{pH}$...............................................................................

Sea-level Rise ............................................................................................................

Spatial Sea-level Rise Vulnerability Assessment (Objective 3) ......................................................

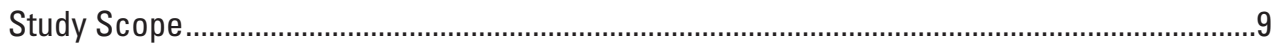

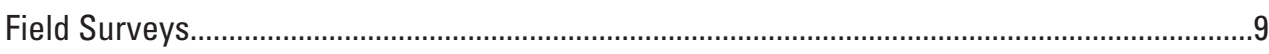

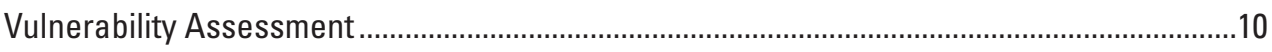

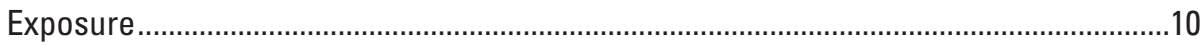

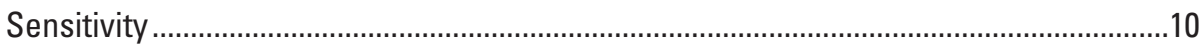

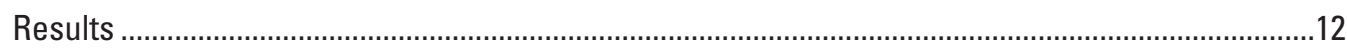

Physical and Geological Features ............................................................................12

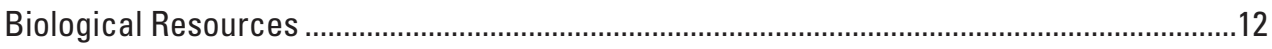

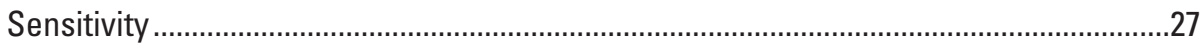

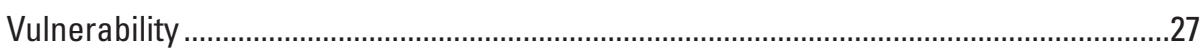

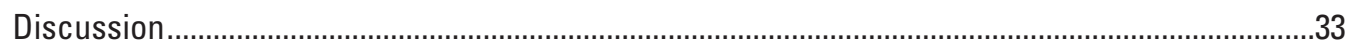

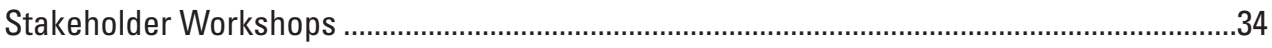

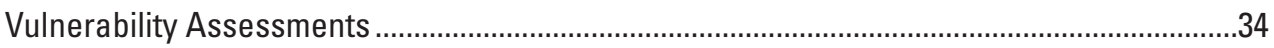

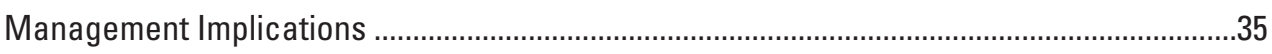

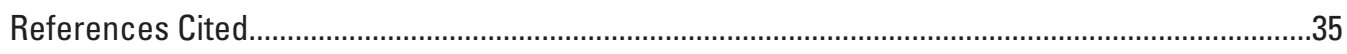

Appendix 1. California Coastal National Monument Stakeholder Workshops Summary ............40

\section{Figures}

1. Diagram showing conceptual model demonstrating the potential shift in number, area, and slope of offshore rocks and shorelines as a result of sea-level rise and subsequent changes in habitat availability for sensitive native and protected species.

2. Images showing California Coastal National Monument Trinidad and Point

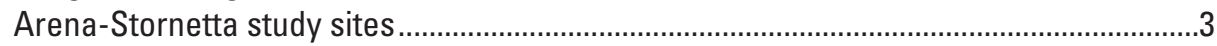

3. Images showing study extent of Trinidad and Point Arena-Stornetta Units in the California Coastal National Monument... 
4. Photographs showing boat surveys that were conducted for rocky shoreline habitats and avian and pinniped presence at the Point-Arena Stornetta and Trinidad Units

5. Images showing vulnerability analysis for the California Coastal National Monument.

6. Site map showing all 138 surveyed shoreline rocks within the Trinidad Unit used in the Vulnerability Analysis

7. Graph showing Trinidad Unit rock area versus rock height illustrates the variation in rock heights

8. Site map showing all surveyed rocks at the Point Arena-Stornetta Unit

9. Graph showing Point Arena-Stornetta Unit rock areas versus rock heights illustrates that mostly small rocks were in the area but varied in height

10. Graph showing exposure category related to size and shape of each surveyed offshore rock feature within the Trinidad Unit

11. Graph showing bird species observed and total count within the Trinidad Unit............22

12. Graph showing Pinniped species observed and total count for Trinidad Unit................23

13. Images showing number of avian and mammal species observed during boat surveys, by rock feature, in the Trinidad Unit

14. Images showing number of individual avian and mammals observed during boat surveys, by rock feature, in the Trinidad Unit

15. Images showing counts of three indicator species by rock feature .24

16. Graph showing bird species observed and total count within Point Arena-Stornetta Unit.

17. Images showing number of avian and mammal species observed during boat surveys, by rock feature, in Point Arena-Stornetta Unit

18. Images showing number of individual birds and mammals observed during boat surveys, by rock feature, in Point Arena-Stornetta Unit.

19. Graph showing sensitivity ranking relative to rock exposure classification for the Trinidad Unit.

20. Images showing Trinidad Unit offshore rocks and their associated exposure, sensitivity, and vulnerability scores.

21. Images showing Trinidad Unit exposure, sensitivity, and vulnerability scores based on an inverse distance weighted raster heat map

22. Images showing number of avian and mammal species observed by rock feature in relation to exposure of the study area.

23. Graph showing sensitivity ranking relative to rock exposure classification for the Point Arena-Stornetta Unit.

24. Images showing Point Arena-Stornetta Unit offshore rocks and their associated exposure, sensitivity, and vulnerability scores.

25. Images showing Point Arena-Stornetta Unit exposure, sensitivity, and vulnerability scores based on an inverse distance weighted raster heat map.

26. Images showing number of avian and mammal species observed by rock feature in relation to exposure at the Point Arena-Stornetta Unit.

27. Graph showing comparison of Bureau of Land Management 2017 Trinidad nesting surveys and U.S. Geological Survey 2017 post-breeding surveys of major seabird colony rocks with their associated rock exposure

28. Images showing Bureau of Land Management species richness data for Trinidad major seabird colonies compared to our vulnerability scores 


\section{Tables}

1. Definition of terms used for this vulnerability assessment..................................................5

2. Exposure ranking based on rock height and area ..........................................................11

3. Summary of data collected on rocky shoreline habitats within Trinidad and Point Arena-Stornetta Units..

4. All rocky shoreline habitats within Trinidad and Point Arena-Stornetta Units ...............17

5. List of all avian and pinniped species observed during boat surveys in Trinidad Unit occupying offshore rocks

6. List of all species observed within the Point Arena-Stornetta Unit..................................26

\section{Conversion Factors}

International System of Units to U.S. customary units

\begin{tabular}{|c|c|c|}
\hline Multiply & By & To obtain \\
\hline \multicolumn{3}{|c|}{ Length } \\
\hline centimeter $(\mathrm{cm})$ & 0.3937 & inch (in.) \\
\hline millimeter (mm) & 0.03937 & inch (in.) \\
\hline meter $(\mathrm{m})$ & 3.281 & foot $(\mathrm{ft})$ \\
\hline kilometer $(\mathrm{km})$ & 0.6214 & mile (mi) \\
\hline kilometer $(\mathrm{km})$ & 0.5400 & mile, nautical (nmi) \\
\hline meter (m) & 1.094 & yard (yd) \\
\hline \multicolumn{3}{|c|}{ Area } \\
\hline hectare (ha) & 0.003861 & square mile $\left(\mathrm{mi}^{2}\right)$ \\
\hline square meter $\left(\mathrm{m}^{2}\right)$ & 0.0002471 & acre \\
\hline square meter $\left(\mathrm{m}^{2}\right)$ & 10.76 & square foot $\left(\mathrm{ft}^{2}\right)$ \\
\hline \multicolumn{3}{|c|}{ Rate } \\
\hline millimeter per year $\left(\mathrm{mm} \mathrm{yr}^{-1}\right)$ & 0.03937 & inch per year (in $\mathrm{yr}^{-1}$ ) \\
\hline centimeters per year $\left(\mathrm{cm} \mathrm{yr}^{-1}\right)$ & 0.3937 & inch per year (in $\mathrm{yr}^{-1}$ ) \\
\hline
\end{tabular}

Temperature in degrees Fahrenheit $\left({ }^{\circ} \mathrm{F}\right)$ may be converted to degrees Celsius $\left({ }^{\circ} \mathrm{C}\right)$ as follows:

$$
{ }^{\circ} \mathrm{C}=\left({ }^{\circ} \mathrm{F}-32\right) / 1.8 \text {. }
$$

\section{Datum}

Vertical coordinate information is referenced to the North American Vertical Datum of 1988 (NAVD 88). 
viii

\section{Abbreviations}

$\begin{array}{ll}\text { BLM } & \text { Bureau of Land Management } \\ \mathrm{CO}_{2} & \text { carbon dioxide } \\ \text { CCNM } & \text { California Coastal National Monument } \\ \text { HSD } & \text { Honestly Significant Difference } \\ \text { ISD } & \text { Inverse Simpson diversity } \\ \text { SLR } & \text { sea-level rise } \\ \text { USGS } & \text { U.S. Geological Survey }\end{array}$




\title{
Climate Change Vulnerability Assessment for the California Coastal National Monument: Trinidad and Point Arena-Stornetta Units
}

\author{
By Karen M. Thorne, ${ }^{1}$ Chase M. Freeman, ${ }^{1}$ Kevin Buffington, ${ }^{1}$ and Susan E.W. De La Cruz ${ }^{2}$
}

\section{Executive Summary}

- The California Coastal National Monument protects islets, reefs, and rock outcropping habitats in six onshore units, including the Trinidad and Point Arena-Stornetta Units.

- The California Coastal National Monument provides crucial habitat for resident and migratory species of seabirds, marine mammals, and invertebrates, which includes several federally listed threatened and endangered species. Also, the California Coastal National Monument encompasses important tribal, cultural, and historical sites along the coastline of California.

- We used three approaches to assess the climate change vulnerability of the Trinidad and Point Arena-Stornetta Units: (1) a qualitative approach using peer-reviewed literature and previous work done in the Climate Change Vulnerability Assessment for the North-central California Coast and Ocean (Hutto and others, 2015), (2) interactive workshops with local stakeholders to identify specific resources, and (3) spatial analysis to estimate sea-level rise vulnerability for the rocky shoreline and key resources within the units.

- Information from stakeholder workshops held (in 2017) in the cities of Point Arena and Trinidad identified climate change impacts as an important management concern for the resilience, health, and ecosystem services of the California Coastal National Monument units. Impacts that were identified included sea-level rise, changes in precipitation and fog, warming oceans, and loss of species (birds, fisheries, marine mammals).

${ }^{1}$ U.S. Geological Survey, Western Ecological Research Center, Davis Field Station, One Shields Ave, Davis, CA, 95616

${ }^{2}$ U.S. Geological Survey, Western Ecological Research Center, San Francisco Bay Estuary Field Station, P.O. Box 158, Moffett Field, CA, 94035
- Boat surveys were done for each unit to estimate the number of rocky features and the biota using the rocks. At the Trinidad Unit, 138 rocks were surveyed and 17 different wildlife species were observed, whereas at the Point Arena-Stornetta Unit, 40 rocks were surveyed and 10 different wildlife species were observed.

- Individual rocky features surveyed within the units were then ranked on sea-level rise exposure and vulnerability scales with 1 being the least vulnerable/exposed and 5 the most.

- Forty-nine and fifty-eight percent of surveyed rocks had a sea-level rise exposure ranking of 4 or 5 (high) for the Trinidad Unit and Point Arena-Stornetta Units respectively.

- Forty-eight percent of offshore rocks had a sea-level rise vulnerability score of 3 or greater (high) for the Trinidad Unit, and forty-three percent of rocks had a vulnerability score of 3 or greater for the Point Arena-Stornetta Unit.

- When examining guild use of vulnerable rocks (vulnerability score greater than 3 ), at the Trinidad Unit alcid species (here defined as common murres and pigeon guillemots) were observed on only 28 percent of vulnerable rocks, shorebirds on 30 percent, sea lions on 40 percent, gulls on 43 percent, seabirds on 58 percent, and mammals on 75 percent, whereas at the Point Arena-Stornetta Unit alcid species were observed on 0 percent of vulnerable rocks, gulls on 33 percent, seabirds on 57 percent, and mammals on 50 percent.

- Sea-level rise has the potential to submerge small low-relief offshore rocks and make them uninhabitable for birds and marine mammals but could provide more intertidal and subtidal rocky habitats. We found that nearly half of the offshore rocks at both sites are vulnerable and have the potential to realize this outcome; however, the larger and tall-relief rocks at these sites are less vulnerable to sea-level rise and are expected to continue to provide habitat for avian species. 


\section{Introduction}

Climate change can negatively affect rocky shoreline habitats and productivity in several ways (Hutto and others, 2015). Atmospheric warming is expected to accelerate the current rate of sea-level rise (SLR), inundating many low-lying coastal and intertidal areas, submerging low relief habitats (Cloern and others, 2016), and posing a threat to important coastal resources (Mitchell and others, 2015). Changing climate also is projected to alter precipitation amounts and timing, air and water temperatures, and overall storm patterns (Intergovernmental Panel on Climate Change, 2014), including more frequent extreme wave events (fig. 1). Many coastal areas are already experiencing early impacts of climate change, including drought, flooding from SLR, and increasing storm intensity and frequency (Griggs and others, 2017, Vitousek and others, 2017).

Sea-level rise could result in the loss and isolation of rocky shoreline island features and pose a threat to wildlife species that depend on these islands as crucial resting and nesting habitats (fig. 1). However, new offshore rocky islands could be created as mainland areas are cleaved off through increased erosional impacts. Vulnerability of biological resources is mediated by characteristics of species' ecology, particularly selection of feeding grounds and nest sites, phenology, and species competition. Marine mammal species use low-lying offshore rocks to haul out and rest between feedings. Particularly, bird species with strong site fidelity, such as the black oystercatcher (Haematopus bachmani), could be more vulnerable to environmental changes because of their limited dispersal ability (Johnson and others, 2010). Other migratory birds (for example, Brandt's cormorant [Phalacrocorax. penicillatus], common murre [Uria aalge], western gull [Larus occidentalis]) also use these offshore features for roosting and nesting (Buchanan and others, 2001). The loss of these species could have significant effects on the biodiversity and functions of rocky shoreline ecosystems.

Vulnerability assessments are an important tool for informing adaptation planning because they consider uncertainty about future climate. Such assessments can help managers and other resource professionals plan and implement actions to lessen climate impacts to important resources such as in rocky shoreline ecosystems. The California Coastal National Monument (CCNM) protects coastline that is nationally recognized for its scenic beauty and diverse array of biological, cultural, and physical resources, including rocky intertidal communities, habitat for seabirds, marine mammals, invertebrates and plant species, and important cultural and historical sites. In this study, we used a vulnerability assessment approach to identify the rocky shoreline features and species that could be the most affected by climate change and SLR within two subunits of the CCNM (fig. 2).

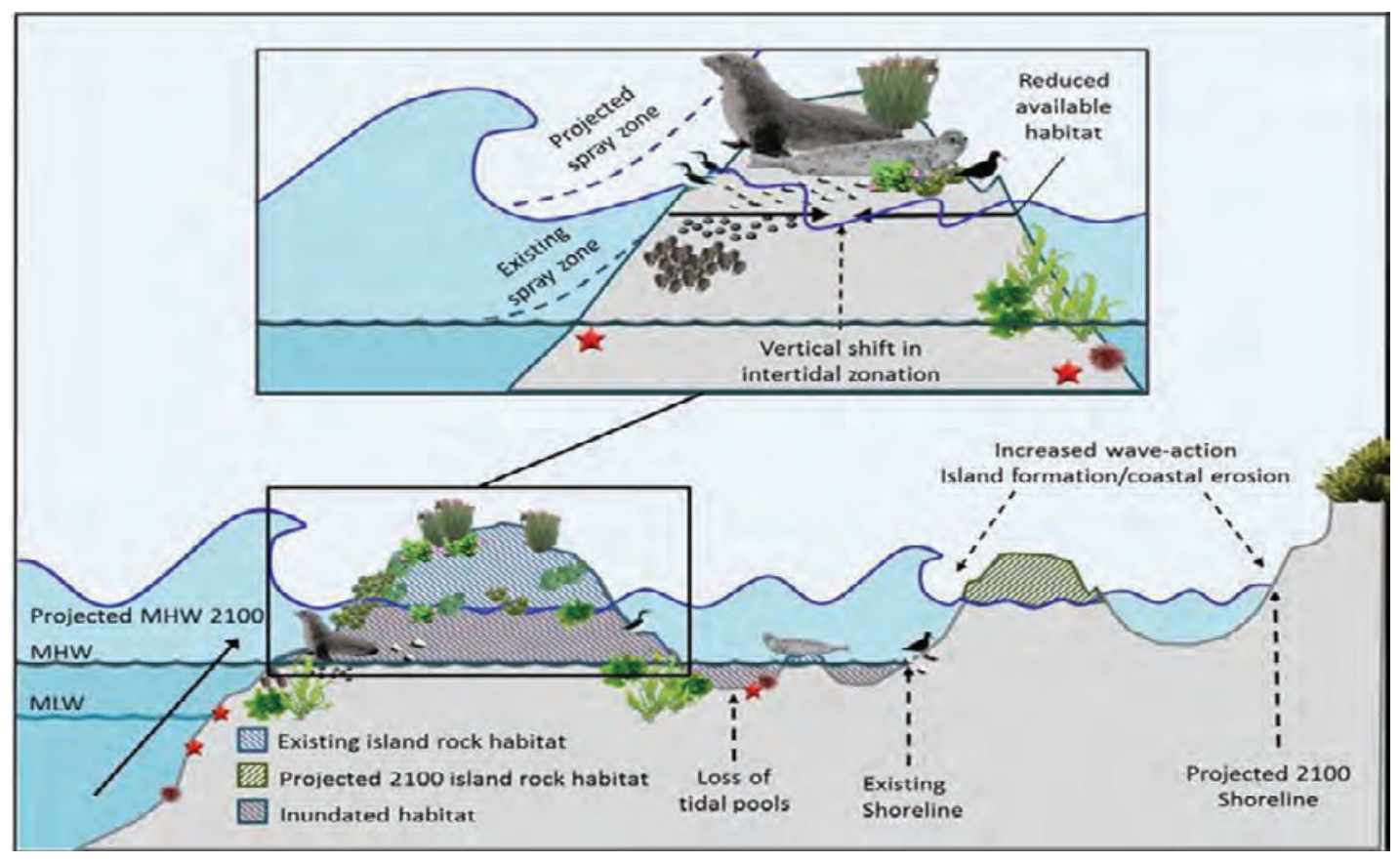

Figure 1. Conceptual model demonstrating the potential shift in number, area, and slope of offshore rocks and shorelines as a result of sea-level rise and subsequent changes in habitat availability for sensitive native and protected species. 

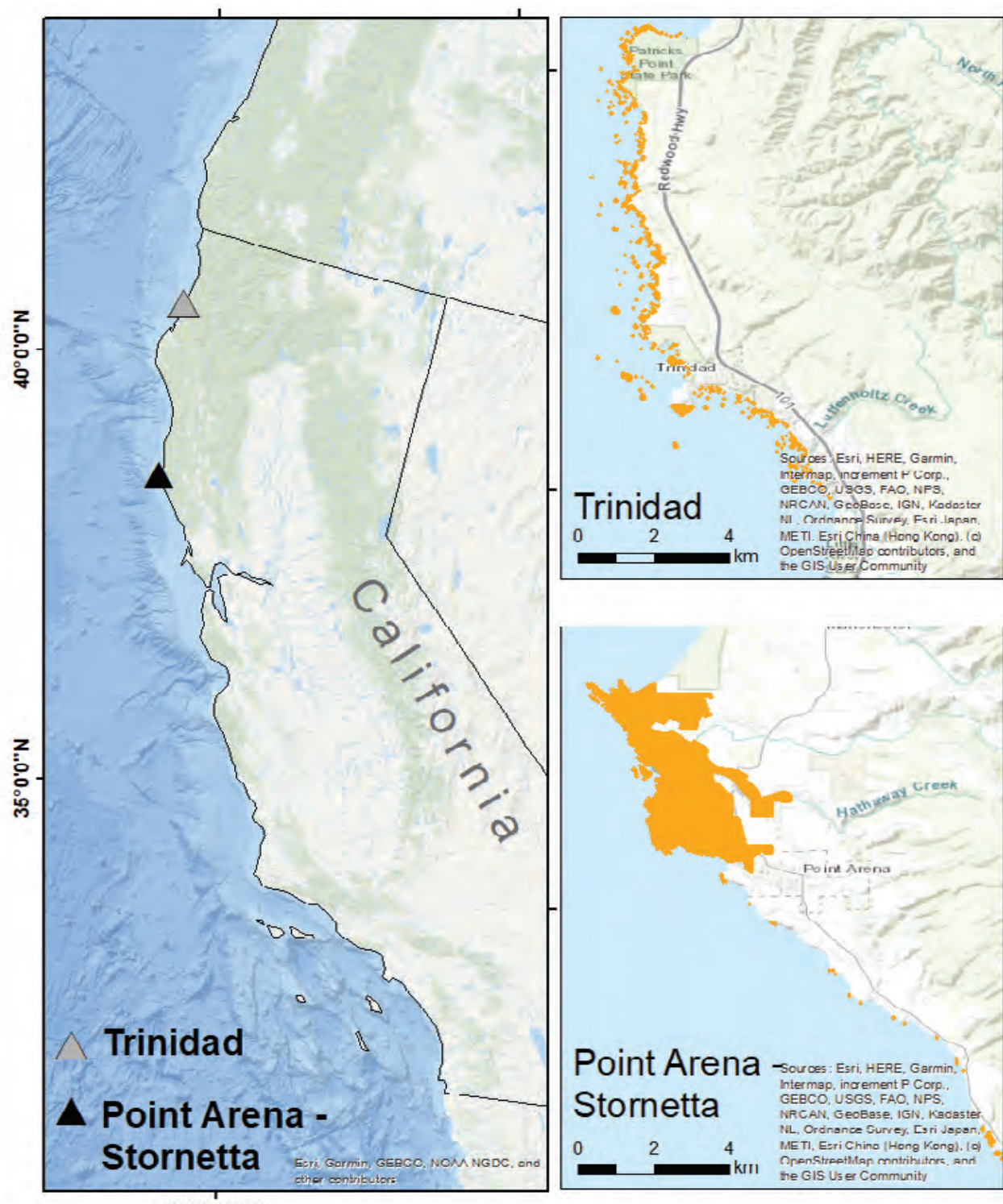

$120^{\circ} 0^{\prime} 0^{\prime \prime} \mathrm{W}$

Map image is the intellectual property of Esri and is used herin under license. Copyright 2020 Esri and its licensors. All rights reserved.

Figure 2. California Coastal National Monument Trinidad and Point Arena-Stornetta study sites. Orange areas represent the extent of each unit. 


\section{Study Area}

The CCNM is situated along the California Current Ecosystem, where strong upwelling of cold, nutrient-rich subsurface waters makes a highly productive area for marine life. Climate change drivers will influence the CCNM by changing habitat availability and food resources as well as affect species interactions such as predation and competition (Harley and others, 2006). The CCNM encompasses more than 20,000 small islands, rocks, exposed reefs, and pinnacles on the California coast between Baja California and Oregon. The CCNM was established on January 11, 2000, through Presidential Proclamation 7264 (65 FR 2821, 2000 ) to "protect the biological treasures situated offshore on thousands of unappropriated or unreserved islands, rocks, exposed reefs, and pinnacles owned or controlled by the Government of the United States within 12 nautical miles of the shoreline of the State of California." Establishment of the national monument, and subsequent additions to the CCNM (Presidential Proclamations 9089, 79 FR 14601, 2014 and 9563, 82 FR 6131, 2017), fall under the Antiquities Act of 1906, which permits a president to reserve the smallest area that is sufficient to protect "historic landmarks, historic and prehistoric structures, and other objects of historic or scientific interest." The Presidential Proclamations declaring the CCNM and its subsequent expansions specify the value of the seabird and pinniped habitat, the cultural sites, archeological sites, and artifacts, as well as the coastal scenery itself. These protected areas offer environmental services to the local community, important habitat areas, and recreational and commercial opportunities.

The Trinidad and the Point Arena-Stornetta Units were identified as representative regions within the northern extent of the CCNM to explore climate change and SLR vulnerability of rocky shorelines and to inform climate change adaptation planning and vulnerability assessment. Point Arena-Stornetta Public Lands were incorporated into the CCNM in 2014 as the first mainland-based unit. Trinidad Head was designated part of the CCNM by presidential proclamation on January 12, 2017. The Trinidad and Point Arena-Stornetta Units support colony nesting sites for a variety of seabird species and provide pupping, nursery and haul out habitat for marine mammals (Capitolo and others, unpub. data, 2006; Robinette and McChesney, unpub. data, 2013). Trinidad Head, a promontory near the southern end of the Trinidad Unit, encompasses approximately 5 hectares.

Trinidad Head is home to important sites for the Cher-Ae Heights Indian Community of the Trinidad Rancheria, the Yurok Tribe, and the Tsurai Ancestral Society. These sites include the Tsurai ancestral village and burial sites. Trinidad Head also hosts the Trinidad Memorial Lighthouse, constructed in 1871, and Bell, installed in 1898, a memorial marking where the Yurok community had first contact with
Spanish ships. Adjacent is a harbor where commercial and recreational boats moor. Trinidad Unit is home to diverse coastal vegetation, rocky intertidal shoreline, and offshore rocks which provide habitat for multiple species. These are known to include three species of cormorants (Brandt's, P. penicillatus; double crested, P. auratus; and pelagic, $P$. pelagicus), common murres (U. aalge), pigeon guillemots (Cepphus columba), tufted puffins (Fratercula cirrhata), Leach's storm-petrels (Oceanodroma leucorhoa), fork-tailed storm-petrels (O. furcata), black oystercatchers (H. bachmani), harbor seals (Phoca vitulina), California sea lions (Zalophus californianus), Steller sea lions (Eumetopias jubatus), marine-adapted river otters (Lontra canadensis) and many species of intertidal invertebrates (Proclamation 9563, 82 FR 6131, 2017).

\section{Objectives}

Our objectives for the Trinidad and Point Arena-Stornetta Units were to:

1. Host interactive workshops to gather ideas from local stakeholders on key resources and climate change vulnerabilities.

2. Summarize climate change vulnerability and identify indicator species of the CCNM based on published information.

3. Produce a quantitative SLR vulnerability assessment for rocky shoreline resources by using spatial modeling and a standardized vulnerability assessment approach (table 1).

\section{Interactive Workshops (Objective 1)}

We hosted interactive workshops with local stakeholders to gather information about key resources and which climate change drivers we could focus on for the vulnerability assessments. The 1-day workshops were held in Trinidad, California, in June 2017 and Point Arena-Stornetta, California, in October 2017. Workshop participants took part in a pre-workshop survey and interactive workshop exercises; they asked questions about important key resources within the units and expressed their biggest management concerns. A detailed summary of the methods and results can be found in appendix 1. Workshop participants at both sites were particularly concerned about the following issues:

- Sea-level rise damaging or limiting access to important tribal, cultural, recreational, commercial, and historic sites. 
Table 1. Definition of terms used for this vulnerability assessment (modified from Hutto and others, 2015).

[=, equals]

\begin{tabular}{|c|c|}
\hline Term & Definition \\
\hline $\begin{array}{l}\text { Climate exposure } \\
\qquad(1=\text { no exposure, } 5=\text { extreme exposure })\end{array}$ & A measure of how much change a resource is likely to experience from climate change. \\
\hline $\begin{array}{l}\text { Adaptive capacity } \\
\qquad(1=\text { no adaptive capacity, } 5=\text { extreme } \\
\text { adaptive capacity })\end{array}$ & $\begin{array}{l}\text { The ability of a resource to accommodate or cope with climate change impacts with minimal } \\
\text { disruption (Glick and others, 2013). }\end{array}$ \\
\hline $\begin{array}{l}\text { Vulnerability } \\
(1=\text { no vulnerability, } 5=\text { extreme } \\
\text { vulnerability })\end{array}$ & $\begin{array}{l}\text { The propensity or predisposition to be adversely affected. Vulnerability encompasses a variety } \\
\text { of concepts and elements including sensitivity or susceptibility to harm and lack of capacity } \\
\text { to cope and adapt (Intergovernmental Panel on Climate Change, 2014). }\end{array}$ \\
\hline
\end{tabular}

- The impact of sea-level rise and erosion on offshore rock, cliff, and intertidal seabird and marine mammal habitats.

- Fisheries and nesting seabirds as the most important biological resources for management.

- Changes in precipitation, fog, and sea-level rise as a result of climate change.

- Other climate change impacts to key resources for nesting and roosting seabirds.

\section{Climate Change Vulnerability Assessment (Objective 2)}

\section{Overview}

Climate change could negatively affect rocky habitat through several mechanisms, including changes in atmospheric and ocean conditions. A comprehensive climate change vulnerability assessment, which included portions of the rocky features within the CCNM, was created for the north-central California Coast and Ocean (Hutto and others, 2015). We expanded on the assessment by Hutto and others (2015) to cover the Trinidad region and conducted a literature search for additional information on specific impacts to the northern units of the CCNM (fig. 2) and observed indicator species. We addressed the potential impacts of changes in weather, precipitation, fog, storms, ocean conditions, and SLR, with a special focus on expected impacts in the Trinidad and Point Arena-Stornetta Units. Finally, for each impact, we used information derived from Hutto and others (2015) to assess vulnerability of rocky coast habitats and avian indicator species. We include a more comprehensive and spatially explicit SLR vulnerability assessment of rocky shoreline habitats later in this report (Objective 3).

We selected three avian indicator species: (1) black oystercatcher, (2) common murre, and (3) Brandt's cormorant, based on their reliance on rocky coastal habitat and their abundance observed during surveys in the Trinidad and Point Arena-Stornetta Units of the CCNM. Black oystercatchers are dependent on marine shorelines for foraging and nesting. Breeding pairs establish composite feeding and nesting territories along low-relief, gradually sloping, rocky shorelines and generally occupy the same territory year after year (Andres, 1998). Nests typically are placed just above the high-tide line and adults use the adjacent intertidal zone to feed themselves and provision their chicks (Andres and Falxa, 1995). Given their use of the low rocky intertidal zone and high site fidelity, black oystercatchers are expected to be vulnerable to SLR effects on rocky shorelines (Johnson and others, 2010; Weinstein and others, 2014). Common murre are a highly social species that breeds in high-density colonies along island cliff ledges, rocky slopes, and flat surfaces. Murres depart colonies synchronously, and most of the chick development takes place at sea, in the company of the male parent. Chick survival is dependent on the availability of abundant, energy-rich prey within 60-70 kilometers $(\mathrm{km})$ of the breeding area (Ainley and others, 2002). Brandt's cormorant is also a colonial nesting seabird that nests on the windward side of islands along gentle slopes or steep cliffs with ledges (Hubbs and others, 1970; Hunt and others, 1981; Boekelheide and others, 1990). Adults forage at sea and provision chicks on the nest until fledging (Carter and Hobson, 1988). Like the common murre, this species is expected to be sensitive to changes in rocky coast nesting habitat as well as ocean conditions that influence fish productivity. 


\section{Vulnerability Analysis}

Vulnerability was calculated using the formula from Glick and others (2013). Exposure, sensitivity, and adaptive capacity terms for indicator species and habitats were used from Hutto and others (2015) to determine relative vulnerability scores. Vulnerability of habitat or species to climate drivers was calculated using the following equation:

$$
V=\frac{\left(\mathrm{CE}^{*} 0.5\right)+\mathrm{S}}{\mathrm{AC}}
$$

where

$\begin{aligned} V & \text { is overall vulnerability; } \\ \mathrm{CE} & \text { is exposure to climate drivers; } \\ \mathrm{S} & \text { is sensitivity to climate drivers; } \\ \mathrm{AC} & \text { is adaptive capacity to climate drivers. }\end{aligned}$

\section{Climate Drivers}

\section{Weather-Precipitation, Fog, and Temperature}

Along the northern California coastline, air temperatures will likely vary over the coming century (Cayan and others, 2008). This region experiences moderate temperatures throughout the year, with no average monthly temperature falling below 32 degrees Fahrenheit $\left({ }^{\circ} \mathrm{F}\right)$ and at least 3 months of the year rising above $50^{\circ} \mathrm{F}$. However, increases in atmospheric carbon dioxide levels have resulted in gradually warming air and water temperatures, leading to cascading effects on winds, precipitation, fog, and ocean circulation (Scavia and others, 2002).

The seasonal precipitation regime along the north-central California coast has most rain falling between November and April. Climate-related changes in precipitation and runoff primarily are related to reduced snowpack due to warmer winter storms (Stewart and others, 2005; Knowles and others, 2006). In smaller coastal watersheds, more extreme winter rainfall events are expected; further, it is projected that annual precipitation during the 21 st century will show greater annual variability (such as, drier dry years and wetter wet years; Dettinger, 2011). Changes in runoff and river discharge can be expected to lead to increased flooding of coastal lowlands, erosion of cliffs and beaches, increased delivery of watershed material to the ocean, expanded plume areas, and increased nearshore stratification.
Many California coastal regions experience frequent fog in the summer due to rapid cooling of warm, moist air as it travels over colder ocean water (as seen at these study locations; Byers, 1930; Koračin and others, 2001). Coastal fog primarily reduces air temperature and reflects solar radiation. Broadly, coastal fog forms when a subsiding dry warm air mass moves across cooler sea surface temperatures (SST; made cooler from upwelling), forming a temperature inversion that caps a marine layer (Rastogi and others, 2016). The marine layer is cool and humid, resulting in the formation of fog and low clouds (O'Brien and others, 2013; Rastogi and others, 2016). Some studies have hypothesized that summer fog could become more frequent as upwelling increases due to increasing atmospheric carbon dioxide $\left(\mathrm{CO}_{2}\right)$ concentrations (Snyder and others, 2003). However, some models show a decline in fog along coastlines as atmospheric warming proceeds. One analysis, based in part on data collected at the California Redwood Coast - Humboldt County Airport in McKinleyville, California, projected a decreasing trend in mean summer fog frequency between 1951 and 2008 and a decline in frequency by 33 percent over the past century (Johnstone and Dawson, 2010).

Trinidad and Point Arena-Stornetta Units: How air temperature, precipitation, and fog patterns will change in this region of California is unknown; however, at the time of this report, most of the area's freshwater supply comes from rain, runoff, and fog. In general, air temperatures are expected to increase throughout California. Changing precipitation patterns could alter the amount and timing of estuarine salinity, thus influencing the community composition of aquatic species. More local information is needed to fully characterize the vulnerability from changes in weather patterns and availability of fog.

Values derived from Hutto and others (2015) for exposure, sensitivity, and adaptive capacity using the formula in equation 1 provided the following scores in relation to weather, precipitation, and fog for habitat and indicator species observed in the CCNM offshore rocks.

Rock Habitat: Exposure (1, low), Sensitivity (1, low), Adaptative Capacity $(1$, low), therefore Vulnerability score is 1.5 (low).

Black Oystercatcher: Exposure (4, moderately high for changes in precipitation), Sensitivity (1, low for air temperature; 4, moderately high for precipitation $=2.5$ average), average Adaptative Capacity (3, moderate), therefore Vulnerability score is 1.6 (low).

Brandt's Cormorant and Common Murre (surface nesters): Exposure (2.5, low moderate), Sensitivity (2, low), average Adaptative Capacity ( 3 , moderate), therefore Vulnerability score is 1.08 (low). 


\section{Storms}

Interannual variability in ocean conditions, such as that driven by the El Niño phase of the El Niño Southern Oscillation (ENSO), has been found to have a significant impact on the California coast. El Niño events are associated with warmer oceans, increased wave energy and ocean levels, directional shifts of both ocean and air circulation, and heavier precipitation (Storlazzi and Griggs, 2000; Barnard and others, 2015). Increased storm intensity in El Niño events results in increasing wave heights, which are greater at higher latitudes (Allan and Komar, 2006). Based on data collected by the National Data Buoy Center (NDBC) Point Arena Buoy (\#46014), wave heights in the area have increased by an average rate of approximately $1.5-2 \mathrm{~cm} \mathrm{yr}^{-1}$ (centimeters per year), driven in part by extreme waves occurring during El Niño events (Menéndez and others, 2008; Largier and others, 2011). El Niño events also result in reduced primary productivity because of warmer sea surface temperatures and reduced ocean upwelling, resulting in more nutrient-poor waters off the coast. The shift to lower productivity affects organisms throughout the food chain (McGowan and others, 1998; Schwing and others, 2006). Climate models show that the overall number of El Niño events is expected to increase, and it is projected that El Niño events will become more extreme when they occur (Cai and others, 2014).

Another effect of increases in atmospheric temperature is the development of atmospheric rivers (also referred to as a "Pineapple Express"), where currents of high-moisture high in the atmosphere result in high-intensity precipitation events along the northern coast of California. Atmospheric rivers often generate extreme precipitation amounts, which strongly influence hydrologic impacts by altering the timing and magnitude of rainfall and runoff (Guan and others, 2010; Dettinger, 2011).

Changes in atmospheric river temperatures have important implications for regional hydroclimate, especially in locations where a shift to more rain-dominated atmospheric river precipitation could affect snowpack and flood risk in the California Coast Range. A recent study by Gonzales and others (2019) detected monthly scale and seasonal atmospheric river warming between 1980 and 2016 along the U.S. West Coast with the most widespread warming occurring in November and March. Warm atmospheric rivers account for 30-50 percent of California's winter precipitation (Dettinger, 2011); this increased amount of precipitation and ratio of rain to snow can increase flood risks. The altered timing for snowpack melt (Guan and others, 2010) also incurs heightened hazards from intensified precipitation, wind damage, and mudslides (Ralph and others, 2006; Neiman and others, 2011; Waliser and Guan, 2017; Oakley and others, 2018).
Trinidad and Point Arena-Stornetta Units: Frequency and intensity of coastal storms are projected to increase. Current projections point to reduced snowpack but more extreme precipitation events, including atmospheric rivers. In addition, the frequency of El Niño events that bring warmer ocean waters and more precipitation is expected to increase and affect this region of the coast (Dettinger, 2011).

Values derived from Hutto and others (2015) for exposure, sensitivity, and adaptive capacity using the formula in equation 1 provided the following scores in relation to coastal storms for habitat and indicator species observed in the CCNM offshore rocks.

Rock Habitat: Exposure (3, high), Sensitivity (2, moderate), Adaptative Capacity (1, low) therefore Vulnerability score is 3.5 (moderate).

Black Oystercatcher: Exposure (5, high), Sensitivity (5, high), average Adaptative Capacity (3, moderate), Vulnerability score is 4.2 (moderate high).

Brandt's Cormorant and Common Murre (surface nesters): Exposure (3), Sensitivity (5, high), average Adaptative Capacity (3, moderate) therefore Vulnerability score is 2.5 (low to moderate).

\section{Ocean Conditions-Temperature, $\mathrm{pH}$}

Ocean temperature change is spatially and seasonally variable, but studies have found net warming trends in sea surface temperature in the Pacific Ocean (Legaard and Thomas, 2006; L'Heureux and others, 2013). Other research has shown a cooling trend over the continental shelf off the California coast at local levels, due to more intense and prolonged local upwelling of cold waters (Schwing and Mendelssohn, 1997; Snyder and others, 2003; Hutto and others, 2015). This cooling effect is thought to be due to increased atmospheric $\mathrm{CO}_{2}$ causing a larger gradient between the air pressure over land and ocean and resulting in alongshore winds that intensify upwelling (García-Reyes and Largier, 2010). Increased upwelling has been found to be strongest on the central California coast, south of our study sites (García-Reyes and Largier, 2010). However, the effects of stronger upwelling conditions may be offset or negated because warming temperatures over the ocean may result in a warmer sea surface temperature, deeper mean thermocline, and more stratification (García-Reyes and Largier, 2010). Conditions in waters over the continental shelf likely will not affect temperatures expected to increase in nearshore and enclosed waters where upwelling is not occurring (Largier and others, 2011). 
Ocean acidification is a reduction in $\mathrm{pH}$ caused by chemical reactions when atmospheric $\mathrm{CO}_{2}$ is absorbed by ocean water. Since the start of the industrial revolution, the global average surface water $\mathrm{pH}$ has declined by around $0.1 \mathrm{pH}$ units, a roughly 30 -percent increase in acidity (Feely and others, 2016; National Oceanic and Atmospheric Administration, 2019). It is projected that if atmospheric $\mathrm{CO}_{2}$ concentrations reach 800 parts per million toward the end of the century, $\mathrm{pH}$ will decrease by approximately another $0.4 \mathrm{pH}$ units (Feely and others, 2016). The capacity of ocean waters to take up surplus anthropogenic $\mathrm{CO}_{2}$ has been decreasing rapidly and could decline as much as 34 percent by 2100 , under a RCP8.5 scenario (Representative Concentration Pathways; Jiang and others, 2019). The ocean's role in buffering global climate change will gradually diminish, and ocean acidification could accelerate. In part, due to the seasonal upwelling of waters undersaturated with carbonate, the continental shelf region off the west coast of North America is particularly vulnerable to unbuffered acidification from increased $\mathrm{CO}_{2}$ (Feely and others, 2016). At Point St. George, just north of Trinidad, a 2007 survey indicated that there was an undersaturation of aragonite (a carbonate mineral; Feely and others, 2008) throughout the entire water column of inshore waters. It is projected that shallower waters of the California Current will be undersaturated more often and for longer periods over the next several decades to a century, and that over half of the waters in the California Current will be undersaturated by 2050 (Gruber and others, 2012; Feely and others, 2016).

Trinidad and Point Arena-Stornetta Units: The nearshore ecosystems within the units provide complex heterogeneous environments that maintain diversity and productivity; this is driven in combination by upwelling, layer mixing, currents, and stratification. Changes in water conditions (for example, temperature or $\mathrm{pH}$ ) could have important consequences to the food webs and productivity of terrestrial and marine wildlife.

Values derived from Hutto and others (2015) for exposure, sensitivity, and adaptive capacity using the formula in equation 1 provided the following scores in relation to ocean conditions for habitat and indicator species observed in the CCNM offshore rocks.

Rock Habitat: Exposure (1, low), Sensitivity (1, low), Adaptative Capacity $(1$, low) therefore Vulnerability score is 1.5 (low).

Black Oystercatcher: Exposure (5, high), Sensitivity (4, moderate-high), average Adaptative Capacity $(2$, low) therefore Vulnerability score is 5 (high).

Brandt's Cormorant and Common Murre (surface nesters): Exposure (3, moderate), Sensitivity (2, low-moderate), average Adaptative Capacity ( 3 , moderate) therefore Vulnerability score is 1.0 (low).

\section{Sea-level Rise}

Warming oceans from increased $\mathrm{CO} 2$ concentrations and resulting atmospheric warming lead to thermal expansion of the ocean waters and melting of land ice at the poles, which all augment the volume of the ocean and therefore raise sea levels. Global mean sea level has increased by about 24 centimeters $(\mathrm{cm})$ since 1880 , with $8 \mathrm{~cm}$ occurring since 1993 (Sweet and others, 2017). Projections of mean SLR to the year 2100 are largely uncertain because of the difficulty in modeling melting ice-sheet dynamics and other ocean processes (Mouginot and others, 2014). However, at the time of this report, global estimates range from 0.5 to 1.8 meters (m) of SLR by 2100 (Le Bars and others, 2017). Regional relative SLR models for the area nearest to the CCNM units project a 0.53 -millimeter $(\mathrm{mm})$ increase in mean sea-level every year at Arena Cove and a 4.68 millimeters per year $(\mathrm{mm} / \mathrm{yr})$ increase at North Spit, the gauge nearest to Trinidad ( \pm 1.10 and $\pm 1.01 \mathrm{~mm} / \mathrm{yr}$, respectively, 95 -percent confidence interval; https://tidesandcurrents.noaa.gov/sltrends/). The differences in SLR rate are largely due to local tectonic activity; subsidence increases the relative rate of SLR, whereas uplift reduces the rate of relative SLR.

Trinidad and Point Arena-Stornetta Units: Increasing ocean levels are projected to inundate and submerge low-lying areas within the units. Increasing mean SLR over the coming century is expected to inundate new areas or increase the time an area is submerged and decrease the amount of time an area is exposed. Many low relief offshore rocks could become completely submerged with accelerating SLR. Waves and ocean swells also could increase realized sea levels locally.

Values derived from Hutto and others (2015) for exposure, sensitivity, and adaptive capacity using the formula in equation 1 provided the following scores in relation to SLR for habitat and indicator species observed in the CCNM offshore rocks.

Rock Habitat: A refined quantitative vulnerability score was calculated for each rock feature per unit. See "Vulnerability Assessment" section.

Black Oystercatcher: Exposure (5, high), Sensitivity (5, moderate-high), average Adaptative Capacity (3, low) therefore Vulnerability score is 4.2 (high).

Brandt's Cormorant and Common Murre (surface nesters): Exposure $(1$, low), Sensitivity $(1$, low), average Adaptative Capacity (3, moderate) therefore Vulnerability score is 0.17 (low). 


\section{Spatial Sea-level Rise Vulnerability Assessment (Objective 3)}

\section{Study Scope}

The scope of this study encompassed the offshore extents of the Point Arena-Stornetta and Trinidad Units and rocky shoreline habitats within those units (fig. 3). Here we focus on the units that are Rocky Intertidal defined as “... rocky substrate found between high and low tide water levels" (Hutto and others, 2015).

\section{Field Surveys}

To assess avian and pinniped presence and resource vulnerability of off-shore rocky habitat, we conducted boat-based surveys on July 21, 2017, at Trinidad and on July 26, 2017, at Point Arena-Stornetta Units (fig. 3). Surveys were conducted within a few hours of low tide to capture low-lying rocks and peak wildlife presence on these rocks as well as to maintain survey consistency among study sites. We conducted surveys at each site, traversing the length of the unit coastline, documenting observed presence of birds or pinnipeds, and photographing all the offshore rocks. Boat surveys were conducted from a rigid-hulled inflatable boat with a 1.82 meter viewing tower attached to the deck (fig. 4) where observations were made with unaided sight and with a Swarovski Habicht 10x42 WB SLC scope (www.swarovskioptik.com). We approached rocks from the seaward side and collected data from the ocean-facing side of the rocks. Data collection included identification to species, sex and age, and the behavior (for example, roosting, nesting, hauled-out) of each individual. Photographs of the ocean-facing side of each encountered rock were taken using a Canon PowerShot SX530 HS, lens model 4.3-215.0 $\mathrm{mm}$ to validate species observations. Because boat surveys were done late in the nesting season, we also used supplemental information from stakeholders to inform which rocky shoreline habitats were important for nesting species (S. Murphy, Bureau of Land Management and Humboldt State University, North Coast Seabird Protection Network, written commun., 2019).

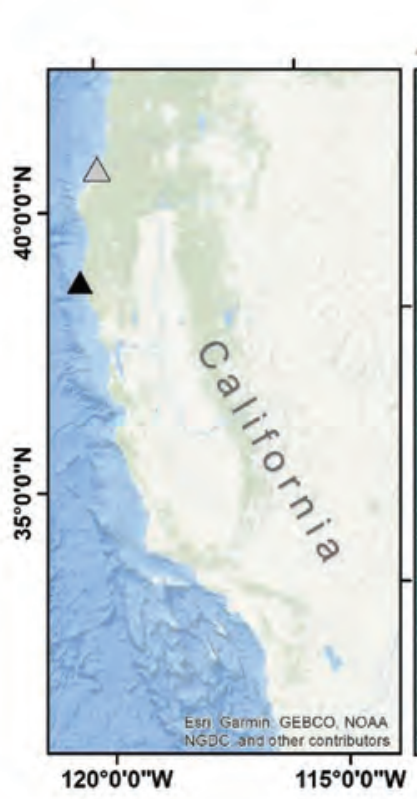

\section{Trinidad}

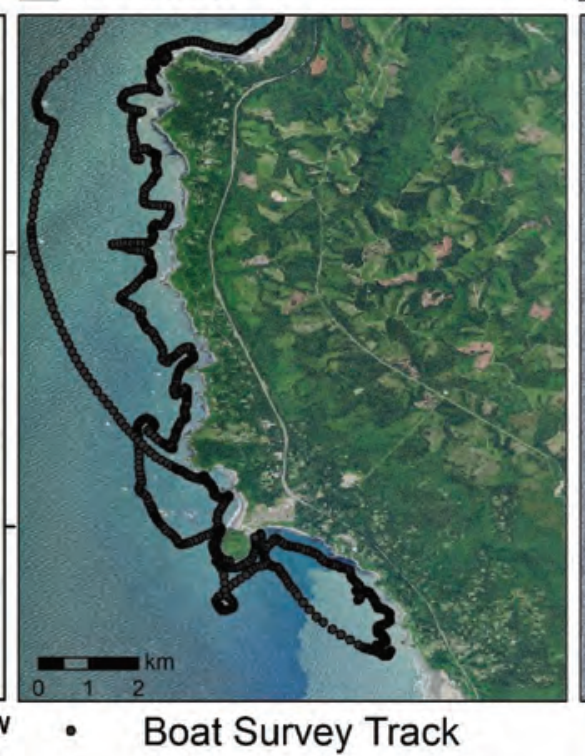

$\Delta$ Point Arena - Stornetta

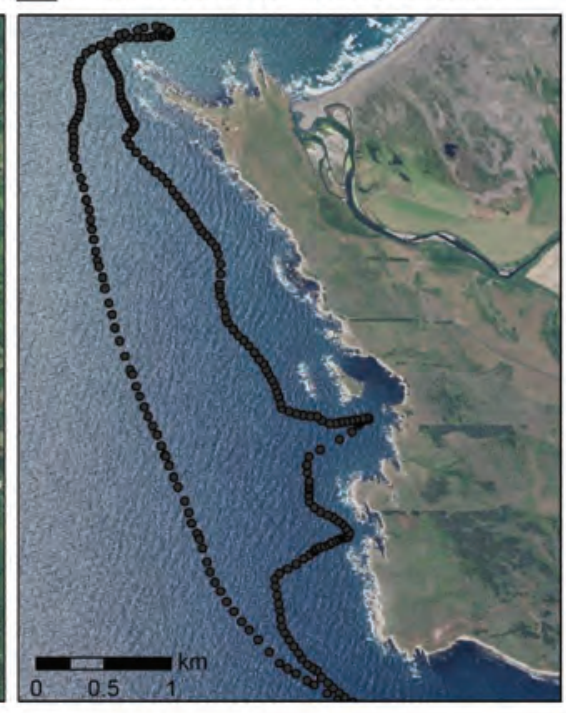

Map image is the intellectual property of Esri and is used herin under license. Copyright 2020 Esri and its licensors. All rights reserved.

Figure 3. Study extent of Trinidad and Point Arena-Stornetta Units in the California Coastal National Monument. Black lines indicate the boat survey tracks used to conduct the surveys for bird and marine mammal using the rocky shoreline habitats. 

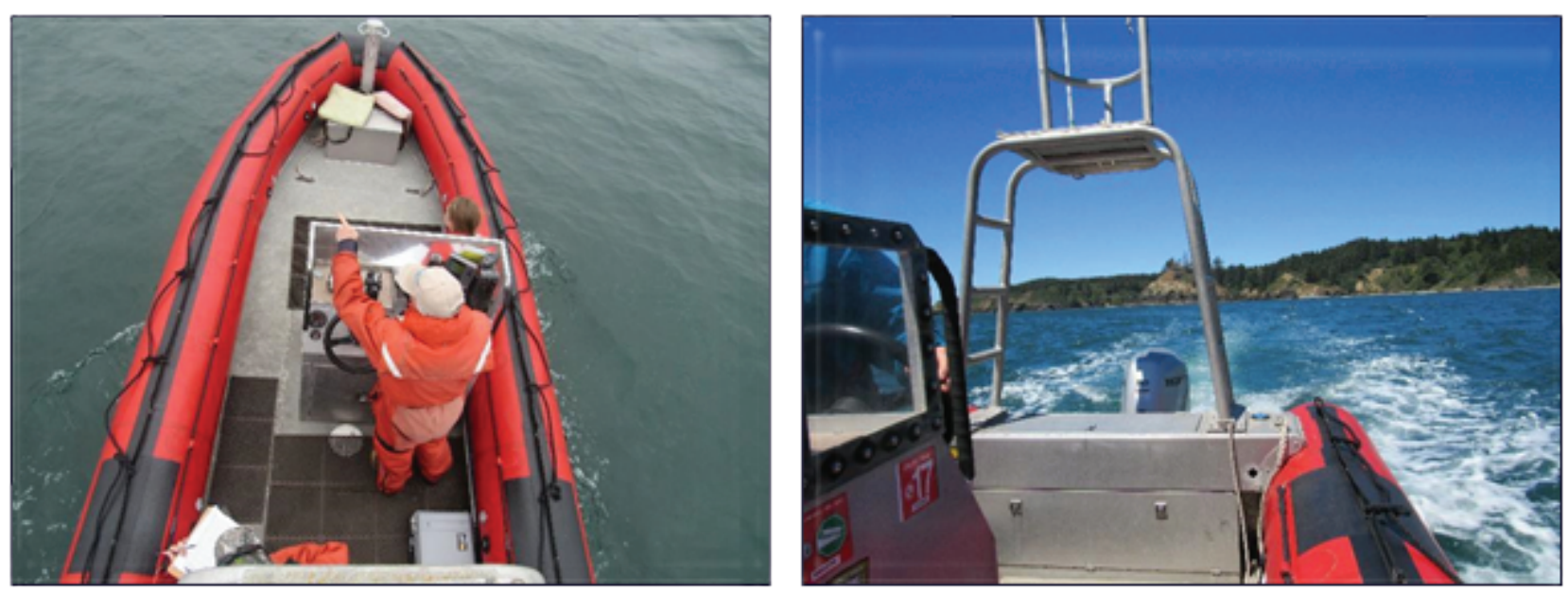

Figure 4. Boat surveys were conducted for rocky shoreline habitats and avian and pinniped presence at the Point-Arena Stornetta and Trinidad Units. Photograph taken by Karen Backe, July 2017.

\section{Vulnerability Assessment}

Rocky resource vulnerability was calculated using rock exposure and biological resource sensitivity, replicated from Glick and others (2013; fig. 5). As generally static landscape features, we assumed rocks have a low adaptive capacity to SLR (adaptive capacity $=1$ ), and therefore, we removed the term Adaptive Capacity from the Vulnerability equation. It is worth noting that cliffs could experience some negative capacity impacts in the form of erosion and cliff retreat. Thus, we used a modified formula:

$$
V=\left(C E^{*} 0.5\right)+S
$$

where

$$
\begin{aligned}
V & \text { is overall vulnerability; } \\
C E & \text { is exposure to climate drivers; } \\
S & \text { is sensitivity to climate drivers. }
\end{aligned}
$$

\section{Exposure}

Physical exposure was defined by offshore rock geomorphic shape related to area and height relative to the North American Vertical Datum of 1988 (NAVD 88). Rocks were categorically grouped by area and height. Surface area was calculated (square meters $\left[\mathrm{m}^{2}\right]$ ) in ArcGIS by manually digitizing the extent of each rock that was visible from orthoimagery; rocks were then grouped into "small $\left(<150 \mathrm{~m}^{2}\right)$," "medium $\left(150-2,000 \mathrm{~m}^{2}\right)$," and "large $\left(>2,000 \mathrm{~m}^{2}\right)$ " categories. Height in meters relative to NAVD 88 was extracted for each rock extent from the 2009-11 California Coastal Conservancy Lidar Digital Elevation Model: Coastal California, which was downloaded from the NOAA data access viewer (https://coast.noaa.gov/dataviewer); heights were categorically binned as "low (<3 meters [m])," "intermediate (3-12 m)" or "high (>12 m)." Rocks were then assigned a ranking of exposure from 1 (no exposure) to 5 (extreme exposure) based on the combination of height and area (table 2). Rocks that were not covered by the digital elevation model extent were categorized by expert visual observations by estimating height relative to the observed low-tide line. For the "low" rocks, all or nearly all vertical habitat may be inundated with SLR at high tide, "intermediate" rocks may have notable vertical habitat inundated with SLR at high tide, and "high" rocks likely will have a small percentage of total vertical habitat inundated with SLR at high tide.

\section{Sensitivity}

To examine wildlife community structure and rock use, we calculated species richness and the Inverse Simpson diversity (ISD) index for each rock. We included avian and pinniped observations. Inverse Simpson diversity is calculated as

$$
I S D=\frac{1}{\sum_{i}\left(\frac{n_{i}}{N}\right)^{2}}
$$

where

$$
\begin{aligned}
n_{i} & \text { is the abundance of species } \mathrm{i}, \text { and } \\
N & \text { is the total abundance of all species. } \\
I S D & \text { Inverse Simpson diversity }
\end{aligned}
$$

Summed over all species, the metric tells us the sum of squares of all abundance ratios. 


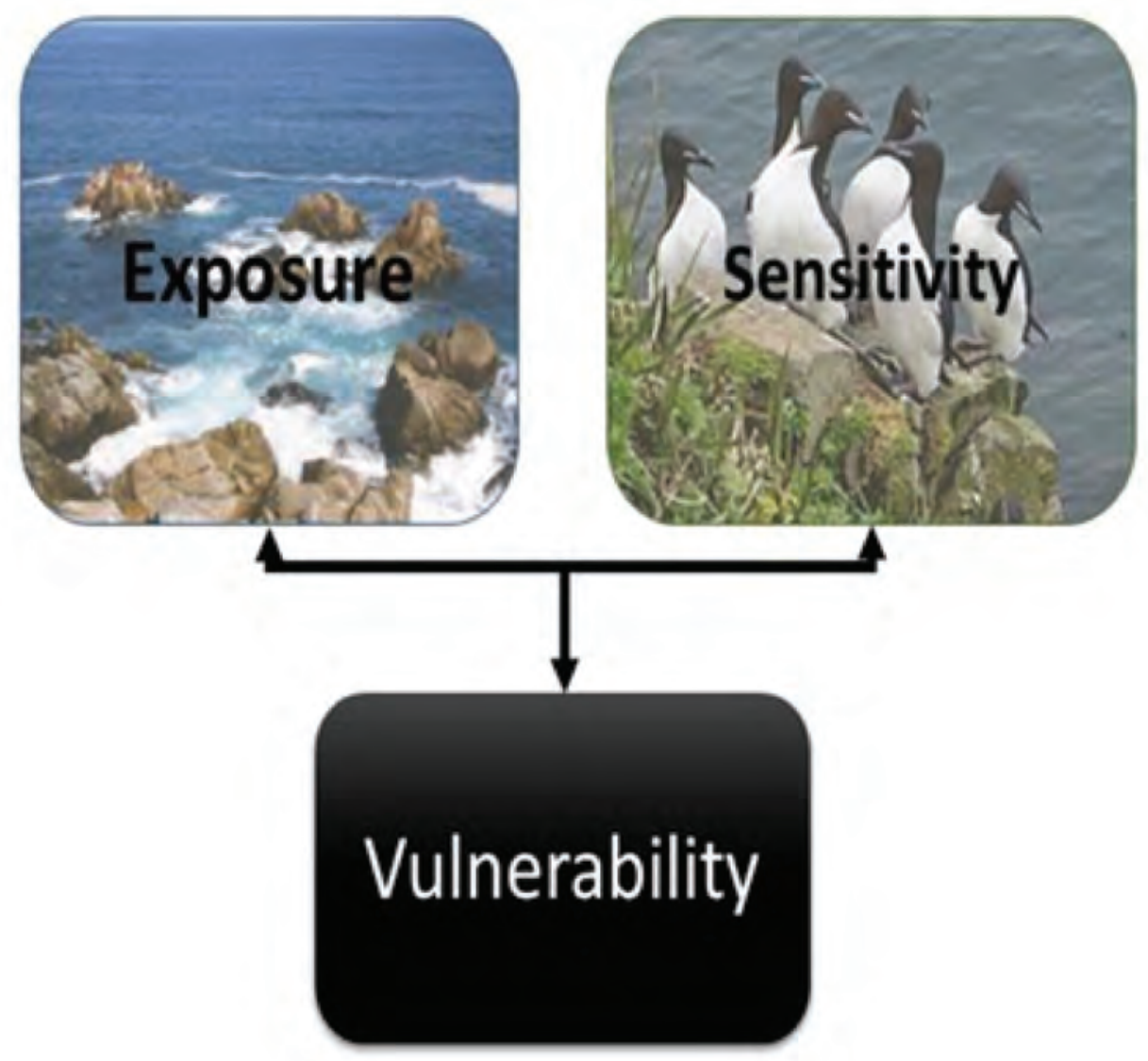

Figure 5. Vulnerability analysis for the California Coastal National Monument (exposure of rocky shoreline habitats and sensitivity of the biological community [birds and marine mammals]).

Table 2. Exposure ranking based on rock height and area.

$\left[>\right.$, greater than; $\mathrm{m}$, meter; $<$, less than; $\mathrm{m}^{2}$, square meter $]$

\begin{tabular}{lccc}
\hline \multirow{2}{*}{ Size } & \multicolumn{3}{c}{ Height } \\
\cline { 2 - 4 } & $\begin{array}{c}\text { High } \\
(>\mathbf{1 2} \mathbf{~ m})\end{array}$ & $\begin{array}{c}\text { Intermediate } \\
(\mathbf{3}-\mathbf{1 2} \mathbf{~ m})\end{array}$ & $\begin{array}{c}\text { Low } \\
(<\mathbf{3 ~} \mathbf{~})\end{array}$ \\
\hline Large $\left(>2,000 \mathrm{~m}^{2}\right)$ & 1 & 2 & 3 \\
Medium $\left(150-2,000 \mathrm{~m}^{2}\right)$ & 2 & 3 & 4 \\
Small $\left(<150 \mathrm{~m}^{2}\right)$ & 3 & 4 & 5 \\
\hline
\end{tabular}


We choose the ISD index because it has a lower limit of 1 (for example, one species observed), making it more suitable for the vulnerability calculation than other diversity indices, which have a lower limit of zero. Rocks that had no observed species received a sensitivity score of 0.5 ; this was done to account for any detection issues and the mobile nature of the species we were surveying. We calculated species (avian and pinniped) richness and sensitivity by individual rock. We used an analysis of variance to test for differences in rock size class, height class, and exposure metrics. Rock vulnerability was described relative to habitat loss (for example, nesting and roosting habitat by avian species and potential pinniped haul-out areas). Trinidad and Point Arena-Stornetta Unit data were combined to determine the sensitivity scores because of the low number of species counted in Point Arena-Stornetta Unit. To account for the timing of our surveys, which occurred after the peak of the breeding season, we used feedback from the workshop and local surveys of seabird colonies to compare our data to data collected during nesting season.

\section{Results}

\section{Physical and Geological Features}

A total of 138 offshore rocks were identified within the Trinidad Unit (fig. 6) and summarized in table 3. The rock area ranged from 0.5 to 16,638 square meters $\left(\mathrm{m}^{2}\right)$ with an average area of $789 \mathrm{~m}^{2}$ and a standard deviation (SD) of $2,277 \mathrm{~m}^{2}$. Rock height ranged from 0.39 to 47.7 meters (m) with an average height of 11.7 and a SD of 10.87 meters relative to NAVD 88. Rocks were almost evenly split across three rock height categories and rock area and height were well correlated. Most (39 percent) of the Trinidad Unit rocks fell within the intermediate rock height bin, with 32 percent in the low and 29 percent in the high rock height categories. Rock exposure analysis, which is directly related to the height of the rock, showed that 49 percent of surveyed rocks had an exposure ranking of 4 or 5 (fig. 7).

A total of 40 offshore rocks were surveyed within the Point Arena-Stornetta Unit (fig. 8) and summarized in table 3. Within rock size classes, 2.5 percent were large, 47.5 percent were medium, and 50 percent were small (fig. 9). The highest rock exposure class (class 5), calculated by composite size and height (table 2), amounted to 30 percent of rocks surveyed, and class 4 , the second most exposed, held 27.5 percent of the rocks (fig. 10).

\section{Biological Resources}

Seabird roosting and nesting on offshore rocks comprised most of the avian behaviors observed during the Trinidad Unit boat surveys (table 4, 5; fig. 11). Three different pinniped species were observed, all of which are protected under the federal Marine Mammal Protection Act (MMPA; table 5; fig. 12).Birds were observed on features of every size, from roosting on the smallest and lowest rocks, to major nesting colonies on larger rock features (for example, Flatiron Rock; figs. 13-15). Pinnipeds were observed on nearshore shelves and offshore rocks (for example, Cone and Turtle Rocks; figs. 13, 14).

Birds and mammals mainly were observed on onshore cliff habitat, coastal shelves, the Sea Lion Rock feature, and a small number of offshore rocks in the Point Arena-Stornetta Unit. Seabirds (table 4, 6; figs. 16-18) were observed only on 10 of the 40 rocks surveyed. Harbor seals only were observed on 2 of the 40 rocks but were found in higher concentrations than at the Trinidad Unit.

Table 3. Summary of data collected on rocky shoreline habitats within Trinidad and Point Arena-Stornetta Units.

[ $\mathrm{m}^{2}$, square meter; LiDAR, light detection and ranging; $\mathrm{m}$, meter; Min, minimum; Max, maximum]

\begin{tabular}{|c|c|c|c|c|c|c|c|c|}
\hline Site & $\begin{array}{c}\text { Area } \\
\left(\mathrm{m}^{2}\right)\end{array}$ & $\begin{array}{c}\text { Height } \\
\text { (LiDAR; m) }\end{array}$ & Exposure & Sensitivity & Vulnerability & $\begin{array}{c}\text { Total number } \\
\text { of species } \\
\text { observed }\end{array}$ & $\begin{array}{c}\text { Number of } \\
\text { avian species } \\
\text { observed }\end{array}$ & $\begin{array}{c}\text { Number of } \\
\text { mammal species } \\
\text { observed }\end{array}$ \\
\hline \multicolumn{9}{|c|}{ Trinidad } \\
\hline Min & 0.49 & 0.39 & 1.00 & 0.50 & 1.00 & 0.00 & 0.00 & 0.00 \\
\hline Max & $16,638.40$ & 47.69 & 5.00 & 2.80 & 4.42 & 5.00 & 5.00 & 2.00 \\
\hline Mean & 789.67 & 11.67 & 3.42 & 0.96 & 2.67 & 1.03 & 0.93 & 0.09 \\
\hline Min & 23.31 & 0.11 & 1.00 & 0.50 & 1.00 & 0.00 & 0.00 & 0.00 \\
\hline Max & $20,261.40$ & 15.60 & 5.00 & 2.97 & 4.47 & 2.00 & 2.00 & 1.00 \\
\hline Mean & 774.01 & 4.75 & 3.78 & 0.65 & 2.54 & 0.35 & 0.30 & 0.05 \\
\hline
\end{tabular}




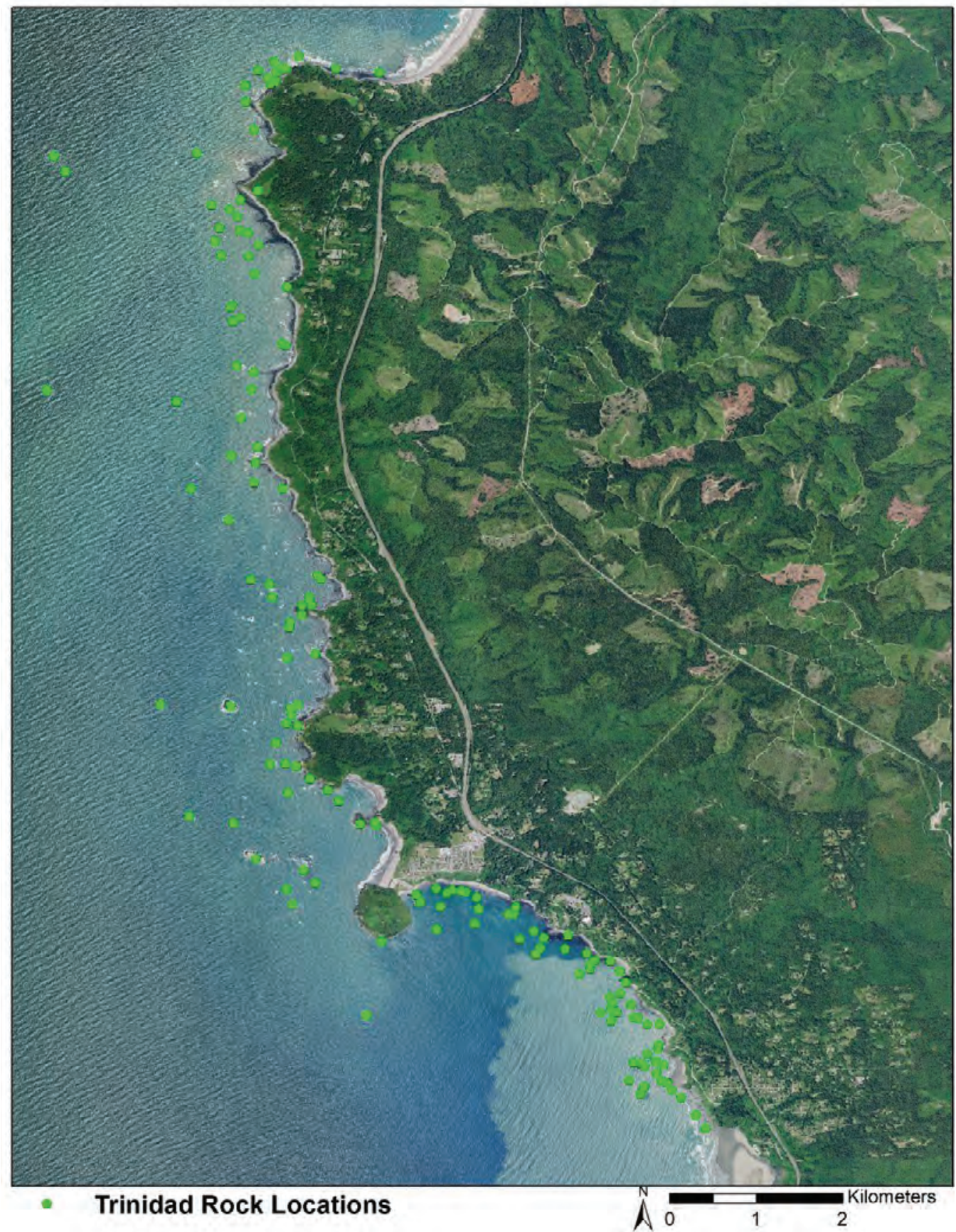

Map image is the intellectual property of Esri and is used herin under license. Copyright 2020 Esri and its licensors. All rights reserved.

Figure 6. Site map of all 138 surveyed shoreline rocks within the Trinidad Unit used in the Vulnerability Analysis. 


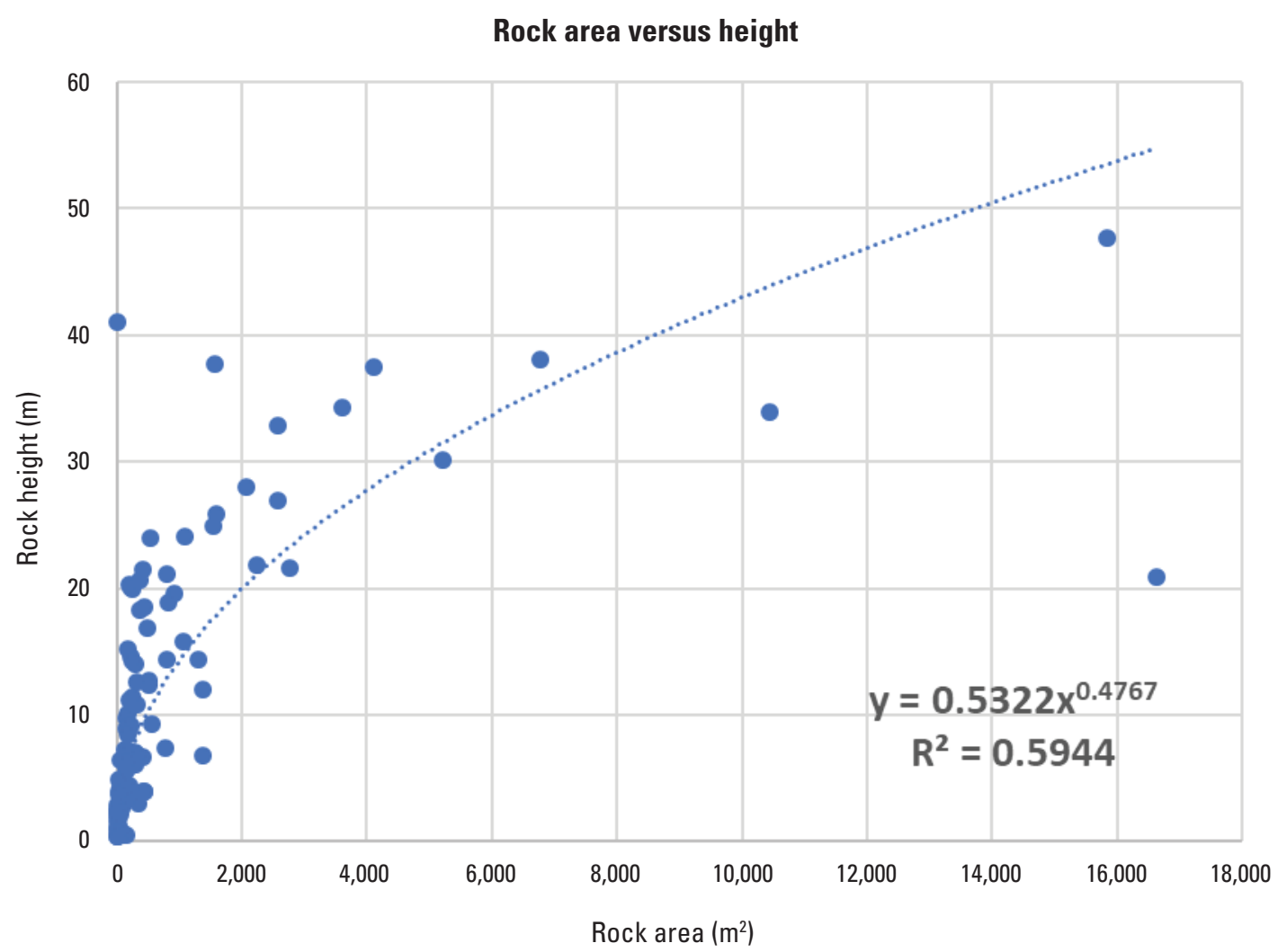

Figure 7. Trinidad Unit rock area versus rock height illustrates the variation in rock heights. The unit contained many low elevation rocks that were generally less than 2,000 square meters $\left(\mathrm{m}^{2}\right)$. Height and area were used to develop the exposure rank. 


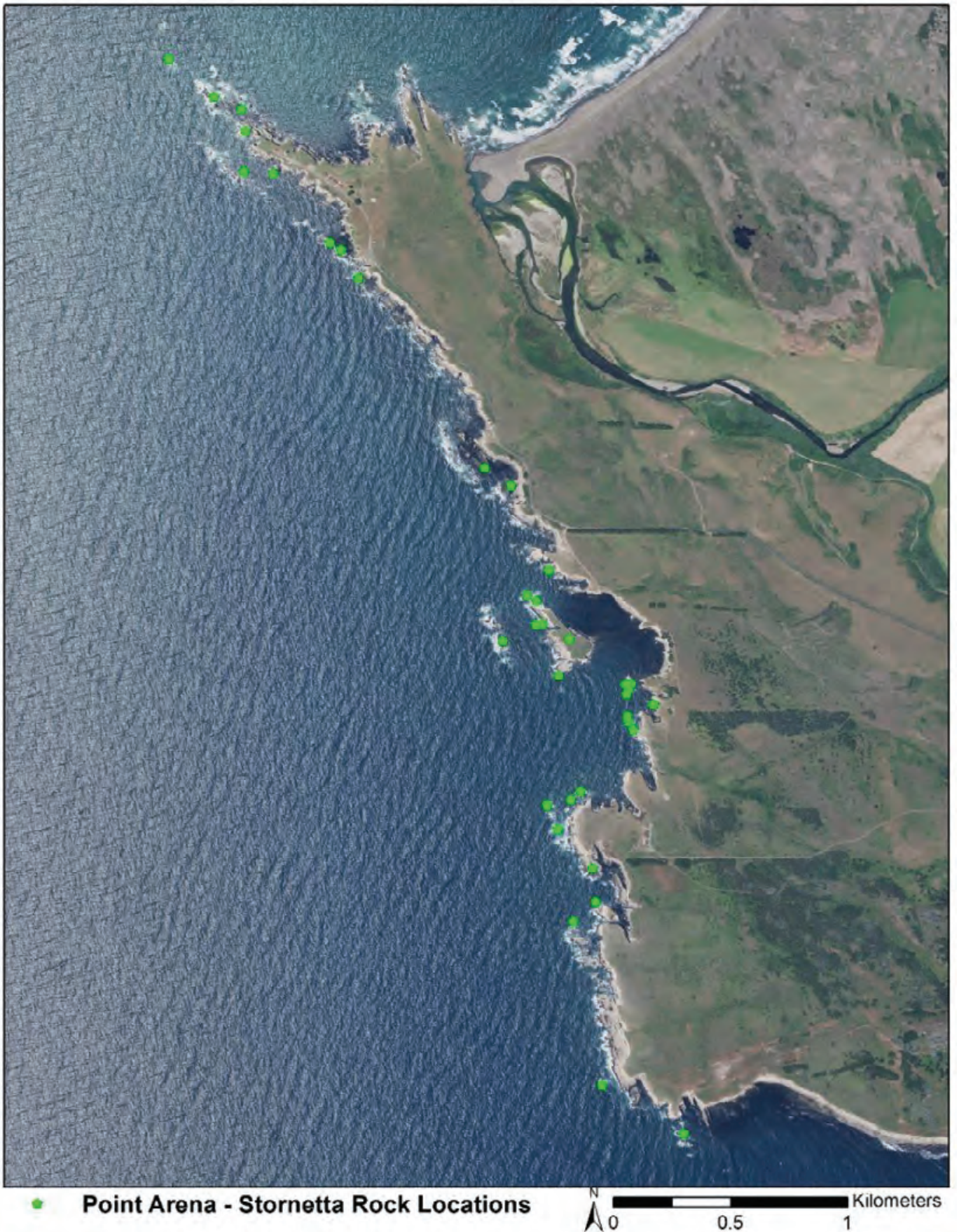

Map image is the intellectual property of Esri and is used herin under license. Copyright 2020 Esri and its licensors. All rights reserved.

Figure 8. Site map of all surveyed rocks at the Point Arena-Stornetta Unit. 


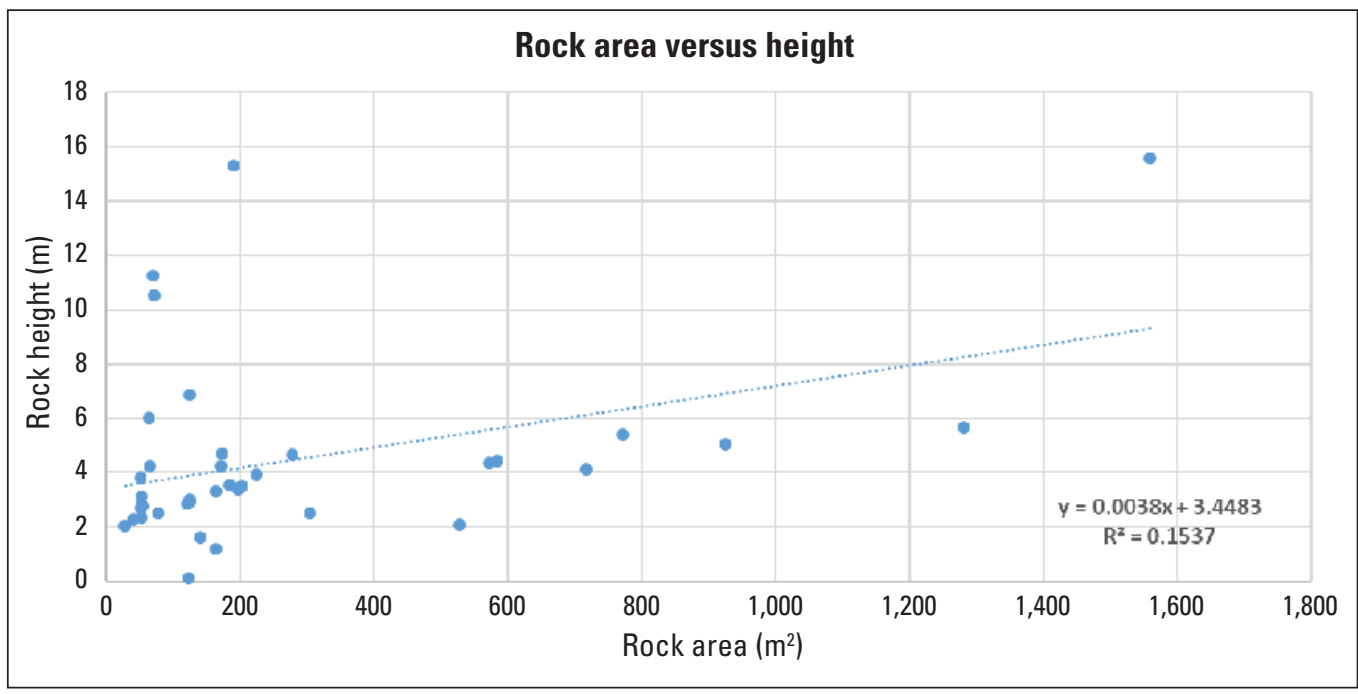

Figure 9. Point Arena-Stornetta Unit rock areas versus rock heights illustrates that mostly small rocks were in the area but varied in height. Height and area were used to develop the exposure rank.

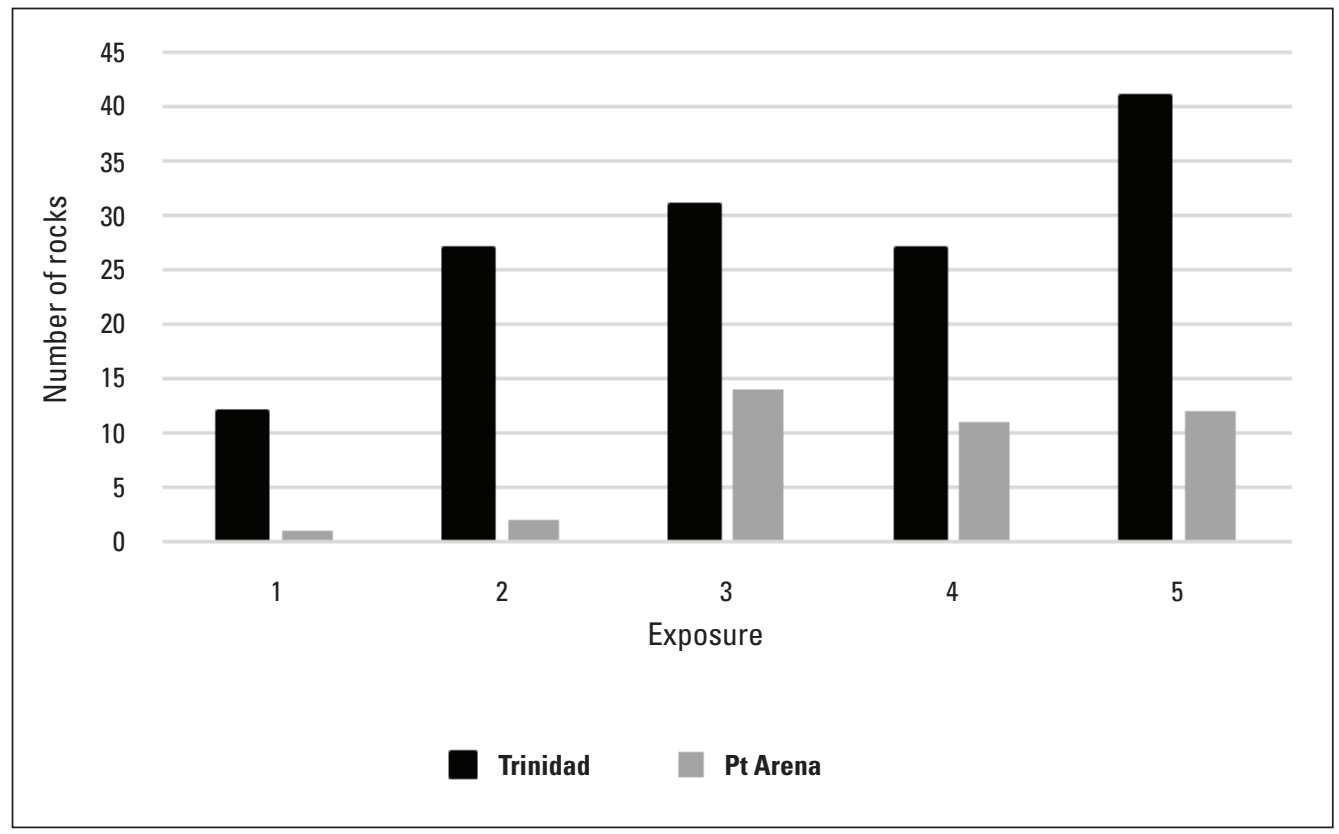

Figure 10. Exposure category related to size and shape of each surveyed offshore rock feature within the Trinidad Unit. Exposure is from 1 (least) to 5 (highest). 
Table 4. All rocky shoreline habitats within Trinidad and Point Arena-Stornetta Units. Names were identified on local maps and from the Bureau of Land Management (BLM) staff. If a rock did not have a name, it was assigned a number.

[Names were identified on local maps and from BLM staff. If a rock did not have a name, it was assigned a number. Abbreviations: $\mathrm{m}^{2}$, square meter; LiDAR, light detection and ranging; m, meter; NA, not applicable]

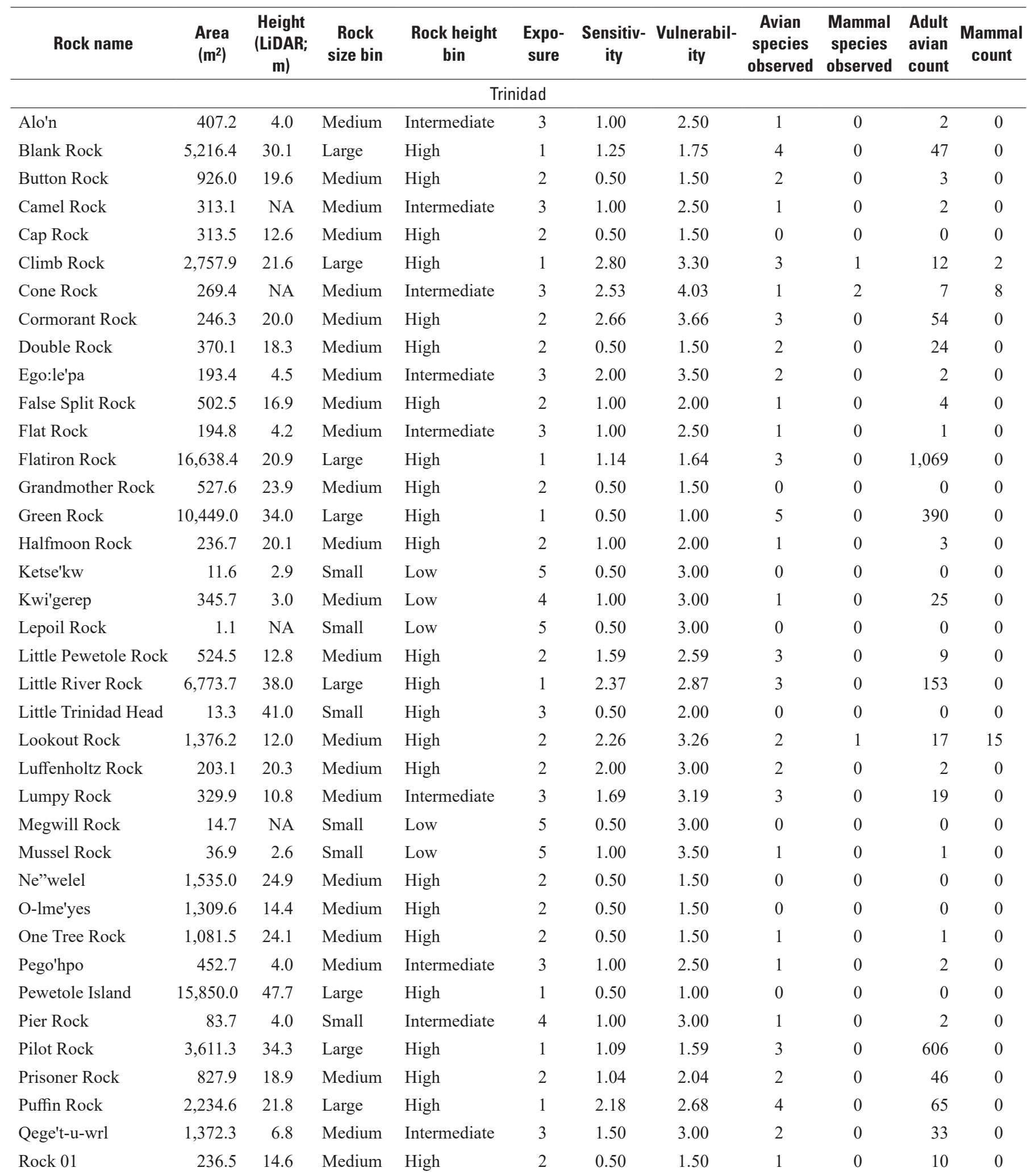


Table 4. All rocky shoreline habitats within Trinidad and Point Arena-Stornetta Units. Names were identified on local maps and from the Bureau of Land Management (BLM) staff. If a rock did not have a name, it was assigned a number.—Continued

[Names were identified on local maps and from BLM staff. If a rock did not have a name, it was assigned a number. Abbreviations: $\mathrm{m}^{2}$, square meter; LiDAR, light detection and ranging; $\mathrm{m}$, meter; NA, not applicable]

\begin{tabular}{|c|c|c|c|c|c|c|c|c|c|c|c|}
\hline Rock name & Area $\left(\mathrm{m}^{2}\right)$ & $\begin{array}{c}\text { Height } \\
\text { (LiDAR; } \\
\text { m) }\end{array}$ & $\begin{array}{c}\text { Rock } \\
\text { size bin }\end{array}$ & $\begin{array}{c}\text { Rock height } \\
\text { bin }\end{array}$ & $\begin{array}{l}\text { Expo- } \\
\text { sure }\end{array}$ & $\begin{array}{l}\text { Sensitiv- } \\
\text { ity }\end{array}$ & $\begin{array}{c}\text { Vulnerabil- } \\
\text { ity }\end{array}$ & $\begin{array}{c}\text { Avian } \\
\text { species } \\
\text { observed }\end{array}$ & $\begin{array}{l}\text { Mammal } \\
\text { species } \\
\text { observed }\end{array}$ & $\begin{array}{l}\text { Adult } \\
\text { avian } \\
\text { count }\end{array}$ & $\begin{array}{c}\text { Mammal } \\
\text { count }\end{array}$ \\
\hline \multicolumn{12}{|c|}{ Trinidad-Continued } \\
\hline Rock 02 & 451.4 & 4.0 & Medium & Intermediate & 3 & 1.99 & 3.49 & 2 & 0 & 24 & 0 \\
\hline Rock 03 & 794.9 & 14.4 & Medium & High & 2 & 1.00 & 2.00 & 1 & 0 & 1 & 0 \\
\hline Rock 04 & 185.0 & 5.9 & Medium & Intermediate & 3 & 0.50 & 2.00 & 0 & 0 & 0 & 0 \\
\hline Rock 06 & 515.2 & 12.4 & Medium & High & 2 & 1.00 & 2.00 & 1 & 0 & 1 & 0 \\
\hline Rock 07 & 64.6 & NA & Small & Intermediate & 4 & 0.50 & 2.50 & 0 & 0 & 0 & 0 \\
\hline Rock 08 & 362.5 & 20.7 & Medium & High & 2 & 1.00 & 2.00 & 1 & 0 & 1 & 0 \\
\hline Rock 09 & 138.3 & 7.2 & Small & Intermediate & 4 & 0.50 & 2.50 & 0 & 0 & 0 & 0 \\
\hline Rock 13 & 86.7 & NA & Small & Intermediate & 4 & 1.69 & 3.69 & 2 & 0 & 7 & 0 \\
\hline Rock 14 & 49.3 & NA & Small & Low & 5 & 1.28 & 3.78 & 2 & 0 & 8 & 0 \\
\hline Rock 15 & 194.4 & 7.1 & Medium & Intermediate & 3 & 1.00 & 2.50 & 1 & 0 & 1 & 0 \\
\hline Rock 16 & 304.6 & 14.0 & Medium & High & 2 & 1.00 & 2.00 & 1 & 0 & 4 & 0 \\
\hline Rock 17 & 78.8 & NA & Small & Intermediate & 4 & 0.50 & 2.50 & 0 & 0 & 0 & 0 \\
\hline Rock 18 & 7.6 & NA & Small & Low & 5 & 1.00 & 3.50 & 0 & 1 & 0 & 3 \\
\hline Rock 19 & 33.6 & 2.0 & Small & Low & 5 & 0.50 & 3.00 & 0 & 0 & 0 & 0 \\
\hline Rock 20 & 564.0 & 9.3 & Medium & Intermediate & 3 & 0.50 & 2.00 & 0 & 0 & 0 & 0 \\
\hline Rock 21 & 102.1 & 4.4 & Small & Intermediate & 4 & 1.92 & 3.92 & 2 & 0 & 15 & 0 \\
\hline Rock 28 & 154.8 & 5.8 & Medium & Intermediate & 3 & 1.00 & 2.50 & 1 & 0 & 2 & 0 \\
\hline Rock 29 & 22.6 & NA & Small & Low & 5 & 1.80 & 4.30 & 2 & 0 & 3 & 0 \\
\hline Rock 30 & 57.0 & 4.3 & Small & Intermediate & 4 & 1.00 & 3.00 & 1 & 0 & 16 & 0 \\
\hline Rock 31 & 18.8 & 1.6 & Small & Low & 5 & 1.00 & 3.50 & 1 & 0 & 6 & 0 \\
\hline Rock 32 & 12.8 & 2.5 & Small & Low & 5 & 0.50 & 3.00 & 0 & 0 & 0 & 0 \\
\hline Rock 33 & 250.7 & 14.2 & Medium & High & 2 & 0.50 & 1.50 & 0 & 0 & 0 & 0 \\
\hline Rock 34 & 229.3 & 9.2 & Medium & Intermediate & 3 & 1.27 & 2.77 & 2 & 0 & 25 & 0 \\
\hline Rock 35 & 184.1 & 8.5 & Medium & Intermediate & 3 & 0.50 & 2.00 & 0 & 0 & 0 & 0 \\
\hline Rock 36 & 177.3 & 6.3 & Medium & Intermediate & 3 & 0.50 & 2.00 & 0 & 0 & 0 & 0 \\
\hline Rock 37 & 18.2 & NA & Small & Low & 5 & 1.00 & 3.50 & 1 & 0 & 1 & 0 \\
\hline Rock 38 & 2.8 & 0.4 & Small & Low & 5 & 1.00 & 3.50 & 0 & 1 & 0 & 8 \\
\hline Rock 39 & 36.6 & 4.0 & Small & Intermediate & 4 & 0.50 & 2.50 & 0 & 0 & 0 & 0 \\
\hline
\end{tabular}


Table 4. All rocky shoreline habitats within Trinidad and Point Arena-Stornetta Units. Names were identified on local maps and from the Bureau of Land Management (BLM) staff. If a rock did not have a name, it was assigned a number.-Continued

[Names were identified on local maps and from BLM staff. If a rock did not have a name, it was assigned a number. Abbreviations: $\mathrm{m}^{2}$, square meter; LiDAR, light detection and ranging; m, meter; NA, not applicable]

\begin{tabular}{|c|c|c|c|c|c|c|c|c|c|c|c|}
\hline Rock name & Area $\left(\mathrm{m}^{2}\right)$ & $\begin{array}{c}\text { Height } \\
\text { (LiDAR; } \\
\text { m) }\end{array}$ & $\begin{array}{c}\text { Rock } \\
\text { size bin }\end{array}$ & $\begin{array}{c}\text { Rock height } \\
\text { bin }\end{array}$ & $\begin{array}{l}\text { Expo- } \\
\text { sure }\end{array}$ & $\begin{array}{l}\text { Sensitiv- } \\
\text { ity }\end{array}$ & $\begin{array}{c}\text { Vulnerabil- } \\
\text { ity }\end{array}$ & $\begin{array}{c}\text { Avian } \\
\text { species } \\
\text { observed }\end{array}$ & $\begin{array}{l}\text { Mammal } \\
\text { species } \\
\text { observed }\end{array}$ & $\begin{array}{l}\text { Adult } \\
\text { avian } \\
\text { count }\end{array}$ & $\begin{array}{c}\text { Mammal } \\
\text { count }\end{array}$ \\
\hline \multicolumn{12}{|c|}{ Trinidad-Continued } \\
\hline Rock 40 & 38.3 & 4.9 & Small & Intermediate & 4 & 0.50 & 2.50 & 0 & 0 & 0 & 0 \\
\hline Rock 41 & 31.2 & 3.8 & Small & Intermediate & 4 & 1.00 & 3.00 & 1 & 0 & 1 & 0 \\
\hline Rock 42 & 137.8 & 3.5 & Small & Intermediate & 4 & 0.50 & 2.50 & 0 & 0 & 0 & 0 \\
\hline Rock 44 & 60.1 & 0.8 & Small & Low & 5 & 0.50 & 3.00 & 0 & 0 & 0 & 0 \\
\hline Rock 45 & 146.8 & 9.8 & Small & Intermediate & 4 & 2.00 & 4.00 & 2 & 0 & 2 & 0 \\
\hline Rock 46 & 191.1 & 11.1 & Medium & Intermediate & 3 & 1.00 & 2.50 & 1 & 0 & 2 & 0 \\
\hline Rock 47 & 171.3 & 10.2 & Medium & Intermediate & 3 & 0.50 & 2.00 & 0 & 0 & 0 & 0 \\
\hline Rock 51 & 54.7 & NA & Small & Low & 5 & 0.50 & 3.00 & 0 & 0 & 0 & 0 \\
\hline Rock 52 & 17.6 & NA & Small & Low & 5 & 0.50 & 3.00 & 0 & 0 & 0 & 0 \\
\hline Rock 53 & 81.8 & 0.8 & Small & Low & 5 & 0.50 & 3.00 & 0 & 0 & 0 & 0 \\
\hline Rock 54 & 17.6 & NA & Small & Low & 5 & 0.50 & 3.00 & 0 & 0 & 0 & 0 \\
\hline Rock 55 & 58.0 & NA & Small & Intermediate & 4 & 0.50 & 2.50 & 0 & 0 & 0 & 0 \\
\hline Rock 56 & 10.1 & 0.6 & Small & Low & 5 & 0.50 & 3.00 & 0 & 0 & 0 & 0 \\
\hline Rock 57 & 38.5 & NA & Small & Low & 5 & 0.50 & 3.00 & 0 & 0 & 0 & 0 \\
\hline Rock 58 & 17.2 & 2.2 & Small & Low & 5 & 0.50 & 3.00 & 0 & 0 & 0 & 0 \\
\hline Rock 59 & 68.1 & 6.4 & Small & Intermediate & 4 & 0.50 & 2.50 & 0 & 0 & 0 & 0 \\
\hline Rock 66 & 84.5 & 4.5 & Small & Intermediate & 4 & 0.50 & 2.50 & 0 & 0 & 0 & 0 \\
\hline Rock 67 & 47.8 & 0.5 & Small & Low & 5 & 0.50 & 3.00 & 0 & 0 & 0 & 0 \\
\hline Rock 68 & 150.5 & 0.6 & Medium & Low & 4 & 1.80 & 3.80 & 1 & 1 & 1 & 2 \\
\hline Rock 69 & 781.7 & 7.3 & Medium & Intermediate & 3 & 2.56 & 4.06 & 4 & 0 & 27 & 0 \\
\hline Rock 70 & 75.4 & 2.6 & Small & Low & 5 & 0.50 & 3.00 & 0 & 0 & 0 & 0 \\
\hline Rock 71 & 248.8 & NA & Medium & Low & 4 & 0.50 & 2.50 & 0 & 0 & 0 & 0 \\
\hline Rock 72 & 15.8 & NA & Small & Low & 5 & 0.50 & 3.00 & 0 & 0 & 0 & 0 \\
\hline Rock 73 & 49.7 & NA & Small & Low & 5 & 1.92 & 4.42 & 2 & 0 & 5 & 0 \\
\hline Rock 74 & 65.7 & 2.2 & Small & Low & 5 & 0.50 & 3.00 & 0 & 0 & 0 & 0 \\
\hline Rock 75 & 124.9 & NA & Small & Low & 5 & 1.92 & 4.42 & 2 & 0 & 5 & 0 \\
\hline Rock 76 & 0.5 & 1.0 & Small & Low & 5 & 0.50 & 3.00 & 0 & 0 & 0 & 0 \\
\hline Rock 77 & 117.4 & 4.4 & Small & Intermediate & 4 & 0.50 & 2.50 & 0 & 0 & 0 & 0 \\
\hline
\end{tabular}


Table 4. All rocky shoreline habitats within Trinidad and Point Arena-Stornetta Units. Names were identified on local maps and from the Bureau of Land Management (BLM) staff. If a rock did not have a name, it was assigned a number.—Continued

[Names were identified on local maps and from BLM staff. If a rock did not have a name, it was assigned a number. Abbreviations: $\mathrm{m}^{2}$, square meter; LiDAR, light detection and ranging; m, meter; NA, not applicable]

\begin{tabular}{|c|c|c|c|c|c|c|c|c|c|c|c|}
\hline Rock name & Area $\left(\mathrm{m}^{2}\right)$ & $\begin{array}{c}\text { Height } \\
\text { (LiDAR; } \\
\text { m) }\end{array}$ & $\begin{array}{c}\text { Rock } \\
\text { size bin }\end{array}$ & $\begin{array}{c}\text { Rock height } \\
\text { bin }\end{array}$ & $\begin{array}{l}\text { Expo- } \\
\text { sure }\end{array}$ & $\begin{array}{l}\text { Sensitiv- } \\
\text { ity }\end{array}$ & $\begin{array}{c}\text { Vulnerabil- } \\
\text { ity }\end{array}$ & $\begin{array}{c}\text { Avian } \\
\text { species } \\
\text { observed }\end{array}$ & $\begin{array}{l}\text { Mammal } \\
\text { species } \\
\text { observed }\end{array}$ & $\begin{array}{l}\text { Adult } \\
\text { avian } \\
\text { count }\end{array}$ & $\begin{array}{c}\text { Mammal } \\
\text { count }\end{array}$ \\
\hline \multicolumn{12}{|c|}{ Trinidad-Continued } \\
\hline Rock 78 & 142.9 & 5.7 & Small & Intermediate & 4 & 0.50 & 2.50 & 0 & 0 & 0 & 0 \\
\hline Rock 79 & 78.3 & 0.5 & Small & Low & 5 & 1.00 & 3.50 & 1 & 0 & 1 & 0 \\
\hline Rock 80 & 24.2 & NA & Small & Low & 5 & 0.50 & 3.00 & 0 & 0 & 0 & 0 \\
\hline Rock 82 & 250.2 & 11.5 & Medium & Intermediate & 3 & 1.53 & 3.03 & 2 & 0 & 18 & 0 \\
\hline Rock 83 & 424.7 & 6.7 & Medium & Intermediate & 3 & 0.50 & 2.00 & 0 & 0 & 0 & 0 \\
\hline Rock 84 & 178.4 & 15.2 & Medium & High & 2 & 1.14 & 2.14 & 3 & 0 & 32 & 0 \\
\hline Rock 85 & 14.0 & NA & Small & Low & 5 & 0.50 & 3.00 & 0 & 0 & 0 & 0 \\
\hline Scotty Point Rock & $2,075.4$ & 27.9 & Large & High & 1 & 1.92 & 2.42 & 2 & 0 & 5 & 0 \\
\hline Sea Gull Rock & $2,577.3$ & 26.9 & Large & High & 1 & 0.50 & 1.00 & 0 & 0 & 0 & 0 \\
\hline Sea Lion Rock & $4,108.2$ & 37.4 & Large & High & 1 & 1.85 & 2.35 & 2 & 1 & 3 & 7 \\
\hline Sko"onaw & 299.3 & 7.1 & Medium & Intermediate & 3 & 1.00 & 2.50 & 1 & 0 & 2 & 0 \\
\hline Sme'tsken & 299.5 & 6.1 & Medium & Intermediate & 3 & 0.50 & 2.00 & 0 & 0 & 0 & 0 \\
\hline Snag Rock & $2,577.6$ & 32.8 & Large & High & 1 & 0.50 & 1.00 & 0 & 0 & 0 & 0 \\
\hline Split Rock & $1,597.3$ & 25.9 & Medium & High & 2 & 2.06 & 3.06 & 4 & 0 & 12 & 0 \\
\hline Tepona Rock & 791.9 & 21.1 & Medium & High & 2 & 1.00 & 2.00 & 1 & 0 & 3 & 0 \\
\hline Tsmo"oqwupa"a & 66.4 & 3.8 & Small & Intermediate & 4 & 0.50 & 2.50 & 0 & 0 & 0 & 0 \\
\hline Rock 10 & 123.3 & 0.1 & Small & Low & 5 & 0.50 & 3.00 & 0 & 0 & 0 & 0 \\
\hline Rock 11 & 54.2 & 2.8 & Small & Low & 5 & 0.50 & 3.00 & 0 & 0 & 0 & 0 \\
\hline Rock 12 & 52.9 & 2.4 & Small & Low & 5 & 0.50 & 3.00 & 0 & 0 & 0 & 0 \\
\hline Rock 13 & 124.5 & 2.9 & Small & Low & 5 & 0.50 & 3.00 & 0 & 0 & 0 & 0 \\
\hline Rock 14 & 571.5 & 4.4 & Medium & Intermediate & 3 & 0.50 & 2.00 & 0 & 0 & 0 & 0 \\
\hline Rock 15 & 173.6 & 4.7 & Medium & Intermediate & 3 & 0.50 & 2.00 & 0 & 0 & 0 & 0 \\
\hline Rock 16 & $1,281.3$ & 5.7 & Medium & Intermediate & 3 & 1.00 & 2.50 & 1 & 0 & 23 & 0 \\
\hline Rock 17 & 195.7 & 3.4 & Medium & Intermediate & 3 & 1.00 & 2.50 & 1 & 0 & 5 & 0 \\
\hline Rock 18 & 163.5 & 3.3 & Medium & Intermediate & 3 & 0.50 & 2.00 & 0 & 0 & 0 & 0 \\
\hline Rock 19 & 52.1 & 2.8 & Small & Low & 5 & 0.50 & 3.00 & 0 & 0 & 0 & 0 \\
\hline Rock 2 & 39.4 & 2.3 & Small & Low & 5 & 0.50 & 3.00 & 0 & 0 & 0 & 0 \\
\hline Rock 20 & 528.3 & 2.1 & Medium & Low & 4 & 0.50 & 2.50 & 0 & 1 & 0 & 11 \\
\hline
\end{tabular}


Table 4. All rocky shoreline habitats within Trinidad and Point Arena-Stornetta Units. Names were identified on local maps and from the Bureau of Land Management (BLM) staff. If a rock did not have a name, it was assigned a number.-Continued

[Names were identified on local maps and from BLM staff. If a rock did not have a name, it was assigned a number. Abbreviations: $\mathrm{m}^{2}$, square meter; LiDAR, light detection and ranging; $\mathrm{m}$, meter; NA, not applicable]

\begin{tabular}{|c|c|c|c|c|c|c|c|c|c|c|c|}
\hline Rock name & Area $\left(\mathrm{m}^{2}\right)$ & $\begin{array}{c}\text { Height } \\
\text { (LiDAR; } \\
\text { m) }\end{array}$ & $\begin{array}{c}\text { Rock } \\
\text { size bin }\end{array}$ & $\begin{array}{c}\text { Rock height } \\
\text { bin }\end{array}$ & $\begin{array}{l}\text { Expo- } \\
\text { sure }\end{array}$ & $\begin{array}{l}\text { Sensitiv- } \\
\text { ity }\end{array}$ & $\begin{array}{c}\text { Vulnerabil- } \\
\text { ity }\end{array}$ & $\begin{array}{c}\text { Avian } \\
\text { species } \\
\text { observed }\end{array}$ & $\begin{array}{c}\text { Mammal } \\
\text { species } \\
\text { observed }\end{array}$ & $\begin{array}{l}\text { Adult } \\
\text { avian } \\
\text { count }\end{array}$ & $\begin{array}{c}\text { Mammal } \\
\text { count }\end{array}$ \\
\hline \multicolumn{12}{|c|}{ Point Arena-Continued } \\
\hline Rock 21 & 124.4 & 3.0 & Small & Intermediate & 4 & 0.50 & 2.50 & 1 & 0 & 21 & 0 \\
\hline Rock 22 & 278.4 & 4.7 & Medium & Intermediate & 3 & 0.50 & 2.00 & 0 & 0 & 0 & 0 \\
\hline Rock 23 & 164.1 & 1.2 & Medium & Low & 4 & 0.50 & 2.50 & 0 & 0 & 0 & 0 \\
\hline Rock 25 & 771.0 & 5.4 & Medium & Intermediate & 3 & 0.50 & 2.00 & 0 & 0 & 0 & 0 \\
\hline Rock 26 & 717.0 & 4.1 & Medium & Intermediate & 3 & 0.50 & 2.00 & 0 & 0 & 0 & 0 \\
\hline Rock 27 & 584.4 & 4.4 & Medium & Intermediate & 3 & 2.97 & 4.47 & 2 & 0 & 37 & 0 \\
\hline Rock 28 & 51.6 & 2.7 & Small & Low & 5 & 0.50 & 3.00 & 0 & 0 & 0 & 0 \\
\hline Rock 31 & 71.2 & 10.5 & Small & Intermediate & 4 & 0.50 & 2.50 & 0 & 0 & 0 & 0 \\
\hline $\begin{array}{l}\text { Rock } 32 \text { (Sea Lion } \\
\quad \text { Rock) }\end{array}$ & $20,261.4$ & 14.1 & Large & High & 1 & 0.50 & 1.00 & 0 & 0 & 0 & 0 \\
\hline Rock 33 & 120.7 & 2.9 & Small & Low & 5 & 0.50 & 3.00 & 1 & 0 & 1 & 0 \\
\hline Rock 34 & 184.0 & 3.6 & Medium & Intermediate & 3 & 0.50 & 2.00 & 0 & 0 & 0 & 0 \\
\hline Rock 35 & 52.8 & 3.1 & Small & Intermediate & 4 & 1.00 & 3.00 & 0 & 0 & 0 & 0 \\
\hline $\begin{array}{l}\text { Rock } 36 \text { (whitewash } \\
\text { Rock) }\end{array}$ & 190.0 & 15.3 & Medium & High & 2 & 0.50 & 1.50 & 0 & 0 & 0 & 0 \\
\hline Rock 37 & 69.1 & 11.3 & Small & Intermediate & 4 & 0.50 & 2.50 & 0 & 0 & 0 & 0 \\
\hline Rock 7 & 124.6 & 6.9 & Small & Intermediate & 4 & 1.00 & 3.00 & 1 & 0 & 3 & 0 \\
\hline Rock 8 & 924.7 & 5.0 & Medium & Intermediate & 3 & 1.00 & 2.50 & 2 & 0 & 24 & 0 \\
\hline Rock 9 & 23.3 & NA & Small & Low & 5 & 0.50 & 3.00 & 0 & 0 & 0 & 0 \\
\hline
\end{tabular}




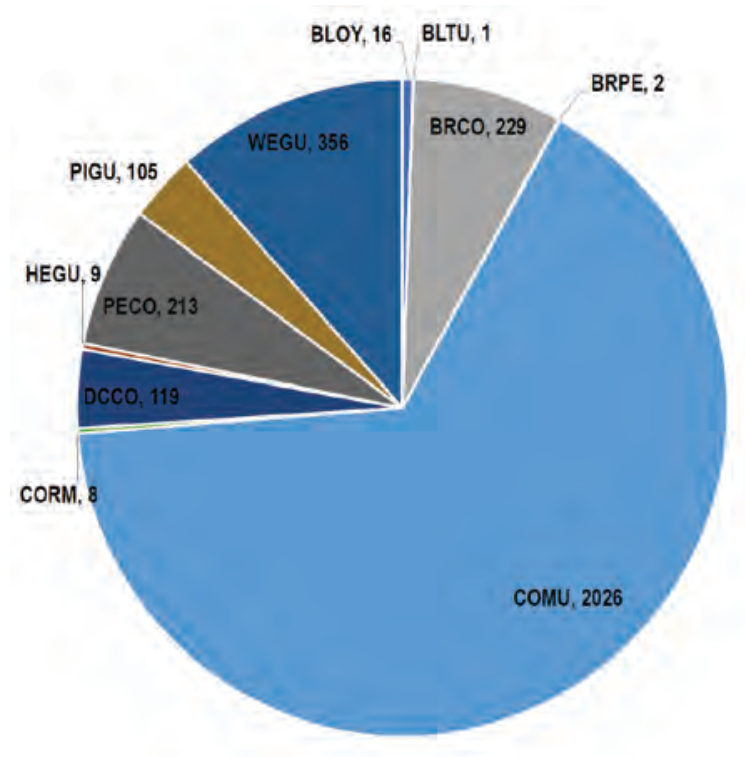

Figure 11. Bird species observed and total count within the Trinidad Unit. See table 5 for species codes.

Table 5. List of all avian and pinniped species observed during boat surveys in Trinidad Unit occupying offshore rocks.

[*Species identified in Hutto and others, 2015.]

\begin{tabular}{llll}
\hline \multicolumn{1}{c}{ Code } & \multicolumn{1}{c}{ Common name } & \multicolumn{1}{c}{ Scientific name } & \multicolumn{1}{c}{ Guild } \\
\hline BLOY & Black oystercatcher* & Haematopus bachmani & Shorebird \\
BLTU & Black turnstone & Arenaria melanocephala & Shorebird (non-breeding) \\
BRCO & Brandt's cormorant* & Phalacrocorax penicillatus & Seabird \\
BRPE & Brown pelican & Pelecanus occidentalis & Seabird (non-breeding) \\
CASL & California sea lion & Zalophus californianus & Sea lion \\
COMU & Common murre* & Uria aalge & Alcid \\
CORM & Cormorant (unidentified species) & Phalacrocorax sp. & Seabird \\
DCCO & Double-crested cormorant & Phalacrocorax auritus & Seabird \\
HASE & Harbor seal & Phoca vitulina richardii & Seal \\
HEGU & Herring gull & Larus argentatus & Gull (non-breeding) \\
PECO & Pelagic cormorant & Phalacrocorax pelagicus & Seabird \\
PIGU & Pigeon guillemot & Cepphus columba & Alcid \\
STSL & Steller sea lion & Eumetopias jubatus & Sea lion \\
WEGU & Western gull & Larus occidentalis & Gull \\
\hline
\end{tabular}




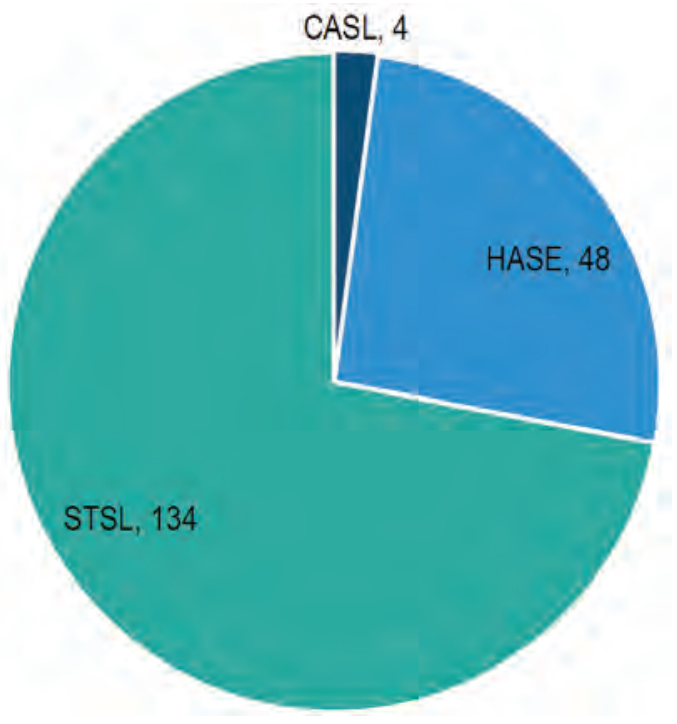

Figure 12. Pinniped species observed and total count in the Trinidad Unit. See table 5 for species codes.

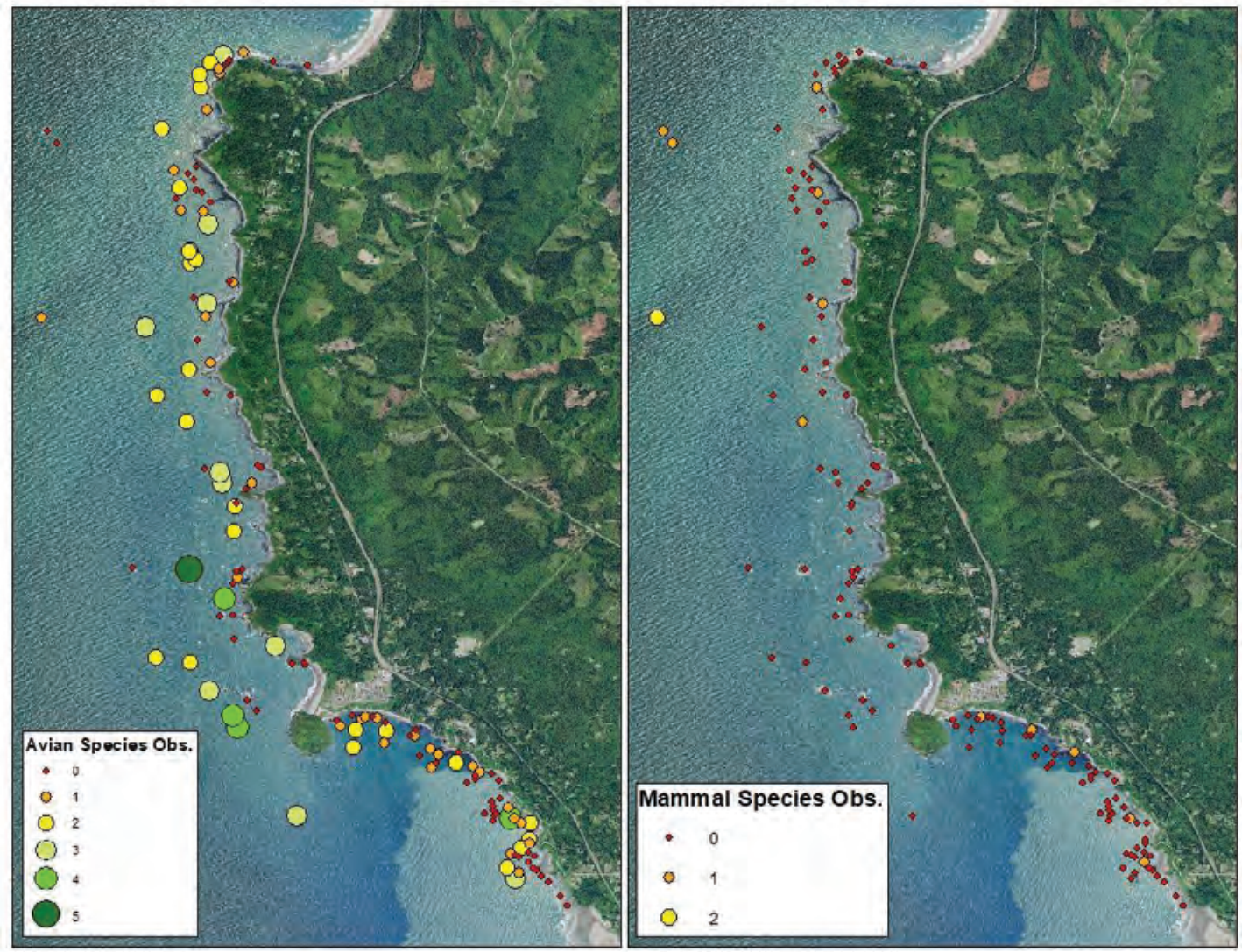

Map image is the intellectual property of Esri and is used herin under license. Copyright 2020 Esri and its licensors. All rights reserved.

Figure 13. Number of avian and mammal species observed during boat surveys, by rock feature, in the Trinidad Unit. 


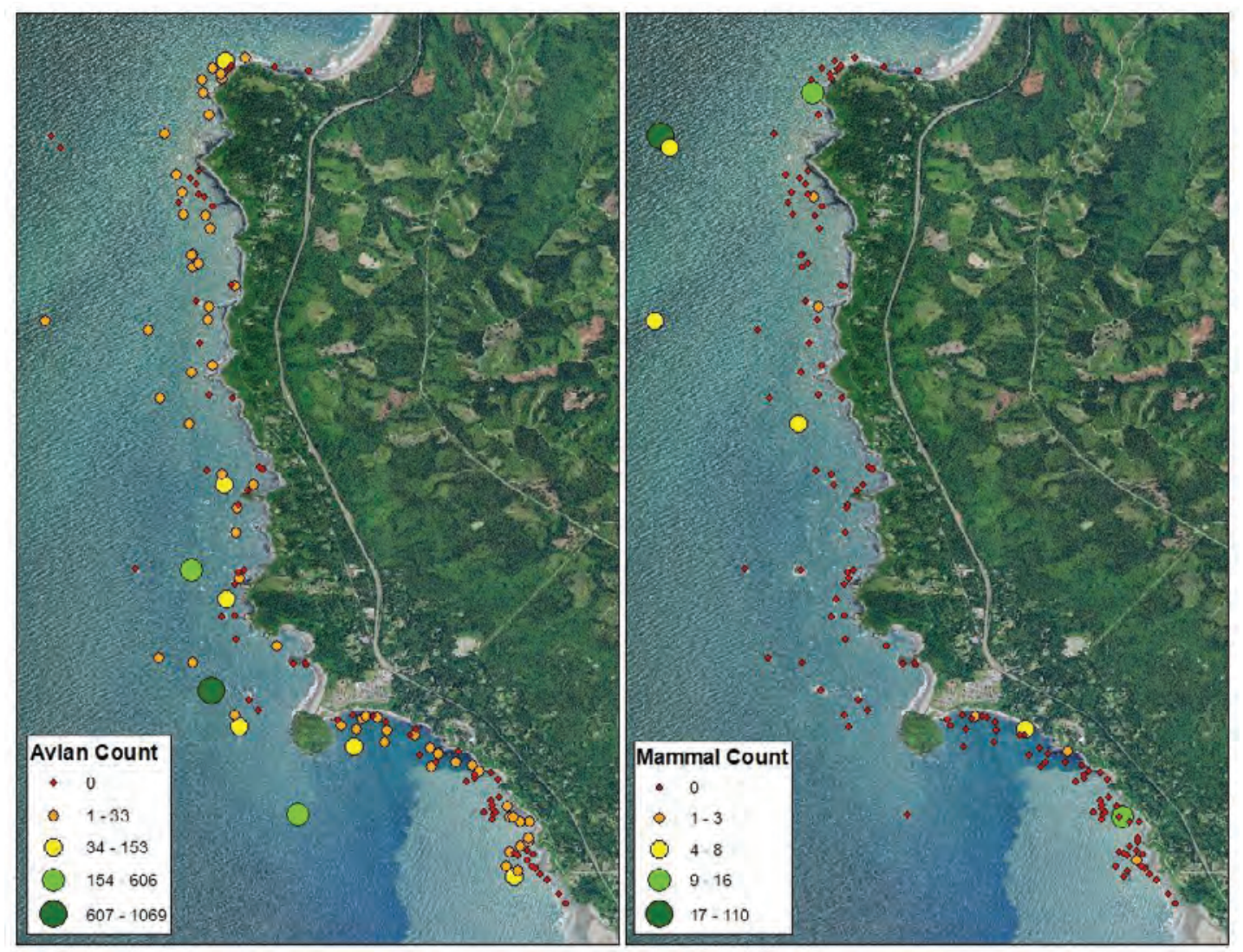

Map image is the intellectual property of Esri and is used herin under license. Copyright 2020 Esri and its licensors. All rights reserved.

Figure 14. Number of individual avian and mammals observed (all taxa combined) during boat surveys, by rock feature, in the Trinidad Unit.
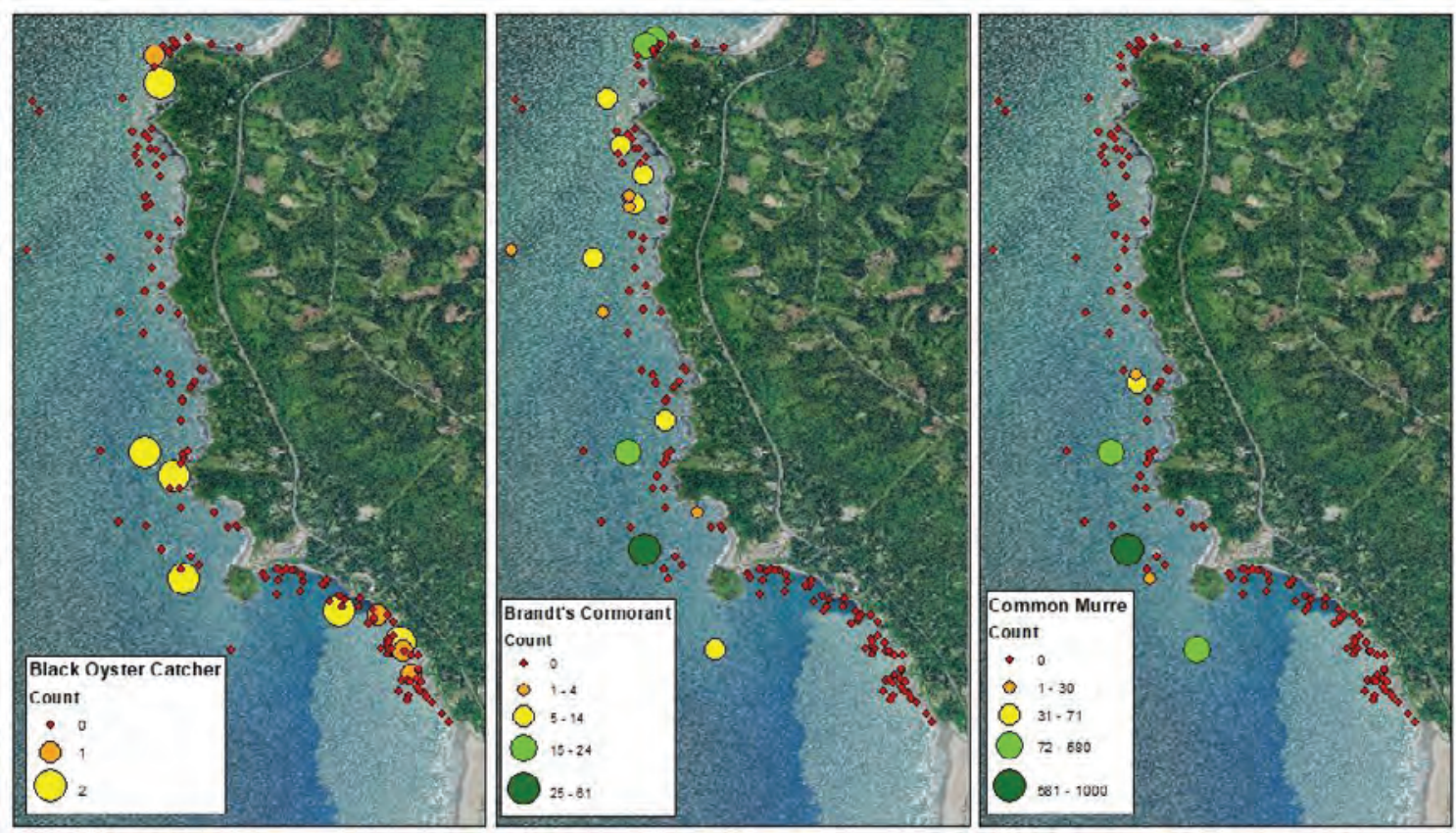

Map image is the intellectual property of Esri and is used herin under license. Copyright 2020 Esri and its licensors. All rights reserved.

Figure 15. Counts of three indicator species (Black Oystercatcher, Brandt's Cormorant, Common Murre) by rock feature. 


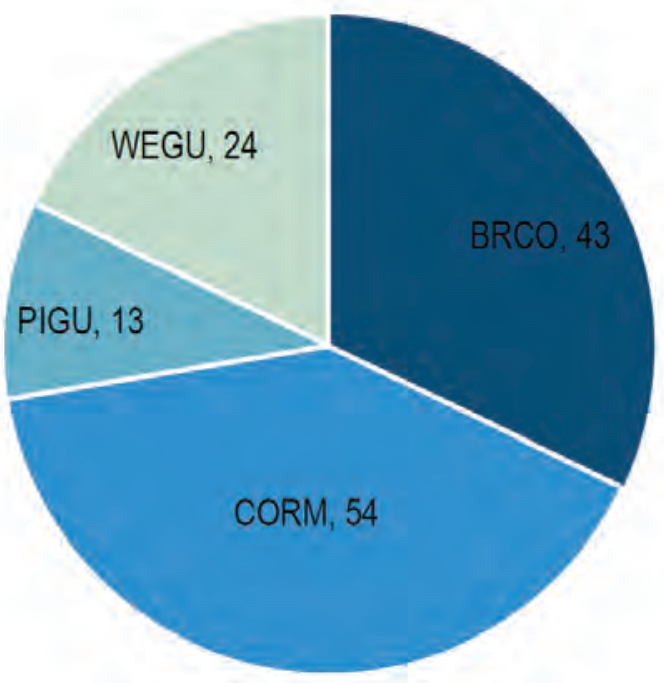

Figure 16. Bird species observed and total count within Point Arena-Stornetta Unit. See table 6 for species codes.
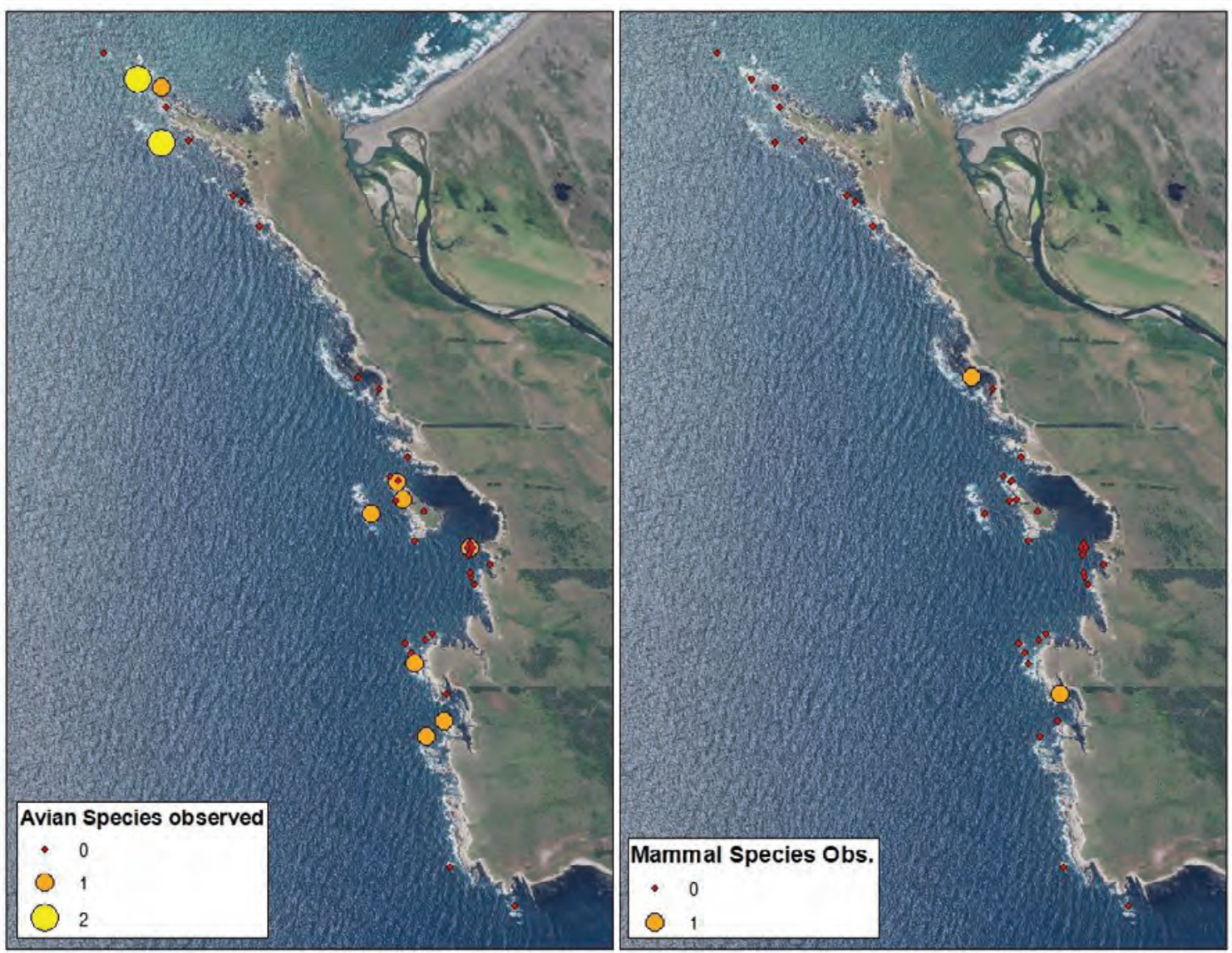

Map image is the intellectual property of Esri and is used herin under license. Copyright 2020 Esri and its licensors. All rights reserved.

Figure 17. Number of avian and mammal species observed during boat surveys, by rock feature, in Point Arena-Stornetta Unit. 

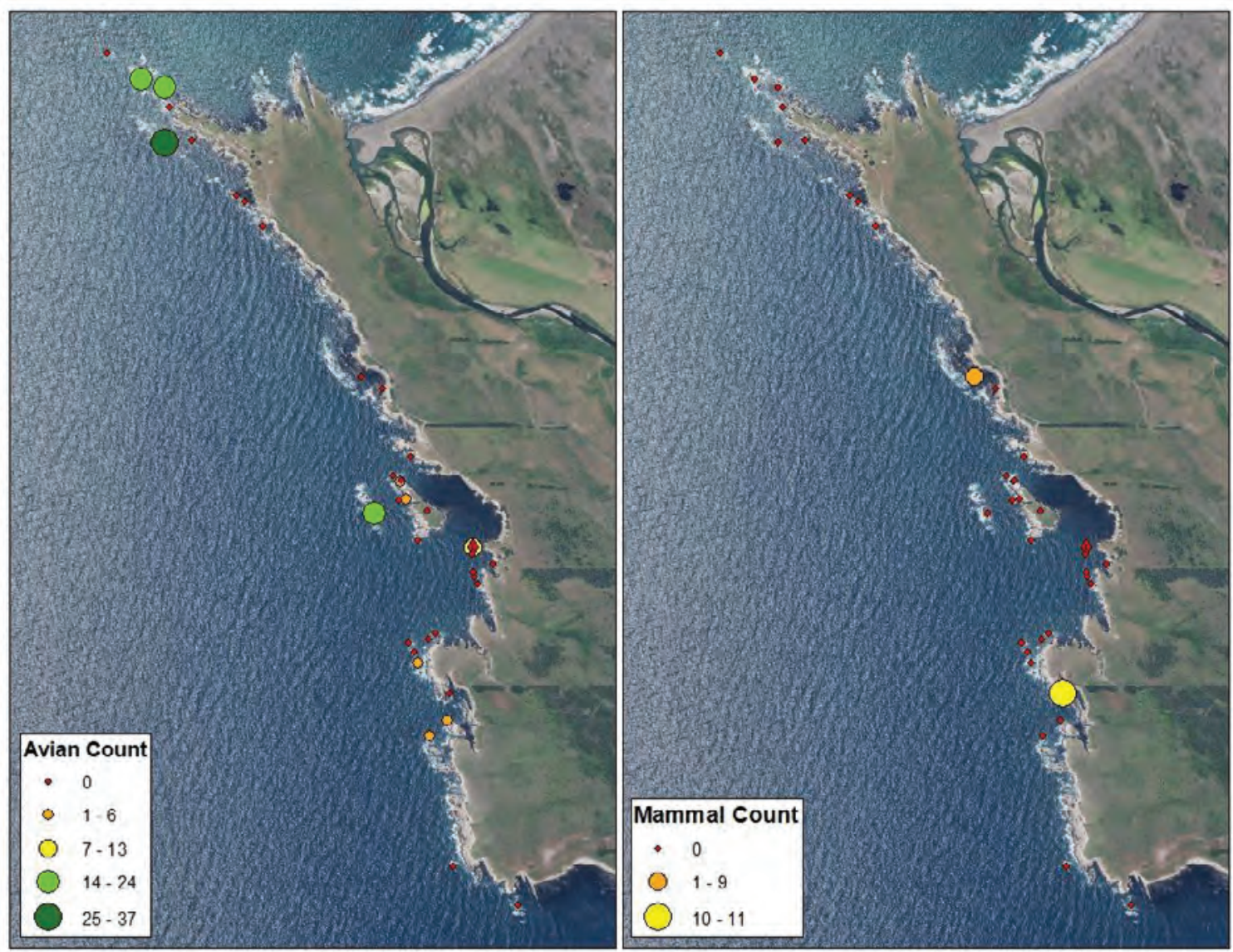

Map image is the intellectual property of Esri and is used herin under license. Copyright 2020 Esri and its licensors. All rights reserved.

Figure 18. Number of individual birds and mammals observed (all taxa combined) during boat surveys, by rock feature, in Point Arena-Stornetta Unit.

Table 6. List of all species (avian and pinniped) observed within the Point Arena-Stornetta Unit.

[*Species identified in Hutto and others, 2015.]

\begin{tabular}{llll}
\hline \multicolumn{1}{c}{ Code } & \multicolumn{1}{c}{ Common name } & \multicolumn{1}{c}{ Scientific name } & \multicolumn{1}{c}{ Guild } \\
\hline BLOY & Black oystercatcher* & Haematopus bachmani & Shorebird \\
BRCO & Brandt's cormorant* & Phalacrocorax penicillatus & Seabird \\
DCCO & Double-crested cormorant & Phalacrocorax auritus & Seabird \\
HASE & Harbor seal & Phoca vitulina richardii & Seal \\
PECO & Pelagic cormorant & Phalacrocorax pelagicus & Seabird \\
PIGU & Pigeon guillemot & Cepphus columba & Alcid \\
WEGU & Western gull & Larus occidentalis & Gull \\
\hline
\end{tabular}




\section{Sensitivity}

Across both sites, species richness was positively correlated with rock size $\left(\mathrm{F}_{2,114}=12.1, \mathrm{p}<0.0001\right)$. Large rocks had an average richness of $2.2(\mathrm{SD}=1.67)$, medium rocks had an average of $1.3(\mathrm{SD}=0.98)$ species, small rocks had an average of $0.74(\mathrm{SD}=0.82)$ species. Taller rocks tended to have greater species richness; however, Tukey Honestly Significant Difference (HSD) post-hoc comparisons between height classes were not significant. Species richness was different across rock exposures, a combined metric of size and height, with an average richness of $2.58(\mathrm{SD}=1.73)$ species in the lowest exposure class $\left(F^{4,112}=7.123, p<0.0001\right)$. Richness declined across higher exposure classes, ranging from $1.38(\mathrm{SD}=1.2)$ species in exposure class 2 to 0.72 $(\mathrm{SD}=0.79)$ species in exposure class 5 , but differences were not significant.

The sensitivity metric was significantly greater for large rocks $(1.46, \mathrm{SD}=0.86)$ compared to small rocks $(0.91$, $\left.\mathrm{SD}=0.49 ; \mathrm{F}^{2,114}=6.24, \mathrm{p}=0.0027\right)$. There were no significant differences in sensitivity across rock heights classes $\left(F^{2,114}=0.42, p=0.658\right)$. Sensitivity tended to be greatest in the lower exposure classes $\left(\mathrm{F}^{4,112}=2.767, \mathrm{p}=0.031\right)$, but pair-wise comparisons with the Tukey HSD test were not significant.

\section{Vulnerability}

Trinidad Unit rock vulnerability ranged from 1 to 4.42 (out of 5) with an average vulnerability score of 2.67. Overall, 48 percent of rocks had a vulnerability score of 3 or greater (figs. 19-22). Avian species were observed on 69 of the 138 rock features at Trinidad Unit, with those rocks having an average vulnerability score of 2.82 and 49 percent of the rocks having a vulnerability score of 3 or greater.

When examining guild use of vulnerable rocks (vulnerability score $>3$ ), alcids (here defined as common murres and pigeon guillemots) were observed on only 28 percent of vulnerable rocks, shorebirds on 30 percent, gulls on 43 percent, and seabirds on 58 percent. However, when examining the three indicator species identified in Hutto and others (2015), we found that common murres were not counted on vulnerable rocks, black oystercatchers were present on only 30 percent of vulnerable rock features, and Brandt's cormorant were present on 64 percent of vulnerable rock features. Mammals were found on 12 rock features with 9 (75 percent) of those rocks ranking highly vulnerable with a score of 3 or greater, with seals on 100 percent of vulnerable rocks and sea lions only on 40 percent.

Point Arena-Stornetta Unit rock vulnerability ranged from 1 to 4.46 (out of 5), with an average vulnerability score of 2.54. Overall, 42.5 percent of rocks had a vulnerability score of 3 or greater (figs. 23-26). Avian species were observed on 10 of the 40 rock features at Point Arena-Stornetta Unit, with those rocks having an average vulnerability score of 2.85 and 50 percent of the rocks having a vulnerability score of 3 or greater. When examining guild use of vulnerable rocks (vulnerability score $>3$ ), alcids were not observed on vulnerable rocks, gulls on 33 percent, seals on 50 percent, and seabirds on 57 percent of vulnerable rocks. Among the three indicator species, we found that Brandt's cormorant occupied 67 percent of vulnerable (vulnerability score $>3$ ) rock features, whereas common murre and black oystercatchers were not observed at the Point Arena-Stornetta Unit. Harbor seals were the only mammals observed and were found on two rock features with one (50 percent) of those rocks ranking highly vulnerable with a score of 3 or greater.

To account for the timing of our surveys, we compared our species richness data to Bureau of Land Management nesting season species richness data for major seabird colonies in both units. We found that the 2017 nesting survey data and our species richness data from the same year were correlated; however, more species were observed during the nesting season (fig. 27). We also observed a relationship between higher species richness and lower exposure scores for the associated rocks for the 2017 nesting and our post-breeding survey data (fig. 27). Although there was no relationship between species richness and sensitivity or vulnerability scores, we were able to spatially assess specific rocks that had high nesting species richness as well as high vulnerability scores (fig. 28).

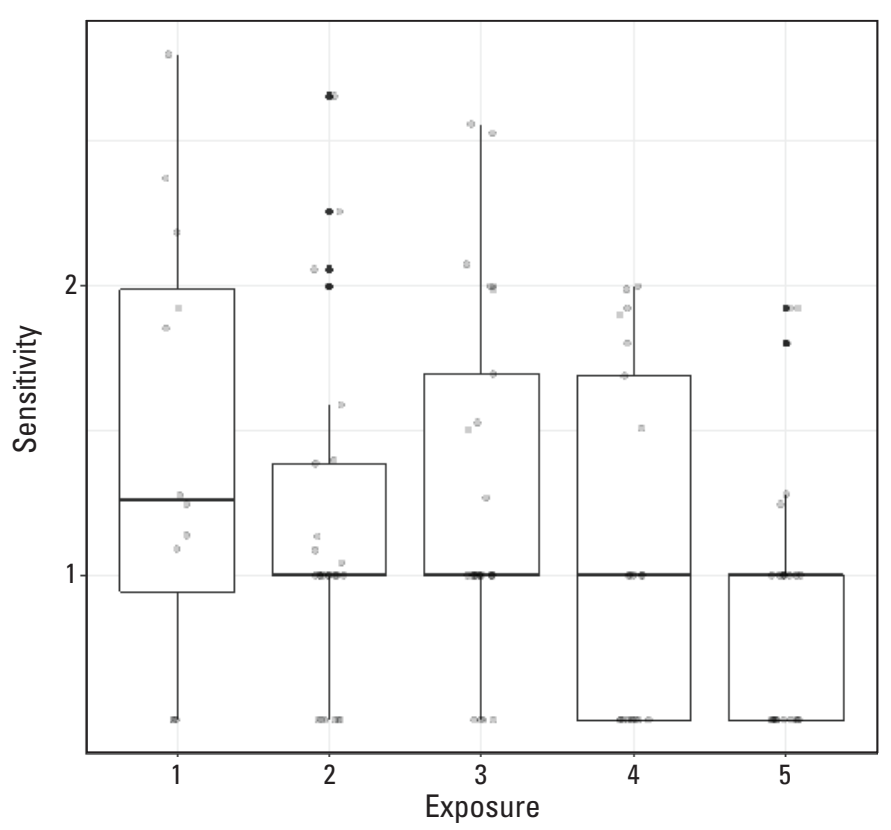

Figure 19. Sensitivity ranking relative to rock exposure classification for the Trinidad Unit. 

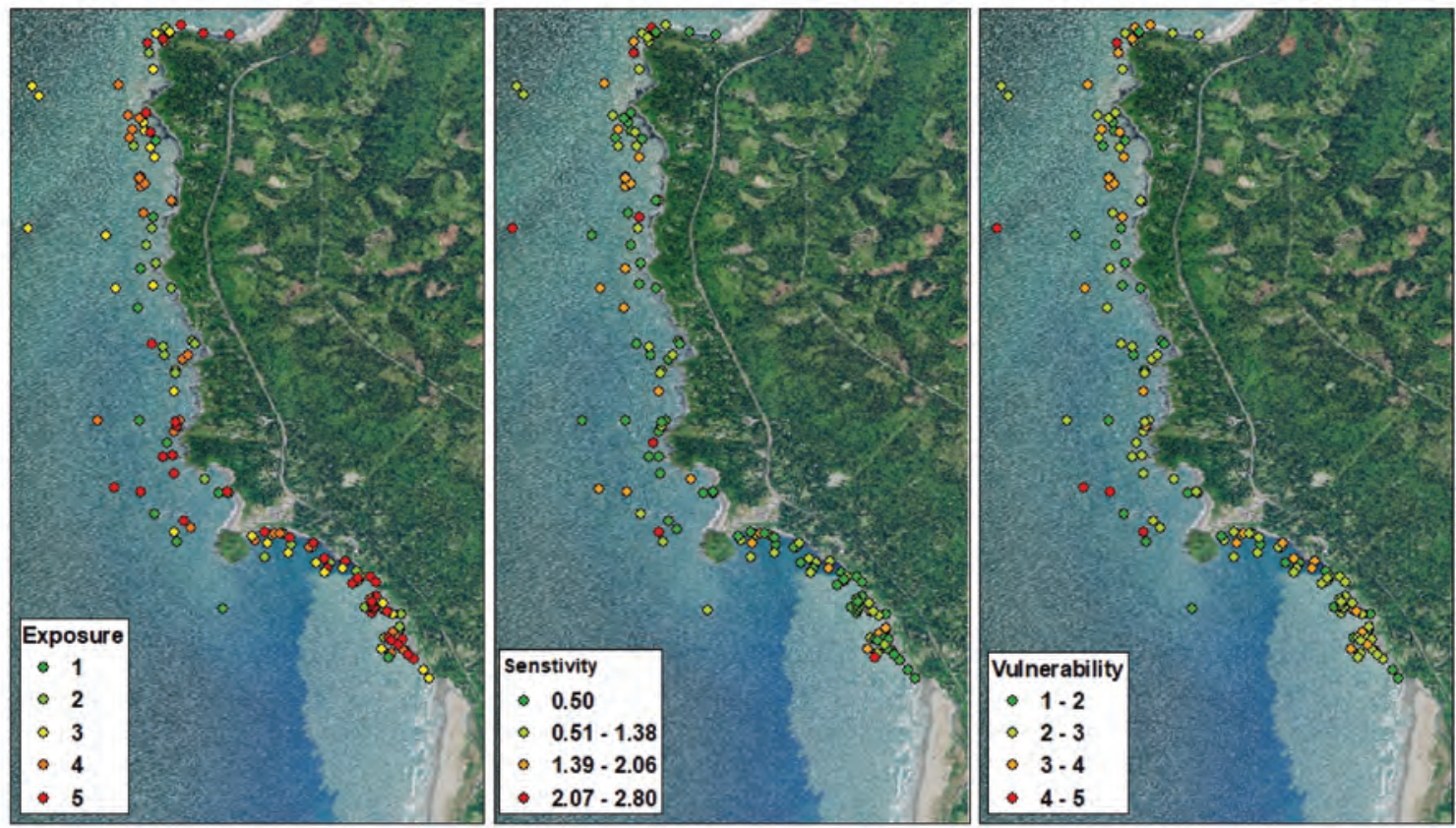

Map image is the intellectual property of Esri and is used herin under license. Copyright 2020 Esri and its licensors. All rights reserved.

Figure 20. Trinidad Unit offshore rocks and their associated exposure, sensitivity, and vulnerability scores. Vulnerability score $1=$ low and $5=$ high.
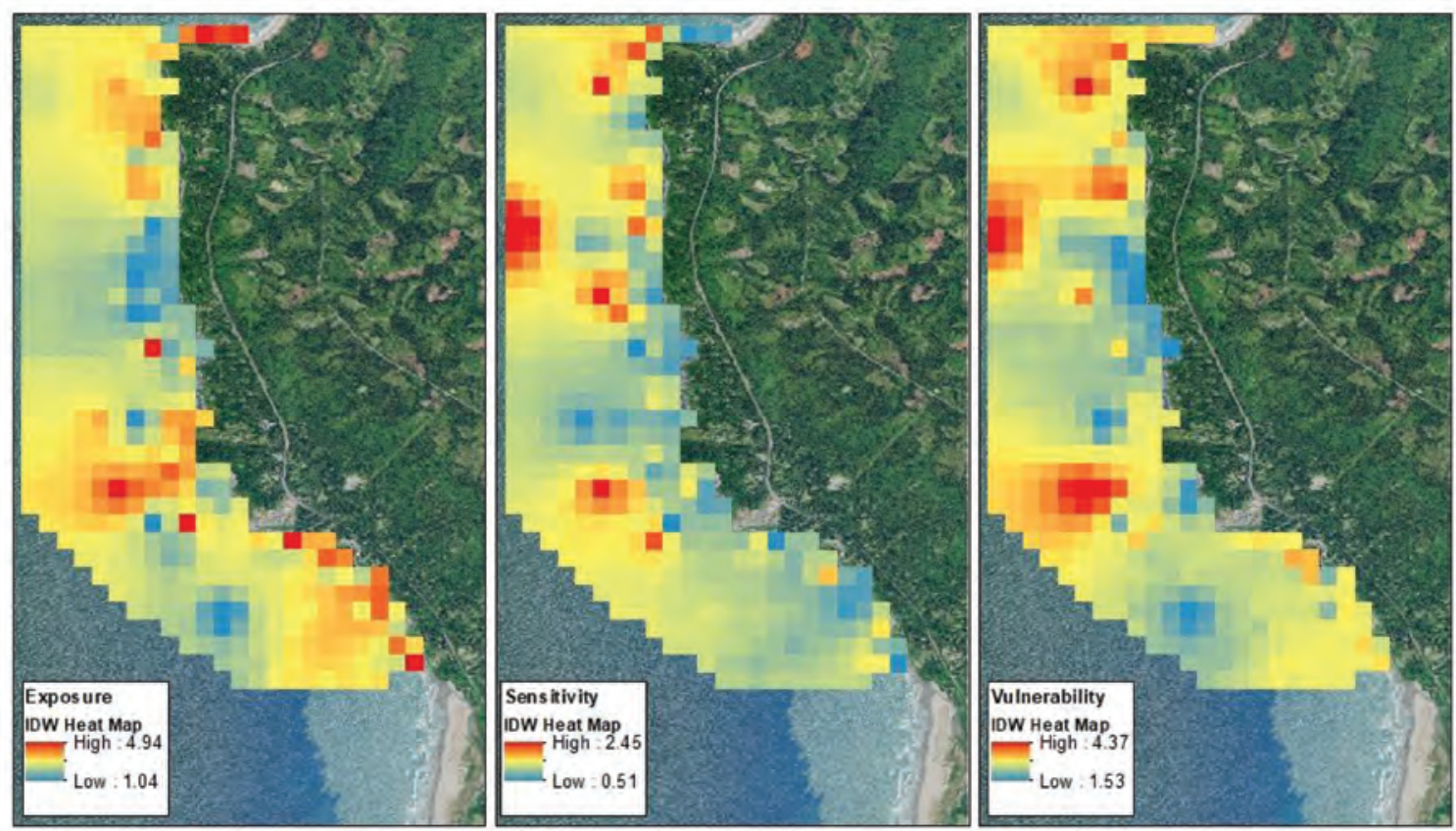

Map image is the intellectual property of Esri and is used herin under license. Copyright 2020 Esri and its licensors. All rights reserved.

Figure 21. Trinidad Unit exposure, sensitivity, and vulnerability scores based on an inverse distance weighted raster heat map. 

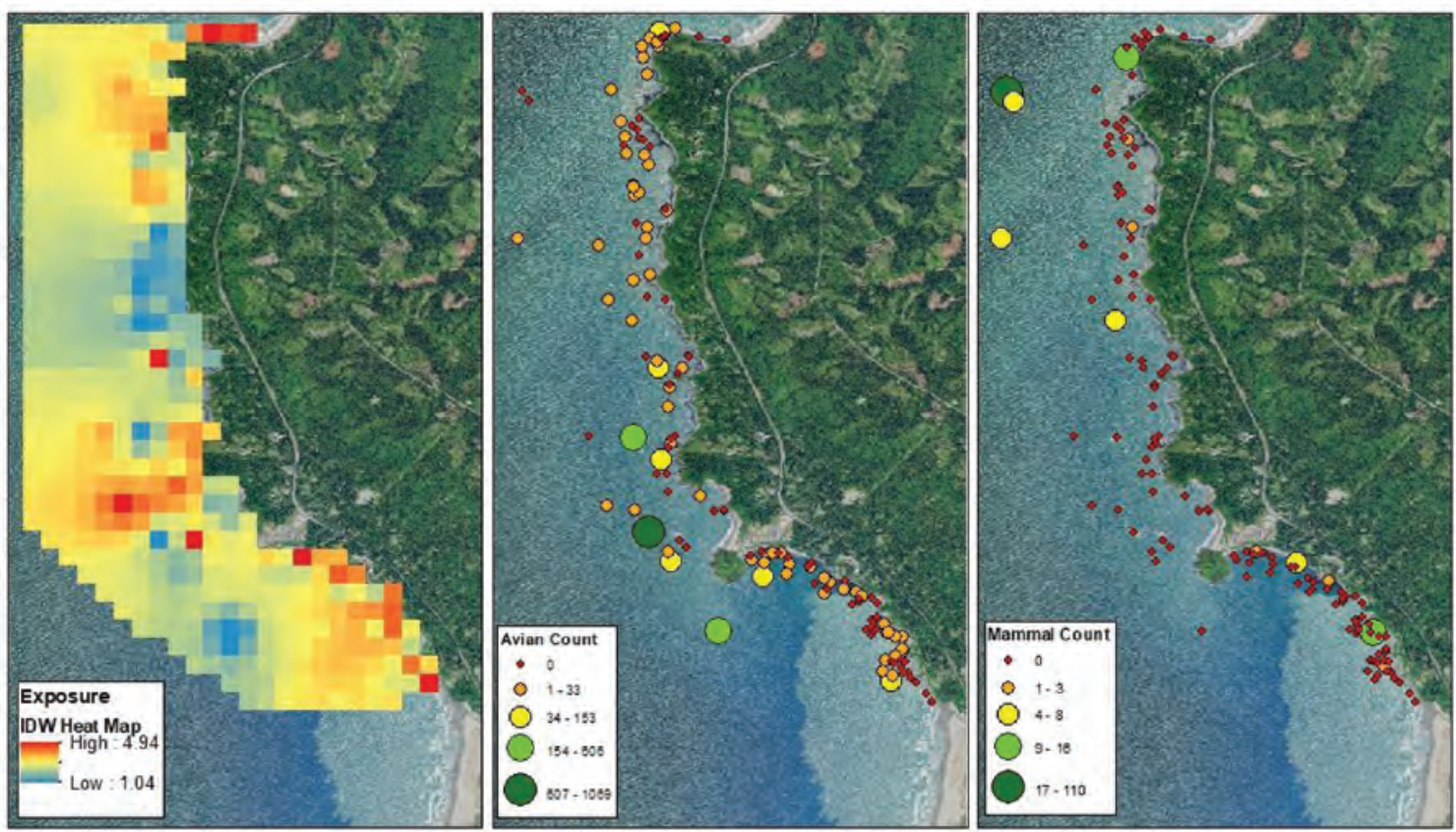

Map image is the intellectual property of Esri and is used herin under license. Copyright 2020 Esri and its licensors. All rights reserved.

Figure 22. Number of avian and mammal species observed by rock feature in relation to exposure of the study area.

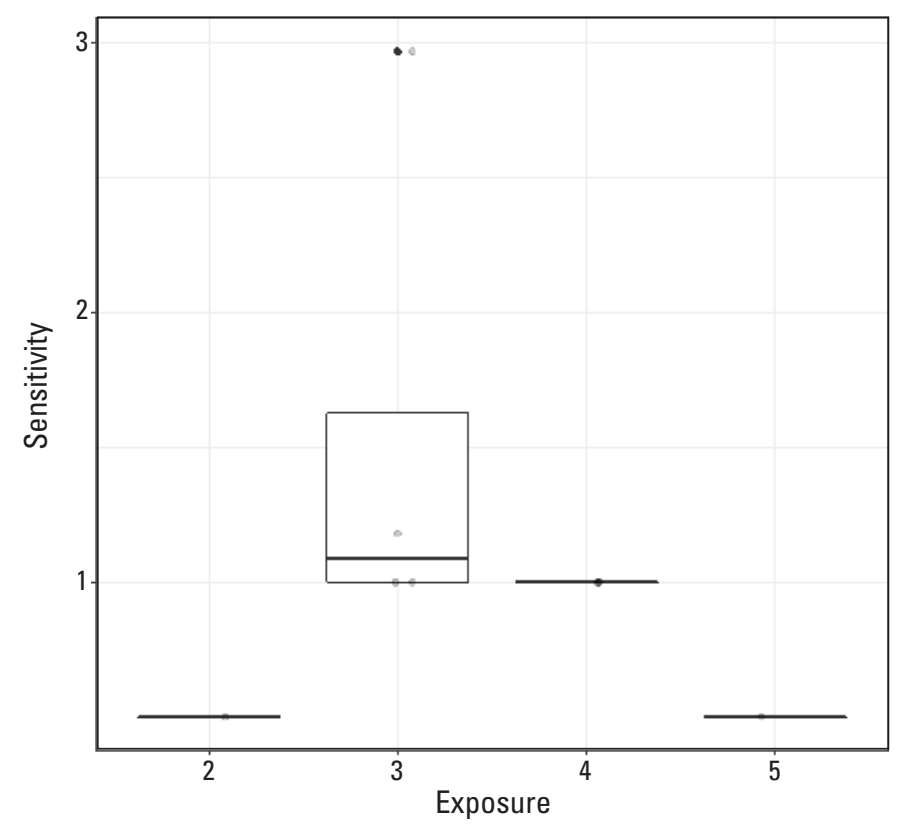

Figure 23. Sensitivity ranking relative to rock exposure classification for the Point Arena-Stornetta Unit. 

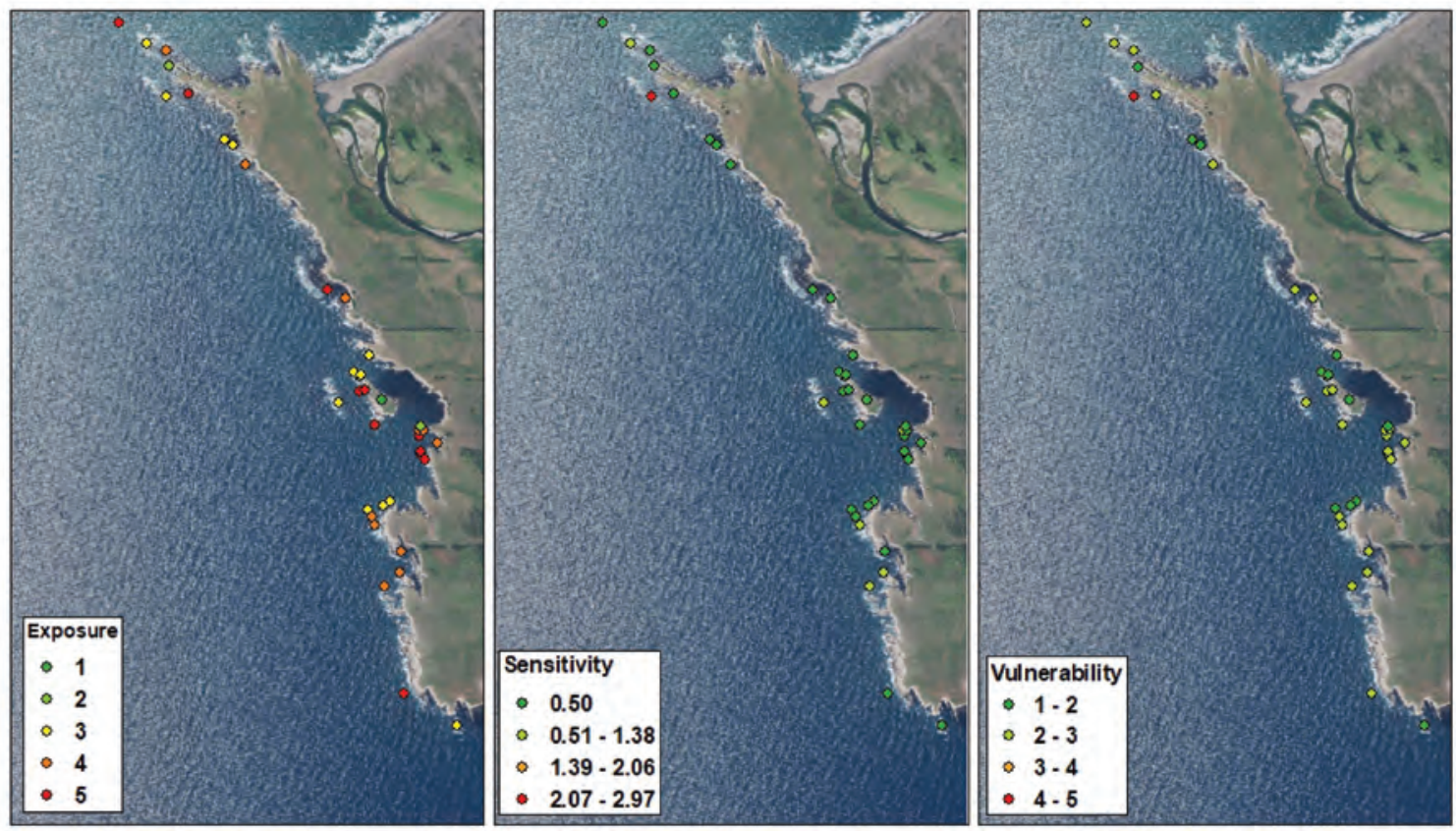

Map image is the intellectual property of Esri and is used herin under license. Copyright 2020 Esri and its licensors. All rights reserved.

Figure 24. Point Arena-Stornetta Unit offshore rocks and their associated exposure, sensitivity, and vulnerability scores. Vulnerability score $1=$ low and $5=$ high.
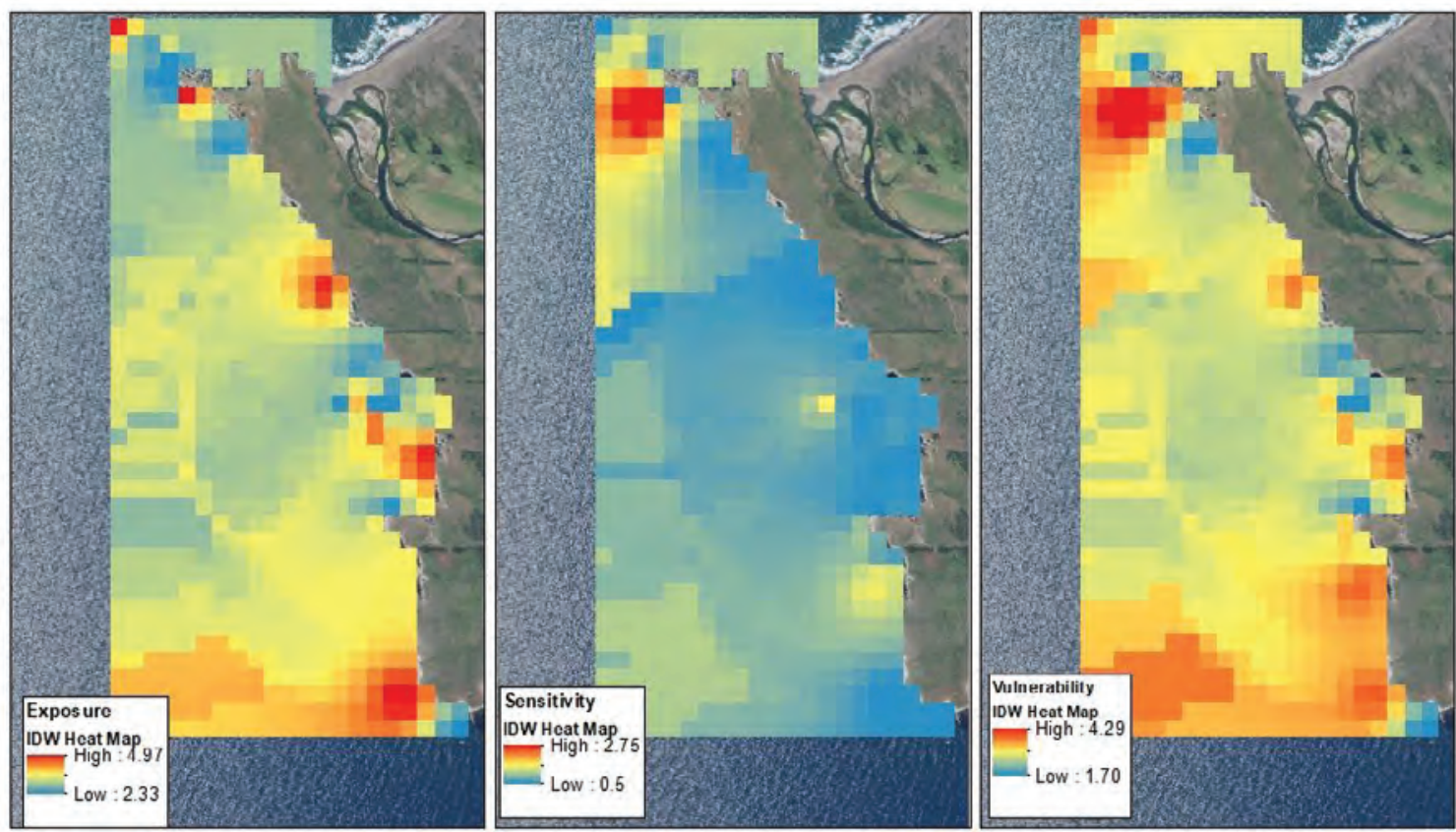

Map image is the intellectual property of Esri and is used herin under license. Copyright 2020 Esri and its licensors. All rights reserved.

Figure 25. Point Arena-Stornetta Unit exposure, sensitivity, and vulnerability scores based on an inverse distance weighted raster heat map. 

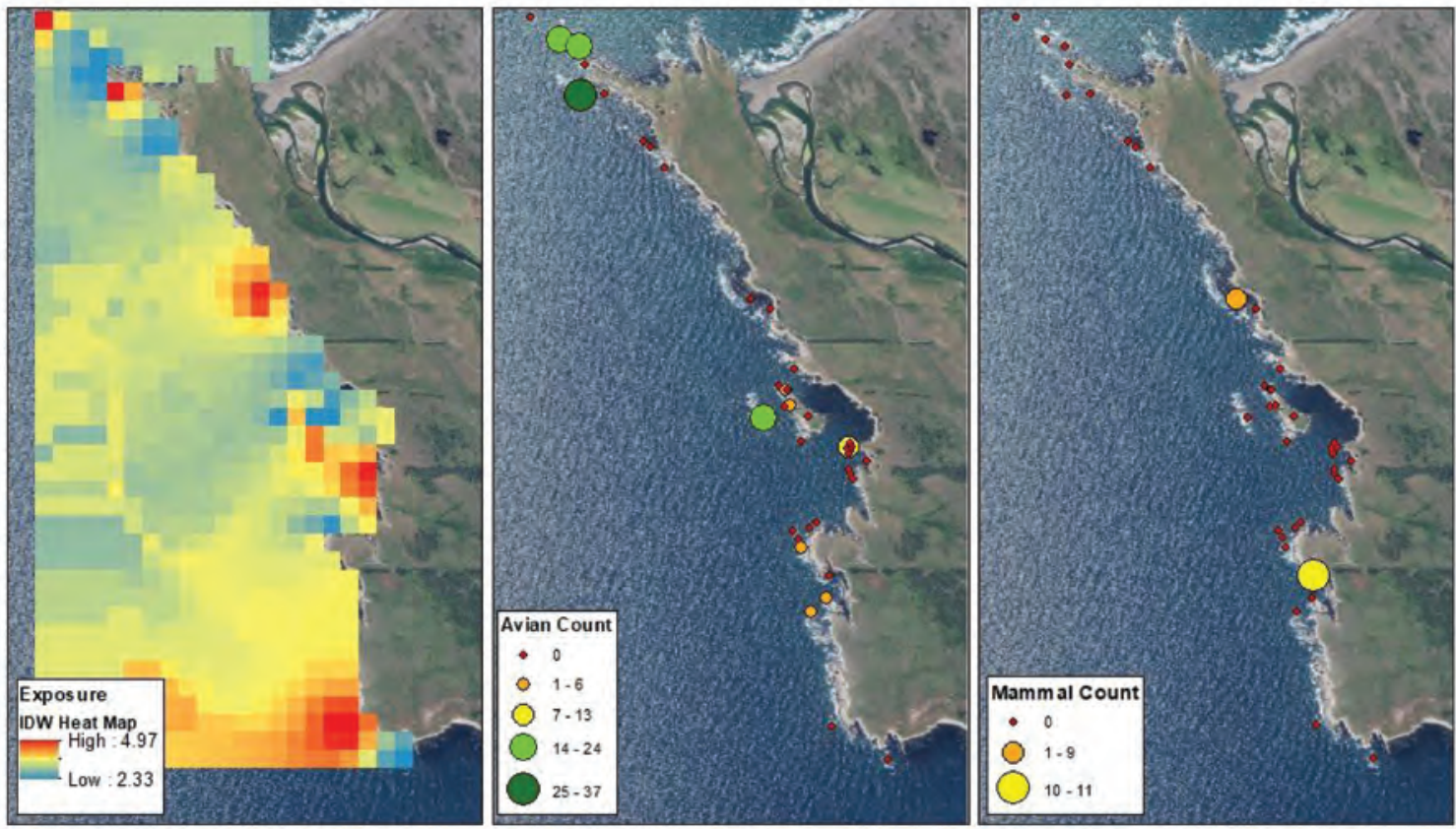

Map image is the intellectual property of Esri and is used herin under license. Copyright 2020 Esri and its licensors. All rights reserved.

Figure 26. Number of avian and mammal species observed by rock feature in relation to exposure at the Point Arena-Stornetta Unit. 

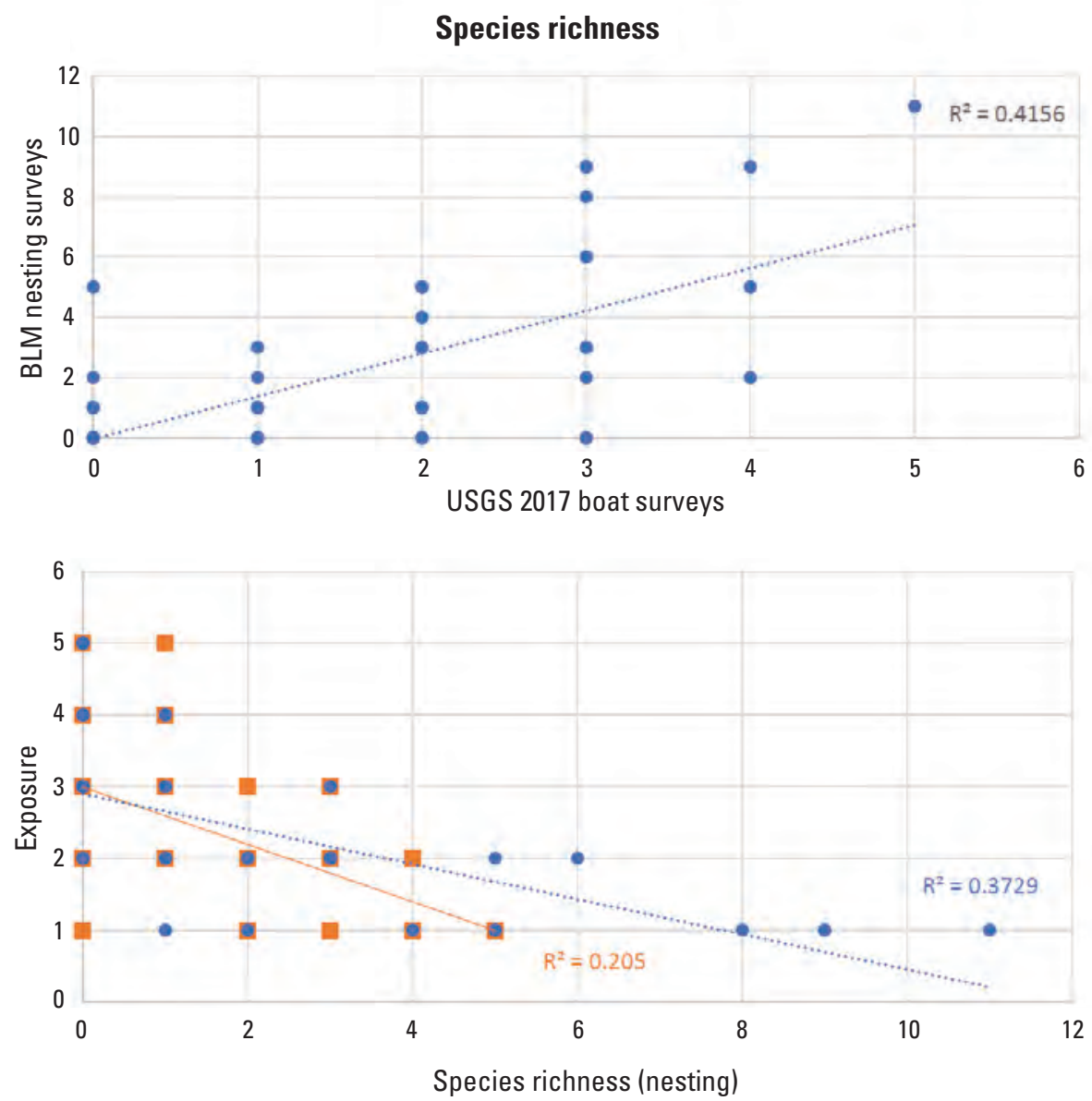

USGS 2017 survey $\quad$ BLM nesting survey

Figure 27. Comparison of Bureau of Land Management (BLM) 2017 Trinidad nesting surveys and U.S. Geological Survey (USGS) 2017 post-breeding surveys of major seabird colony rocks with their associated rock exposure (S. Murphy, Bureau of Land Management and Humboldt State University, North Coast Seabird Protection Network, written commun., 2019). Exposure 5=high and $1=$ low. Both BLM and USGS surveys showed that species richness was highest on rocks with low exposure values. 


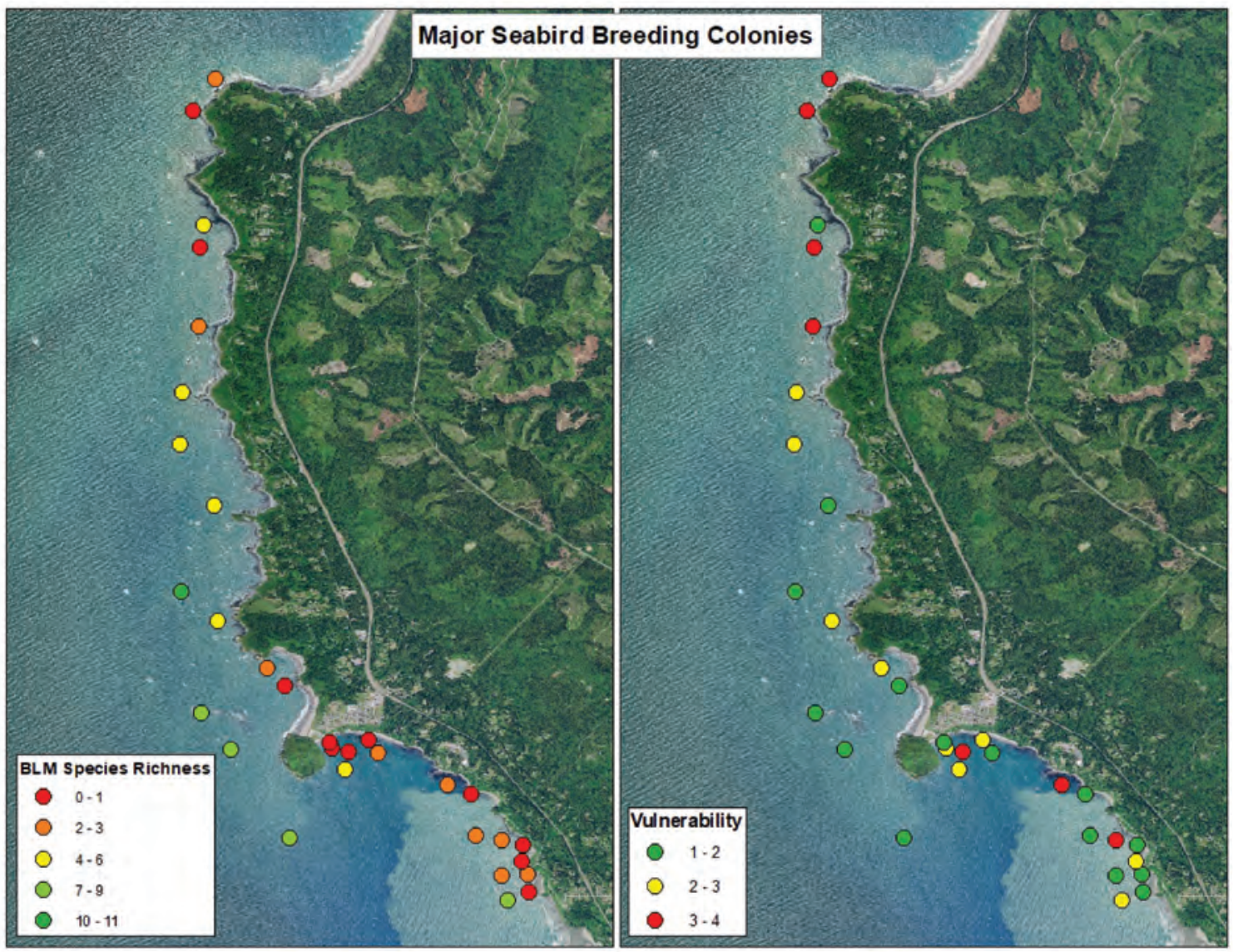

Map image is the intellectual property of Esri and is used herin under license. Copyright 2020 Esri and its licensors. All rights reserved.

Figure 28. Bureau of Land Management species richness data for Trinidad major seabird colonies compared to our vulnerability scores.

\section{Discussion}

Climate change likely will affect the CCNM Trinidad and Point Arena-Stornetta Units in a variety of ways, including changes in ocean conditions (temperature, $\mathrm{pH}$ ), storm frequency and intensity, and precipitation and fog patterns, with the greatest effects likely from SLR on lower lying offshore rocky features and more sensitive species. We used a multi-pronged approach to assess the climate change vulnerability of the Trinidad and Point Arena-Stornetta Units' rocky shoreline habitats, which included interactive workshops with local stakeholders (appendix 1), review of the peer-reviewed literature, including the work done in the Climate Change Vulnerability Assessment for the North-central California Coast and Ocean (Hutto and others, 2015), and a quantitative approach using spatial analysis to estimate SLR vulnerability for individual rocky features within each unit. Using a variety of approaches to assess the vulnerability of the CCNM units provides managers and other stakeholders with information to prioritize and plan for projected climate change and to consider the uncertainty associated with it. Vulnerability assessments allow stakeholders to apply a comprehensive and clear approach to identify and plan for risks for their key resources. 


\section{Stakeholder Workshops}

At the workshops there were marked similarities in the concerns, priorities, and key resources identified by participants, although the landscapes are noticeably different. Workshop participants at both units highlighted the value of habitat for important and sensitive local species (for example, black oystercatchers), nesting seabirds (for example, common murres), marine mammals, and the rocky intertidal ecosystem. Participants at both workshops noted ecologically contiguous areas of concern for these species to the north and south outside of the CCNM unit boundaries were also important. Preserving tribal, cultural, and historic sites and recreational access to these sites was a major concern at both sites in light of SLR. Landscape differences across the two units were reflected in the workshop participants main concerns, with Point Arena-Stornetta Unit participants significantly more concerned about coastal bluff features and erosion; Trinidad Unit has a far greater number of small and large offshore rocks and concern focused on loss of offshore rocky habitat for nesting seabirds.

Vulnerability was largely described as SLR impeding human access to off-shore rocks, affecting seabird and wildlife areas and cliff erosion. Cliff erosion was a major infrastructure concern; concerns were about impacts to coastal community houses, roads, trails, and access to the ocean. Sea-level rise was identified as a major climate change concern affecting low-lying areas and habitats at both units. Participants identified other concerns, such as changes in ocean conditions (warming, acidity) and drought but overall didn't have the information needed to fully understand those impacts to this region.

\section{Vulnerability Assessments}

When conducting a quantitative spatial analysis of rocky shoreline habitats, we reported 48 percent and 42.5 percent of rocks had a SLR vulnerability score of 3 or greater at the Trinidad and Point Arena-Stornetta Units, respectively, indicating areas that could become largely submerged under SLR, with broad impacts to species that use these offshore habitats. In the near-term, accelerating SLR threatens the lowest relief features and the species that rely on them, including pinnipeds that use the area for haul-out and low intertidal foraging areas used by birds such as black oystercatchers.

Our results identified guilds and species that are most associated with vulnerable rock features in the CCNM Units that we studied. Overall, we found that post-breeding avian species were observed on approximately half ( 49 percent at the Trinidad Unit, 50 percent at the Point Arena-Stornetta Unit) of all highly vulnerable rocks (vulnerability score $\geq 3$ ) at our study sites, whereas mammal species used a greater proportion of highly vulnerable rocks than birds did at the Trinidad Unit (75 percent) and a similar proportion to birds at the Point Arena-Stornetta Unit (50 percent). Among avian guilds, seabirds were most frequently observed on highly vulnerable rocks at both units, and among avian and mammal species, Brandt's cormorants and harbor seals were the most associated with highly vulnerable rocks. These findings highlight the likelihood of disproportionate effects of SLR on CCNM species based on their ecology or even specific habitat use during their annual cycle. For example, Brandt's cormorants use less vulnerable higher elevation cliffs for nesting; however, they are frequently observed roosting on highly vulnerable low elevation rocks most likely to be affected by SLR. Pinniped species may be affected differently by SLR driven erosion of cliffs and beaches (Largier and others, 2011; Hutto and others, 2015). Harbor seals are highly flexible in terms of substrate choice (Blundell and others, 2011) but restricted by the slope of the substrate (Montgomery and others, 2007). Because of their physiology, otariids (for example, California sea lions) can access more steeply sloped habitats than phocids (for example, Pacific harbor seals; Arias-del-Razo and others, 2016). This could mean that, as SLR floods low-lying and low-slope rocks, phocids could lose access to more off-shore rocky habitat than otariids.

Although new low-relief habitats may emerge and become available for species as onshore coastal shelves become cut off from land with rising seas, it is uncertain how much low-relief habitat will remain under the highest SLR rates. Erosion poses an immediate risk to cliff and offshore rocky habitats and has been observed progressing at a rapid pace in recent years in California and China (Quan, 2011; Revell and others, 2011). Some cliff-nesting species are sensitive to disturbance of their nest sites and will not return after a year of change (Naves and others, 2006; Buxton and others, 2017). In contrast, species that display high nest-site fidelity could increase their risk of reproductive failure by continuing to nest in a location that has become unstable (Grémillet and Boulinier, 2009; Reynolds and others, 2015). As sea level rises and erosion affects cliff habitats, the location and timing of species interactions likely will be altered, potentially leading to increases in space competition for breeding habitat and foraging resources (Galbraith and others, 2002; Kokko and others, 2004; Nehasil, 2010; Seavey and others, 2011; Funayama and others, 2013).

Our surveys did not measure intertidal invertebrate species on the rocks, though these were observed in many places. How, and at what rate, these intertidal communities will respond to SLR and other changes in oceanic condition with climate change, including changes in temperature and local $\mathrm{pH}$, is important to bear in mind when considering their species composition and longevity (Hutto and others, 2015). In particular, foraging opportunities for avian species that consume rocky intertidal invertebrates can change with modifications to invertebrate abundance, biomass, species composition, or behavior that could ensue as factors such as area, slope, and temperature of rocky habitats shift (Kendall and others, 2004; Jackson and Mcllvenny, 2011). 
Changes in wind and storm events will affect spray and swell profiles, with potential impacts on roosting and nesting sites (Chambers and others, 2012; Young and others, 2012; Reynolds and others, 2015), especially in those areas identified in this study to be low relief. Changes in weather patterns that include precipitation and fog are not well understood for this region of California but are an important abiotic driver for the ecosystem. Overall, this study identified SLR as an important climate change impact to the units, especially if it results in submergence of low-lying rocky features, erosion, and effects on sensitive species.

\section{Management Implications}

Vulnerability assessments can help inform management decisions, especially in light of the uncertainty about climate change and SLR rates. The iconic landscape of the CCNM is rich in biodiversity and provides a plethora of recreational activities. The information presented here can help prioritize species that could be monitored to see if SLR and other changing ocean conditions could be affecting nesting locations or success rates. Also, seals were observed using the low relief rocky shoreline habitats to haul out. With many of these features identified as highly vulnerable to SLR, it could be important to monitor these populations to see if they relocate to new low relief features within the units or disperse along the coastline. A mismatch of haul out locations and food resources could occur and could be monitored through time. Erosion of the cliffs and shoreline habitats is an immediate concern throughout the units because it threatens property and can damage structures. Identifying the severity and rate of cliff retreat could help managers identify where and what preventative measures could avert the loss of public access. As the impacts from SLR become more severe, innovative adaptation strategies could be needed in order to protect coastal resources. Proactive adaptation strategies could include protection of the resource (hard or soft shorelines), accommodation for the projected changes (design and retrofit of existing habitat areas), and retreat (limited development, relocation of vulnerable resources). Often a hybrid approach of these can be successful with strategies evolving over time.

\section{References Cited}

Ainley, D.G., Nettleship, D.N., Carter, H.R., and Storey, A.E., 2002, Common murre (Uria alge), version 2.0, in Poole, A.F., and Gill, F.B., eds., The birds of North America: Ithaca, N.Y., Cornell Lab of Ornithology, https://doi.org/10.2173/bna.666.

Allan, J.C., and Komar, P.D., 2006, Climate controls on US west coast erosion processes: Journal of Coastal Research, v. 223, p. 511-529, https://doi.org/10.2112/03-0108.1.

Andres, B.A., 1998, Shoreline habitat use of Black Oystercatchers in Prince William Sound, Alaska: Journal of Field Ornithology, v. 69, no. 4, p. 626-634.

Andres, B.A., and Falxa, G.A., 1995, Black Oystercatcher (Haematopus bachmani), in Poole, A., and Gill, F., eds., The birds of North America: Washington, D.C., The Academy of Natural Sciences, Philadelphia and the American Ornithologist's Union, no. 155, https://doi.org/10.2173/bna.155.

Arias-del-Razo, A., Heckel, G., Schramm, Y., and Pardo, M.A., 2016, Terrestrial habitat preferences and segregation of four pinniped species on the islands off the western coast of the Baja California Peninsula, Mexico: Marine Mammal Science, v. 32, no. 4, p. 1416-1432, https://doi.org/10.1111/mms.12339.

Barnard, P.L., Short, A.D., Harley, M.D., Splinter, K.D., Vitousek, S., Turner, I.L., Allan, J., Banno, M., Bryan, K.R., Doria, A., and Hansen, J.E., 2015, Coastal vulnerability across the Pacific dominated by El Niño/Southern oscillation: Nature Geoscience, v. 8, no. 10, p. 801-807, https://doi.org/10.1038/NGEO2539.

Blundell, G.M., Womble, J.N., Pendleton, G.W., Karpovich, S.A., Gende, S.M., and Herreman, J.K., 2011, Use of glacial and terrestrial habitats by harbor seals in Glacier Bay, Alaska - Costs and benefits: Marine Ecology Progress Series, v. 429, p. 277-290, https://doi.org/10.3354/meps09073. 
Boekelheide, R.J., Ainley, D.G., Morrel, S.H., and Lewis, T.J., 1990, Brandt's Cormorant, in Ainley, D.J., and Boekelheide, R.J., eds., Seabirds of the Farallon IslandsEcology, dynamics, and structure of an upwelling system community: Palo Alto, Calif., Standard University Press, p. 163-195.

Buchanan, J.B., Johnson, D.H., Greda, E.L., Green, G.A., Wahl, T.R., and Jeffries, S.J., 2001, Wildlife of coastal and marine habitats, in Johnson, D.H., and O'Neil, T.A., eds., Wildlife-habitat relationships in Oregon and Washington: Covallis, Oreg., Oregon State University Press, p. 389-422.

Buxton, R.T., Galvan, R., McKenna, M.F., White, C.L., and Seher, V., 2017, Visitor noise at a nesting colony alters the behavior of a coastal seabird: Marine Ecology Progress Series, v. 570, p. 233-246, https://doi.org/10.3354/meps12073.

Byers, H.R., 1930, Summer sea fogs of the central California coast: University of California Publishing Geography, v. 3, no. 5, p. 291-338.

Cai, W., Borlace, S., Lengaigne, M., van Rensch, P., Collins, M., Vecchi, G., Timmermann, A., Santoso, A., McPhaden, M.J., Wu, L., England, M.H., Wang, G.T., Guilyardi, E., and Jin, F., 2014, Increasing frequency of extreme El Niño events due to greenhouse warming: Nature Climate Change, v. 4, no. 2, p. 111-116, https://doi.org/10.1038/nclimate2100.

Carter, H.R., and Hobson, K.A., 1988, Creching behavior of Brandt's cormorant chicks: The Condor, v. 90, no. 2, p. 395-400, https://doi.org/10.2307/1368568.

Cayan, D.R., Maurer, E.P., Dettinger, M.D., Tyree, M., and Hayhoe, K., 2008, Climate change scenarios for the California region: Climatic Change, v. 87, no. S1, p. 21-42, https://doi.org/10.1007/s10584-007-9377-6.

Chambers, L.E., Dann, P., Devney, C., Dunlop, N., and Woehler, E.J., 2012, Seabirds, in Poloczanska, E.S., Hobday, A.J., and Richardson, A.J., eds., Marine climate change impacts and adaptation report card for Australia 2012.

Cloern, J.E., Abreu, P.C., Carstensen, J., Chauvaud, L., Elmgren, R., Grall, J., Greening, H., Johansson, J.O.R., Kahru, M., Sherwood, E.T., Xu, J., and Yin, K., 2016, Human activities and climate variability drive fast-paced change across the world's estuarine-coastal ecosystems: Global Change Biology, v. 22, no. 2, p. 513-529, https://doi.org/10.1111/gcb.13059.

Dettinger, M., 2011, Climate change, atmospheric rivers, and floods in California-A multimodel analysis of storm frequency and magnitude changes: Journal of the American Water Resources Association, v. 47, no. 3, p. 514-523, https://doi.org/10.1111/j.1752-1688.2011.00546.x.
Feely, R.A., Alin, S.R., Carter, B., Bednaršek, N., Hales, B., Chan, F., Hill, T.M., Gaylord, B., Sanford, E., Byrne, R.H., Sabine, C.L., Greeley, D., and Juranek, L., 2016, Chemical and biological impacts of ocean acidification along the west coast of North America: Estuarine, Coastal and Shelf Science, v. 183, p. 260-270, https://doi.org/10.1016/j.ecss.2016.08.043.

Feely, R.A., Sabine, C.L., Hernandez-Ayon, J.M., Ianson, D., and Hales, B., 2008, Evidence for upwelling of corrosive "acidified" water onto the continental shelf: Science, v. 320, no. 5882, p. 1490-1492, https://doi.org/10.1126/science.1155676.

Funayama, K., Hines, E., Davis, J., and Allen, S., 2013, Effects of sea-level rise on northern elephant seal breeding habitat at Point Reyes Peninsula, California: Aquatic Conservation, v. 23, no. 2, p. 233-245, https://doi.org/10.1002/aqc.2318.

Galbraith, H., Jones, R., Park, R., Clough, J., Herrod-Julius, S., Harrington, B., and Page, G., 2002, Global climate change and sea-level rise-Potential losses of intertidal habitat for shorebirds: Waterbirds, v. 25, no. 2, p. 173-183, https://doi.org/10.1675/1524-4695(2002)025 [0173:GCCASL]2.0.CO;2.

García-Reyes, M., and Largier, J., 2010, Observations of increased wind-driven coastal upwelling off central California: Journal of Geophysical Research, Oceans, v. 115, no. C4, 8 p., https://doi.org/10.1029/2009JC005576.

Glick, P., Clough, J., Polaczyk, A., Couvillion, B., and Nunley, B., 2013, Potential effects of sea-level rise on coastal wetlands in southeastern Louisiana: Journal of Coastal Research, v. 63, p. 211-233, https://doi.org/10.2112/SI63-0017.1.

Gonzales, K.R., Swain, D.L., Nardi, K.M., Barnes, E.A., and Diffenbaugh, N.S., 2019, Recent warming of landfalling atmospheric rivers along the west coast of the United States: Journal of Geophysical Research, D, Atmospheres, v. 124 , no. 13, p. 6810-6826, https://doi.org/10.1029/2018JD029860.

Griggs, G., Árvai, J., Cayan, D., DeConto, R., Fox, J., Fricker, H.A., Kopp, R.E., Tebaldi, C., and Whiteman, E.A., 2017, Rising seas in California-An update on sea-level rise: Science, California Ocean Science Trust, April 2017.

Grémillet, D., and Boulinier, T., 2009, Spatial ecology and conservation of seabirds facing global climate change-A review: Marine Ecology Progress Series, v. 391, p. 121-137, https://doi.org/10.3354/meps08212.

Gruber, N., Hauri, C., Lachkar, Z., Loher, D., Frölicher, T.L., and Plattner, G.K., 2012, Rapid progression of ocean acidification in the California Current System: Science, v. 337, no. 6091, p. 220-223, https://doi.org/10.1126/science.1216773. 
Guan, B., Molotch, N.P., Waliser, D.E., Fetzer, E.J., and Neiman, P.J., 2010, Extreme snowfall events linked to atmospheric rivers and surface air temperature via satellite measurements: Geophysical Research Letters, v. 37, no. 20, 6 p., https://doi.org/10.1029/2010GL044696.

Harley, C.D.G., Hughes, A.R., Hultgren, K.M., Miner, B.G., Sorte, C.J.B., Thornber, C.S., Rodriguez, L.F., Tomanek, L., and Williams, S.L., 2006, The impacts of climate change in coastal marine systems: Ecology Letters, v. 9, no. 2, p. 228-241, https://doi.org/10.1111/j.1461-0248.2005.00871.x.

Hubbs, C.L., Kelly, A.L., and Limbaugh, C., 1970, Diversity in feeding by Brandt's cormorant near San Diego: California Fish and Game, v. 56, no. 3, p. 156-165.

Hunt, G.L., Jr., Eppley, Z., and Drury, W.H., 1981, Breeding distribution and reproductive biology of marine birds in the eastern Bering Sea, chap. 39 of Hood, D., and Calder, J.A., eds., The Eastern Bering Sea shelf-Oceanography and resources: Juneau, Alaska, Office of Marine Pollution Assessment, National Oceanographic and Atmospheric Administration, p. 649-687.

Hutto, S.V., Higgason, K.D., Kershner, J.M., Reynier, W.A., and Gregg, D.S., 2015, Climate change vulnerability assessment for the north-central California coast and ocean-Marine Sanctuaries Conservation Series, ONMS-15-02: Silver Spring, MD, U.S. Department of Commerce, National Oceanic and Atmospheric Administration, Office of National Marine Sanctuaries, $473 \mathrm{p}$.

Intergovernmental Panel on Climate Change (IPCC), 2014, Climate change 2014 - Synthesis report - Core writing team, of Pachauri, R.K., and Meyer, L.A., eds., Contribution of working groups I, II and III to the fifth assessment report of the Intergovernmental Panel on Climate Change: Geneva, Switzerland, Intergovernmental Panel on Climate Change, $151 \mathrm{p}$.

Jackson, A.C., and McIlvenny, J., 2011, Coastal squeeze on rocky shores in northern Scotland and some possible ecological impacts: Journal of Experimental Marine Biology and Ecology, v. 400, no. 1-2, p. 314-321, https://doi.org/10.1016/j.jembe.2011.02.012.

Jiang, L., Carter, B.R., Feely, R.A., Lauvset, S.K., and Olsen, A., 2019, Surface ocean pH and buffer capacityPast, present and future: Scientific Reports, v. 9, no. 1, 11 p., https://doi.org/10.1038/s41598-019-55039-4.

Johnson, M., Clarkson, P., Goldstein, M.I., Haig, S.M., Lanctot, R.B., Tessler, D.F., and Zwiefelhofer, D., 2010, Seasonal movements, winter range use, and migratory connectivity of the Black Oystercatcher: The Condor, v. 112, no. 4, p. 731-743, https://doi.org/10.1525/cond.2010.090215.
Johnstone, J.A., and Dawson, T.E., 2010, Climatic context and ecological implications of summer fog decline in the coast redwood region: Proceedings of the National Academy of Sciences of the United States of America, v. 107, no. 10, p. 4533-4538, https://doi.org/10.1073/pnas.0915062107.

Kendall, M.A., Burrows, M.T., Southward, A.J., and Hawkins, S.J., 2004, Predicting the effects of marine climate change on the invertebrate prey of the birds of rocky shores: The Ibis, v. 146, no. S1, p. 40-47, https://doi.org/10.1111/j.1474-919X.2004.00326.x.

Knowles, N., Dettinger, M.D., and Cayan, D.R., 2006, Trends in snowfall versus rainfall in the western United States: Journal of Climatology, v. 19, no. 18, p. 4545-4559, https://doi.org/10.1175/JCLI3850.1.

Kokko, H., Harris, M.P., and Wanless, S., 2004, Competition for breeding sites and site-dependent population regulation in a highly colonial seabird, the common guillemot Uria aalge: Journal of Animal Ecology, v. 73, no. 2, p. 367-376, https://doi.org/10.1111/j.0021-8790.2004.00813.x.

Koračin, D., Lewis, J., Thompson, W., Dorman, C., and Businger, J., 2001, Transition of stratus into fog along the California Coast - Observations and modeling: Journal of the Atmospheric Sciences, v. 58, no. 13, p. 1714-1731, https://doi.org/10.1175/1520-0469(2001)058\%3C1 714:TOSIFA\%3E2.0.CO;2.

Largier, J.L., Cheng, B.S., and Higgason, K.D., eds., 2011, Climate change impacts - Gulf of the Farallones and Cordell Bank National Marine Sanctuaries-Report of a joint working group of the Gulf of the Farallones and Cordell Bank National Marine Sanctuaries Advisory Councils: National Oceanic and Atmospheric Administration, Marine Sanctuaries Conservation Series ONMS-11-04, $121 \mathrm{p}$.

Le Bars, D., Drijfhout, S., and de Vries, H.A., 2017, A high-end sea level rise probabilistic projection including rapid Antarctic ice sheet mass loss: Environmental Research Letters, v. 12, no. 4, p. 1-10, https://doi.org/10.1088/1748-9326/aa6512.

Legaard, K.R., and Thomas, A.C., 2006, Spatial patterns in seasonal and interannual variability of chlorophyll and sea surface temperature in the California current: Journal of Geophysical Research, Oceans, v. 111, no. C6, 21 p., https://doi.org/10.1029/2005JC003282.

L'Heureux, M.L., Collins, D.C., and Hu, Z., 2013, Linear trends in sea surface temperature of the tropical Pacific Ocean and implications for the El Niño-Southern Oscillation: Climate Dynamics, v. 40, no. 5-6, p. 1223-1236, https://doi.org/10.1007/s00382-012-1331-2. 
Menéndez, M., Méndez, F.J., Losada, I.J., and Graham, N.E., 2008, Variability of extreme wave heights in the northeast Pacific Ocean based on buoy measurements: Geophysical Research Letters, v. 35, no. 22, 6 p., https://doi.org/10.1029/2008GL035394.

McGowan, J.A., Cayan, D.R., and Dorman, L.M., 1998, Climate-ocean variability and ecosystem response in the Northeast Pacific: Science, v. 281, no. 5374, p. 210-217, https://doi.org/10.1126/science.281.5374.210.

Mitchell, S.B., Jennerjahn, T.C., Vizzini, S., and Zhang, W., 2015, Changes to processes in estuaries and coastal waters due to intense multiple pressures-An introduction and synthesis, in Mitchell, S.B., Jennerjahn, T.C., Vizzini, S., and Zhang, W., eds., Changes to processes in estuaries and coastal waters due to intense multiple pressures: Estuarine, Coastal and Shelf Science, v. 156, p. 1-6, https://doi.org/10.1016/j.ecss.2014.12.027.

Montgomery, R.A., Ver Hoef, J.M., and Boveng, P.L., 2007, Spatial modeling of haulout site use by harbor seals in Cook Inlet, Alaska: Marine Ecology Progress Series, v. 341, p. 257-264, https://doi.org/10.3354/meps341257.

Mouginot, J., Rignot, E., and Scheuchl, B., 2014, Sustained increase in ice discharge from the Amundsen Sea Embayment, West Antarctica, from 1973 to 2013: Geophysical Research Letters, v. 41, no. 5, p. 1576-1584, https://doi.org/10.1002/2013GL059069.

National Oceanic and Atmospheric Administration, 2019, Ocean acidification: National Oceanic and Atmospheric Administration PMEL Carbon Program, accessed December 18, 2019, at https://www.pmel.noaa.gov/co2/ story/Ocean+Acidification.

Naves, L.C., Monnat, J.Y., and Cam, E., 2006, Breeding performance, mate fidelity, and nest site fidelity in a long-lived seabird-Behaving against the current?: Oikos, v. 115, no. 2, p. 263-276, https://doi.org/10.1111/j.2006.0030-1299.14883.x.

Nehasil, S., 2010, The impact of sea-level rise on Pinniped haul-out sites along the California coastUniversity of California: San Diego, Center for Marine Biodiversity and Conservation, 33 p., https://escholarship.org/uc/item/9gq660vn.

Neiman, P.J., Schick, L.J., Ralph, F.M., Hughes, M., and Wick, G.A., 2011, Flooding in western WashingtonThe connection to atmospheric rivers: Journal of Hydrometeorology, v. 12, no. 6, p. 1337-1358, https://doi.org/10.1175/2011JHM1358.1.
Oakley, N.S., Lancaster, J.T., Hatchett, B.J., Stock, J., Ralph, F.M., Roj, S., and Lukashov, S., 2018, A 22year climatology of cool season hourly precipitation thresholds conducive to shallow landslides in California: Earth Interactions, v. 22, no. 14, p. 1-35, https://doi.org/10.1175/EI-D-17-0029.1.

O’Brien, T.A., Sloan, L.C., Chuang, P., Faloona, I., and Johnstone, J.A., 2013, Multidecadal simulation of coastal fog with a regional climate model: Climatology Dynamics, v. 40, no. 11-12, p. 2801-2812, https://doi.org/10.1007/s00382-012-1486-x.

Proclamation 7264, Establishment of the California Coastal National Monument, 65 FR 2821, accessed January 11, 2000.

Proclamation 9089, Boundary Enlargement of the California Coastal National Monument, 79 FR 14601, accessed March 11, 2014.

Proclamation 9563, Boundary Enlargement of the California Coastal National Monument, 82 FR 6131, accessed January 12, 2017.

Quan, S., 2011, Using vessel-based LiDAR to quantify coastal erosion during El Niño and Inter-El Niño periods in Monterey, CA: California State University, Monterey Bay, SNS Master's Theses 20, https://digitalcommons.csumb.edu/sns_theses/20.

Ralph, F.M., Neiman, P.J., Wick, G.A., Gutman, S.I., Dettinger, M.D., Cayan, D.R., and White, A.B., 2006, Flooding on California's Russian River-Role of atmospheric rivers: Geophysical Research Letters, v. 33, no. 13, 5 p., https://doi.org/10.1029/2006GL026689.

Rastogi, B., Williams, A.P., Fischer, D.T., Iacobellis, S.F., McEachern, K., Carvalho, L., Jones, C., Baguskas, S.A., and Still, C.J., 2016, Spatial and temporal patterns of cloud cover and fog inundation in coastal California-Ecological implications: Earth Interactions, v. 20, no. 15, p. 1-19, https://doi.org/10.1175/EI-D-15-0033.1.

Revell, D.L., Battalio, R., Spear, B., Ruggiero, P., and Vandever, J., 2011, A methodology for predicting future coastal hazards due to sea-level rise on the California Coast: Climatic Change, v. 109, no. S1, p. 251-276, https://doi.org/10.1007/s10584-011-0315-2.

Reynolds, M.H., Courtot, K.N., Berkowitz, P., Storlazzi, C.D., Moore, J., and Flint, E., 2015, Will the effects of sea-level rise create ecological traps for Pacific Island seabirds?: PLoS One, v. 10, no. 9, 23 p., https://doi.org/10.1371/journal.pone.0136773. 
Scavia, D., Field, J.C., Boesch, D.F., Buddemeier, R.W., Burkett, V., Cayan, D.R., Fogarty, M., Harwell, M.A., Howarth, R.W., Mason, C., Reed, D.J., Royer, T.C., Sallenger, A.H., and Titus, J.G., 2002, Climate change impacts on U.S. coastal and marine ecosystems: Estuaries, v. 25, no. 2, p. 149-164, https://doi.org/10.1007/BF02691304.

Schwing, F.B., and Mendelssohn, R., 1997, Increased coastal upwelling in the California current system: Journal of Geophysical Research, v. 102, no. C2, p. 3421-3438, https://doi.org/10.1029/96JC03591.

Schwing, F.B., Bond, N.A., Bograd, S.J., Mitchell, T., Alexander, M.A., and Mantua, N., 2006, Delayed coastal upwelling along the U.S. West Coast in 2005-A historical perspective: Geophysical Research Letters, v. 33, no. 22, 5 p., https://doi.org/10.1029/2006GL026911.

Seavey, J.R., Gilmer, B., and McGarigal, K.M., 2011, Effect of sea-level rise on piping plover (Charadrius melodus) breeding habitat: Biological Conservation, v. 144, no. 1, p. 393-401, https://doi.org/10.1016/j.biocon.2010.09.017.

Snyder, M.A., Sloan, L.C., Diffenbaugh, N.S., and Bell, J.L., 2003, Future climate change and upwelling in the California current: Geophysical Research Letters, v. 30, no. 15, 4 p., https://doi.org/10.1029/2003GL017647.

Stewart, I.T., Cayan, D.R., and Dettinger, M.D., 2005, Changes toward earlier streamflow timing across western North America: Journal of Climatology, v. 18, no. 8, p. 1136-1155, https://doi.org/10.1175/JCLI3321.1.
Storlazzi, C.D., and Griggs, G.B., 2000, Influence of El Niño-Southern Oscillation (ENSO) events on the evolution of central California's shoreline: Geological Society of America Bulletin, v. 112, no. 2, p. 236-249, https://doi.org/10.1130/0016-7606(2000)112\%3C 236:IOENOE\%3E2.0.CO;2.

Sweet, W.V., Kopp, R.E., Weaver, C.P., Obeysekera, J.T.B., Horton, R.M., Thieler, E.R., and Zervas, C.E., 2017, Global and regional sea level rise scenarios for the United States: Silver Spring, MD, National Oceanic and Atmospheric Administration, Technical Report NOS CO-OPS 083, 65 p.

Vitousek, S., Barnard, P.L., Fletcher, C.H., Frazer, N., Erikson, L., and Storlazzi, C.D., 2017, Doubling of coastal flooding frequency within decades due to sea-level rise: Scientific Reports, v. 7, 9 p., https://doi.org/10.1038/s41598-017-01362-7.

Waliser, D., and Guan, B., 2017, Extreme winds and precipitation during landfall of atmospheric rivers: Nature Geoscience, v. 10, no. 3, p. 179-183, https://doi.org/10.1038/ngeo2894.

Weinstein, A., Trocki, L., LeValley, R., Doster, R.H., Distler, T., and Krieger, K., 2014, A first population assessment of Black Oystercatcher Haematopus bachmani in California: Marine Ornithology, v. 42, no. 1, p. 49-56, https://doi.org/10.13140/2.1.3697.2163.

Young, L., Suryan, R.M., Duffy, D., and Sydeman, W.J., 2012, Climate change and seabirds of the California current and Pacific Island ecosystems-Observed and potential impacts and management applications: Final report to the U.S. Fish and Wildlife Service, Region 1. 


\section{Appendix 1. California Coastal National Monument Stakeholder Workshops Summary}

\section{Executive Summary}

- The U.S. Geological Survey (USGS), in partnership with the Bureau of Land Management, designed and hosted participatory planning workshops at two representative locations in the California Coastal National Monument to engage local stakeholders in the planning process for projected climate change and sea-level rise.

- Workshops were held at the Trinidad and Point Arena-Stornetta California Coastal National Monument units To maximize potential participation, workshops were held on dates that local stakeholder groups already had pre-planned meetings. Invitations were extended to local city and state government representatives, tribes and tribal representatives, researchers and university members, non-profit groups and other agencies, other local federal representatives, and private citizens.

- Invitations to the workshops included an anonymous pre-workshop survey with nine questions. These questions covered respondent affiliations, local climate change drivers and concerns, key resource priorities, and challenges to incorporating climate change information into decision making.

- Pre-workshop survey responses collected at both sites indicated all climate change drivers are perceived as having medium to medium-high effects on the units. Similarly, all categories of key resources, biological, cultural, and physical (infrastructure, human use, and so forth) were ranked as medium to medium-high importance and concern.

- Workshop participants at both sites were particularly concerned about possible issues:

- Sea-level rise damaging or limiting access to important tribal, cultural, recreational, commercial, and historic sites.

- The impact of sea-level rise and erosion on offshore rock, cliff, and intertidal habitats used by seabirds and marine mammals.

- Coastal cliff erosion and its impacts on infrastructure, community transportation and public access.

- Key resources sites in the California Coastal National Monument unit as well as contiguous areas to the north and south of the unit.
- In the Trinidad Unit, primary concerns were potential sea-level rise affecting seabird habitat and damaging or limiting access to important tribal, cultural, and historic sites. Workshop attendees identified specific key resource areas of interest including the Trinidad Head pier and harbor, the historic Trinidad Memorial lighthouse, Old Home Beach, offshore rocks with large seabird colonies or cultural importance, Patrick's Point, and cliffside road access.

- In the Point Arena-Stornetta Unit, primary concerns were potential erosion and sea-level rise impacts to coastal cliffs and their associated habitats, cultural and historical sites, and infrastructure. Specific key resource areas of concern included Sea Lion Rock, the Point Arena Lighthouse and cliff road access, all seabird and pinniped habitat, and Garcia River estuary cultural sites, wildlife habitat and fishing areas.

\section{Background}

The California Coastal National Monument (CCNM) encompasses more than 20,000 small islands, rocks, exposed reefs, and pinnacles between Mexico and Oregon. The CCNM is situated along the California Current Ecosystem, where strong upwelling of cold, nutrient-rich sub-surface waters makes a highly productive area for marine life. Projected climate change drivers, including sea-level rise, could influence the CCNM by changing habitat availability and food resources and could affect the species interactions such as through predation and competition (Asch, 2015). Rising sea levels are predicted to inundate large parts of the California coast if warming temperatures are realized (Cloern and others, 2016). This potential increased inundation poses a threat to important coastal resources (Mitchell and others, 2015), including rocky habitats and species. Many coastal areas, including much of California, are already experiencing early impacts of climate change, including drought, flooding from rising sea-levels, and increasing storm intensity and frequency (Griggs and others, 2017; Vitousek and others, 2017).

The U.S. Geological Survey (USGS) and Bureau of Land Management (BLM) hosted workshops at the Trinidad and Point Arena-Stornetta Units with the goal of engaging local stakeholders in a participatory planning process to identify key resources of concern for each unit. 


\section{Workshop Sites}

The Trinidad and the Point Arena-Stornetta Units were identified as representative regions in the CCNM to explore climate change and sea-level rise vulnerability of rocky coastlines, with the intent to inform climate change adaptation planning and vulnerability assessment research (fig. 1.1). The Point Arena-Stornetta was included in the CCNM in
2014 as the first mainland-based unit, whereas Trinidad was designated in 2017 and is among the most recent areas added to the CCNM. Trinidad and Point Arena-Stornetta are home to established nesting colony sites for several seabird species and provide pupping, nursery, and haul out habitat for marine mammals (Capitolo and others, unpub. data, 2006; Robinette and McChesney, unpub. data, 2013).
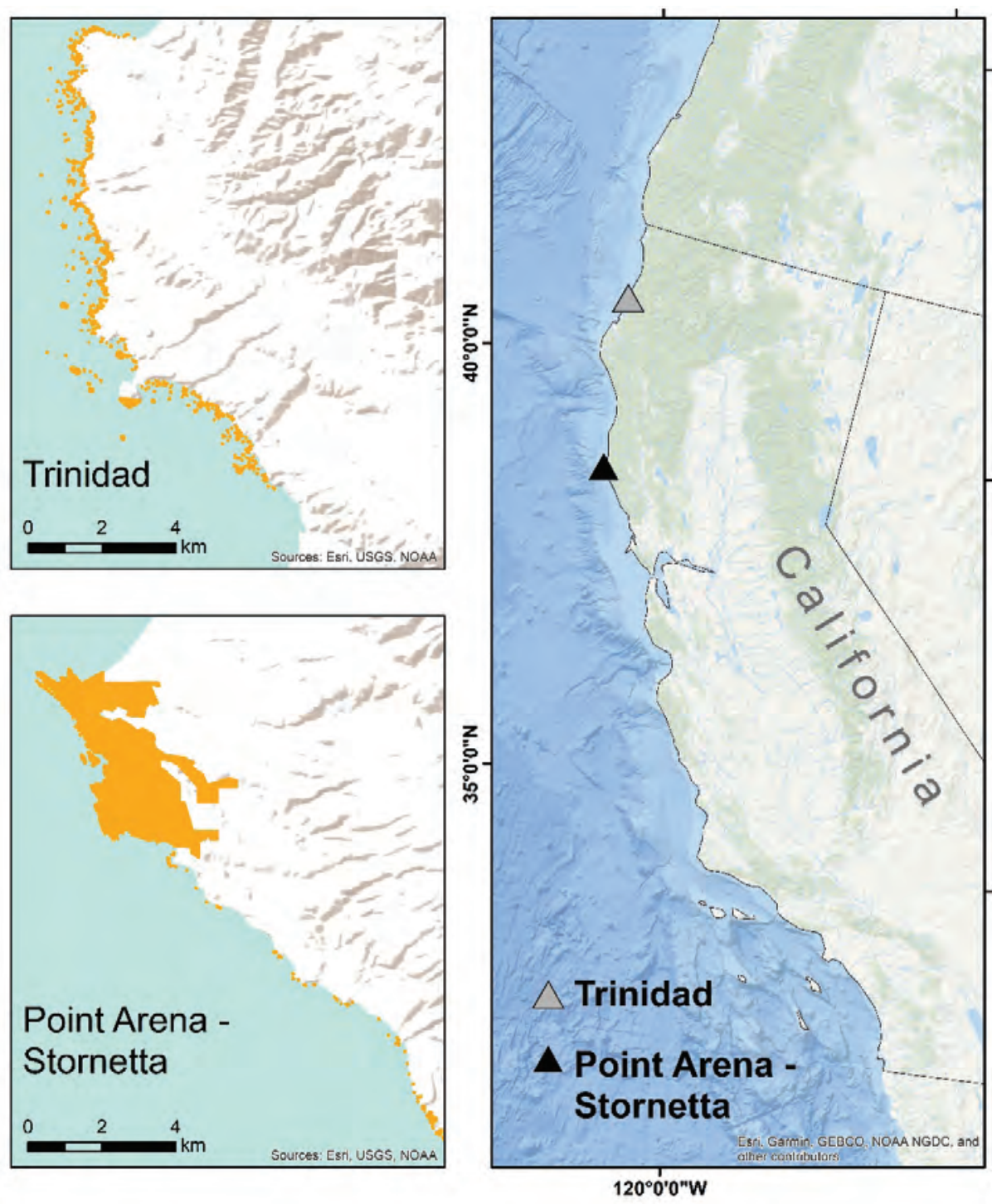

Map image is the intellectual property of Esri and is used herin under license. Copyright 2020 Esri and its licensors. All rights reserved.

Figure 1.1. Workshops were held at the California Coastal National Monument (CCNM) Trinidad and Point Arena-Stornetta Units, the sites chosen to explore sea-level rise impacts on the California Coastal National Monument. The orange depicts the extent of the CCNM units. 
The approximately 674 hectares of the Point Arena-Stornetta Unit include coastal cliffs and bluffs, rocky intertidal habitat, dunes, coastal prairie habitat, and the lower Garcia River and estuary. Point Arena-Stornetta supports pinnipeds, including harbor seals (Phoca vitulina), Steller sea lions (Eumetopias jubatus), California sea lions (Zalophus californianus), and seabirds such as common murres (Uria aalge), cormorants (Phalacrocorax auritus, Phalacrocorax penicillatus, Phalacrocorax pelagicus), black oystercatchers (Haematopus bachmani), American white pelicans (Pelecanus erythrorhynchos), brown pelicans (Pelecanus occidentalis), and pigeon guillemots (Cepphus columba). In addition, this unit supports the federally threatened California red-legged frog (Rana draytonii), the federally endangered Point Arena mountain beaver (Aplodontia rufa), several imperiled salmonids (Oncorhynchus sp.), endemic vegetation, and endemic insects, including the federally endangered Behren's silverspot butterfly (Speyeria zerene behrensii). Point Arena-Stornetta also is within the ancestral lands of the Central Pomo Indians. The unit includes numerous important cultural sites as well as historical and archaeological sites (Proclamation 9089; Robinette and McChesney, unpub. data, 2013).

The Trinidad Unit is included in an area with the nearby Waluplh-Lighthouse Ranch, Lost Coast Headlands, Cotoni-Coast Dairies, and Piedras Blancas Units, which together total 2,521 hectares. Trinidad Head itself, a promontory near the southern end of the Trinidad Unit, encompasses approximately 5 hectares. Trinidad Head is home to important sites for the Cher-Ae Heights Indian Community of the Trinidad Rancheria, the Yurok Tribe, and the Tsurai Ancestral Society. These sites include the Tsurai ancestral village and burial sites. Trinidad Head also hosts the Trinidad Memorial Lighthouse and Bell, the Trinidad Head Lighthouse constructed in 1871, a memorial marking where the Yurok community had first contact with Spanish ships, as well as a harbor where commercial and recreational boats moor. Coastal vegetation, rocky intertidal shoreline, and offshore rocks provide habitat for multiple species, including cormorants (Phalacrocorax auritus, Phalacrocorax penicillatus, Phalacrocorax pelagicus), common murres (Uria aalge), pigeon guillemots (Cepphus columba), tufted puffins (Fratercula cirrhata), Leach's storm petrel (Oceanodroma leucorhoa), harbor seals (Phoca vitulina), California sea lions (Zalophus californianus), Steller sea lions (Eumetopias jubatus), marine adapted river otters (Lontra canadensis), and several species of intertidal invertebrates (National Marine Fisheries Service, 1997; Proclamation 9563).

\section{Workshop Design}

Workshops were held at Trinidad in June 2017 and Point Arena-Stornetta in October 2017. Invitations were extended to local city and state government representatives, tribes and tribal representatives, researchers and university members, nonprofit groups and other agencies, other local federal representatives, and private citizens. To increase attendance, workshops were planned to coincide with established meeting dates of local stakeholder groups, with additional invitations extended to individuals and organizations identified by BLM, local managers, and local stakeholders. At Trinidad, 50 people were invited, and 62 people were invited to the workshop at Point Arena-Stornetta.

Before attending the workshop, participants were asked to complete an anonymous pre-workshop, web-based questionnaire using Survey Monkey (https://www.surveymonkey.com/). Survey respondents were asked to self-assess climate change impacts to their area and rank the resources from highest to lowest vulnerability and concern. Responses were scored and tabulated using nominal or ordinal scales (table 1.1, 1.2). Pre-workshop survey questions were the same at both sites, and local anonymous results were presented at each of the workshops.

Table 1.1. Respondents were asked for a free-response text description of concerns not addressed in this survey.

\begin{tabular}{|c|c|}
\hline \multicolumn{2}{|c|}{ Are there any important climate change concerns that were not addressed in this survey? } \\
\hline Trinidad & Point Arena-Stornetta \\
\hline Isolation due to loss of highway at Clam Beach & $\begin{array}{l}\text { Altered currents; decreased dissolved oxygen; changes in El Niño events; changes } \\
\text { in salinity; changes in sediment supply }\end{array}$ \\
\hline Sea-level rise threat to Highway 101 along Clam Beach & Drought and fire impacts \\
\hline No & Increased runoff, creek erosion, and floods (2) \\
\hline \multirow{3}{*}{ No } & Impact on roads leading to, from, and through the area \\
\hline & Transportation \\
\hline & No \\
\hline
\end{tabular}


Table 1.2. Respondents were asked for a free-response text description of local sea-level rise vulnerabilities.

[Numbers in parenthesis indicate multiple respondents giving the same response.]

\begin{tabular}{|c|c|}
\hline \multicolumn{2}{|c|}{$\begin{array}{l}\text { Is there a specific resource, location, or place of special significance that is important for a sea-level rise } \\
\text { vulnerability assessment in the Trinidad Head/Point Arena area to include? }\end{array}$} \\
\hline Trinidad & Point Arena-Stornetta \\
\hline Important seabird nesting rocks & Rocky intertidal habitat impacts are of great concern \\
\hline Trinidad harbor, pier, wharf, boat launch and port, restaurant (4) & Arena Cove (4) \\
\hline Moonstone Beach (2) & Point Arena Creek valley \\
\hline Nesting seabird species & Point Arena Light Station \\
\hline $\begin{array}{l}\text { Village of Tsuari, Old Home Beach, Old Home Beach cultural } \\
\text { sites, north shore of Trinidad Bay }\end{array}$ & Cliffs, upland areas flooding, Manchester beach \\
\hline $\begin{array}{l}\text { Cultural sites on the Trinidad Head, including the granite cross } \\
\text { memorial and Lighthouse (2) }\end{array}$ & Coho salmon habitat \\
\hline Coastal bluff erosion & Garcia River estuary (3) \\
\hline South of Trinidad Head & Point Arena Pier \\
\hline Trinidad Head parking lot & All habitats, including homes and businesses \\
\hline
\end{tabular}

The workshops were divided into three sections: (1) presentations, (2) small group participatory mapping exercises, and (3) group discussion. Bureau of Land Management staff presented an overview of the CNNM unit and project goals and discussed the process of including the units in the monument. The BLM presentations focused on the importance of including the community in the process of designing the resource protection for the monument with the input of the tribes, local stakeholder groups, and other community members. U.S. Geological Survey research ecologists presented the local pre-workshop survey results, an overview of climate change science and the vulnerabilities of rocky coastline to sea-level rise, and preliminary site-specific sea-level rise vulnerability modeling results.

After the presentations were done, workshop participants were divided into small groups and asked to engage in mapping exercises (fig. 1.2). Poster-sized print-outs of satellite imagery, including the unit(s) of interest and surrounding lands, were given to each group, and participants were asked to mark important areas and resources on the map to address the exercise questions (fig. 1.2). Briefly, each group was asked to identify areas within the unit by (1) type of resource, (2) importance, and (3) perceived climate change vulnerability (fig. 1.2). These exercises facilitated small group discussion to identify and categorize key resources for their units and rank them based on their perceived climate change vulnerabilities. When the small groups had finished their discussion, they nominated a spokesperson to present their group results. Small group findings were discussed in a facilitated full-group discussion. Results of the individual group map exercises are in the site-specific results (see sections "Trinidad Group Mapping Exercise" and "Point Arena-Stornetta Group Mapping Exercises"). Group exercises were combined into a list (tables 1.3, 1.4). U.S. Geological Survey staff converted the exercises into ArcGIS (ESRI 10.4) attributed maps.

$$
\text { 2:15-3:00 pm }
$$

Introduction: To better understand the management concerns of the Trinidad coastal area and the California Coastal National Monument, we would like workshop participants to answer the following questions as a group while working through the exercise below. This exercise will help identify the scope of research and science needs that will help to inform planning and implementing adaptation strategies for climate change for this region.

To do:

1. Identify on the map by drawing a circle or line:

a. The geographic extent of important physical features or resources (e.g., beaches, offshore rock, parking, or other areas of commercial/recreational use)

b. Important cultural resource areas

c. Biological resources of importance (e.g., sea bird nesting area, seal haul out)

2. Rate the importance and vulnerability to climate change of the areas identified in the exercise above. Write ratings on the map using the key below.

\begin{tabular}{|l|l|}
\hline Importance & $\begin{array}{l}\text { Climate change } \\
\text { vulnerability }\end{array}$ \\
\hline H - high & 1 - high \\
\hline M - medium & 2 - medium \\
\hline L - low & 3 - low \\
\hline
\end{tabular}

3. Are there any species of special management concern you think would be important to include in a sea-level rise vulnerability assessment?

4. What additional information do you think this group should know about?

Hang up maps and report out to group

Figure 1.2. Workshop exercises were conducted in small groups. Participants were given a large satellite image map of the unit and asked to address questions in the exercise prompt. Results are summarized in the site-specific results sections. 
Table 1.3. Key resources as identified and ranked by the small groups at the Trinidad workshop.

[ - , not applicable; PECO, pelagic cormorant; H1, high importance, high perceived vulnerability; COMU, common murre; H2, high importance, medium perceived vulnerability; Hwy, highway]

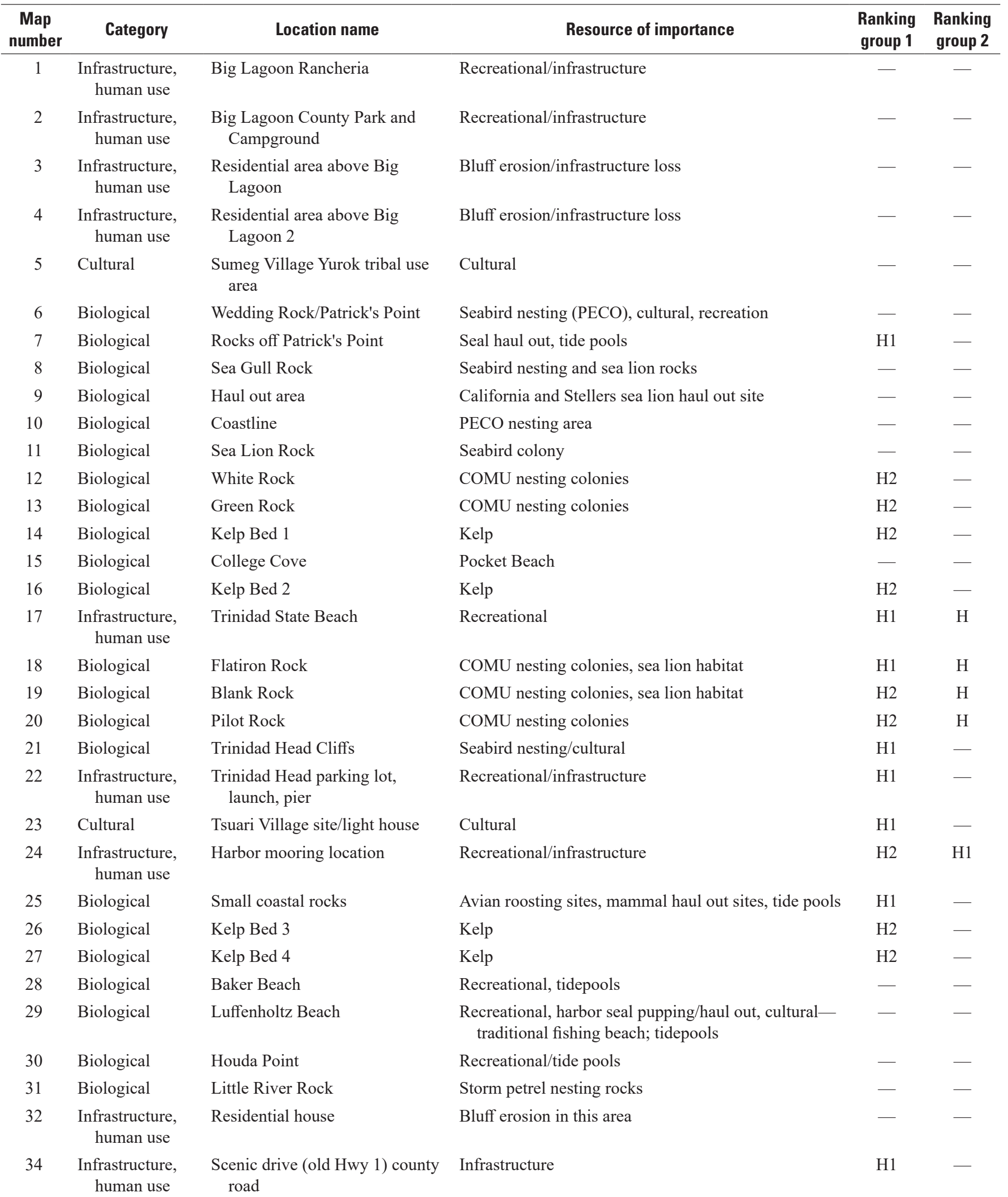


Table 1.3. Key resources as identified and ranked by the small groups at the Trinidad workshop.-Continued

[ - , not applicable; PECO, pelagic cormorant; H1, high importance, high perceived vulnerability; COMU, common murre; H2, high importance, medium perceived vulnerability; Hwy, highway]

\begin{tabular}{|c|c|c|c|c|c|}
\hline $\begin{array}{c}\text { Map } \\
\text { number }\end{array}$ & Category & Location name & Resource of importance & $\begin{array}{c}\text { Ranking } \\
\text { group } 1\end{array}$ & $\begin{array}{c}\text { Ranking } \\
\text { group } 2 \\
\end{array}$ \\
\hline 35 & $\begin{array}{l}\text { Infrastructure, } \\
\text { human use }\end{array}$ & Highway 101 & Infrastructure & - & - \\
\hline 36 & $\begin{array}{l}\text { Infrastructure, } \\
\text { human use }\end{array}$ & Moonstone Beach & Recreational, eroding parking lot area & - & - \\
\hline
\end{tabular}

Table 1.4. Key resources as identified and ranked by the small groups at the Point Arena-Stornetta workshop.

[H1, high importance, high perceived vulnerability; M2, medium importance, medium perceived vulnerability; —, not applicable; H2, high importance, medium perceived vulnerability; M1, medium importance, high perceived vulnerability; SLR, sea-level rise; PECO, pelagic cormorant; BLOY, black oystercatcher]

\begin{tabular}{|c|c|c|c|c|c|}
\hline $\begin{array}{c}\text { Map } \\
\text { number }\end{array}$ & Category & Location name & Resource of importance & $\begin{array}{l}\text { Ranking } \\
\text { group } 1\end{array}$ & $\begin{array}{l}\text { Ranking } \\
\text { group } 2\end{array}$ \\
\hline 1 & $\begin{array}{l}\text { Biological, } \\
\text { cultural }\end{array}$ & $\begin{array}{l}\text { Manchester } \\
\text { Beach }\end{array}$ & $\begin{array}{l}\text { Snowy plover wintering area; dune erosion and king tides; cultural } \\
\text { resources }\end{array}$ & H1 & M2 \\
\hline 2 & Biological & $\begin{array}{l}\text { Freshwater } \\
\text { wetlands }\end{array}$ & Shorebirds, herons, egrets; Saltwater intrusion & - & - \\
\hline 3 & Infrastructure & $\begin{array}{l}\text { access road, } \\
\text { Highway } 1, \\
\text { bridge }\end{array}$ & $\begin{array}{l}\text { Salt water intrusion; vulnerable area mostly impacted by rain but tidal } \\
\text { impacts too; cuts off community; floods due to increased storm } \\
\text { intensity; river bridge creek currently overflows }\end{array}$ & - & - \\
\hline 4 & $\begin{array}{l}\text { Biological, } \\
\text { cultural }\end{array}$ & $\begin{array}{l}\text { Garcia River } \\
\text { estuary mouth }\end{array}$ & $\begin{array}{l}\text { Tidally influenced; salmon habitat; affects the creek; seabirds, sea ducks, } \\
\text { waterfowl }\end{array}$ & $\mathrm{H} 1$ & $\mathrm{H} 1$ \\
\hline 5 & Physical & $\begin{array}{l}\text { Garcia River } \\
\text { mouth beach }\end{array}$ & $\begin{array}{l}\text { Beach erosion; midden site; fishing there since the 1940s; impact from } \\
\text { erosion }\end{array}$ & - & M2 \\
\hline 8 & Biological & $\begin{array}{l}\text { Garcia River } \\
\text { estuary mouth } \\
\text { shoreline }\end{array}$ & $\begin{array}{l}\text { Erosion due to SLR would affect salmon, Steelhead fry, Coho, Chinook; } \\
\text { migratory bird stopover site; cultural areas (midden site) }\end{array}$ & - & $\mathrm{H} 1$ \\
\hline 9 & Biological & $\begin{array}{l}\text { Point Arena } \\
\text { mountain } \\
\text { beaver habitat }\end{array}$ & Habitat at mouth west of Garcia River & $\mathrm{H} 1$ & - \\
\hline 10 & Biological & Brush Creek & Divides the dunes on Manchester Beach from those further North & - & - \\
\hline 11 & Cultural & $\begin{array}{l}\text { Point with } \\
\text { unknown } \\
\text { name }\end{array}$ & Cultural sites in danger from bluff erosion; hiking trail & - & $\mathrm{H} 1$ \\
\hline 15 & Recreational & $\begin{array}{l}\text { Sea Lion Rock } \\
\text { fishing area }\end{array}$ & - & - & - \\
\hline 16 & Biological & $\begin{array}{l}\text { Intertidal rocky } \\
\text { coast }\end{array}$ & Intertidal invertebrates; Harbor seals & M1 & - \\
\hline 17 & Physical & Sinkhole & Sinkhole next to lighthouse; bluff erosion & - & - \\
\hline
\end{tabular}


Table 1.4. Key resources as identified and ranked by the small groups at the Point Arena-Stornetta workshop.-Continued

[H1, high importance, high perceived vulnerability; M2, medium importance, medium perceived vulnerability; —, not applicable; H2, high importance, medium perceived vulnerability; M1, medium importance, high perceived vulnerability; SLR, sea-level rise; PECO, pelagic cormorant; BLOY, black oystercatcher]

\begin{tabular}{|c|c|c|c|c|c|}
\hline $\begin{array}{l}\text { Map } \\
\text { number }\end{array}$ & Category & Location name & Resource of importance & $\begin{array}{l}\text { Ranking } \\
\text { group } 1\end{array}$ & $\begin{array}{l}\text { Ranking } \\
\text { group } 2\end{array}$ \\
\hline 18 & $\begin{array}{l}\text { Infrastructure, } \\
\text { biological, } \\
\text { cultural, } \\
\text { recreational }\end{array}$ & Lighthouse & $\begin{array}{l}\text { Erosion threatening road and lighthouse; major harbor seal haul out; } \\
\text { pelagic cormorant condos, black oystercatcher, migratory birds } \\
\text { (including American white pelican, brown pelican), pigeon guillemot; } \\
8 \text {-20 feet of bluff lost winter 2016-17, fence hanging from cliff, } 20 \\
\text { feet lost at gazebo }\end{array}$ & $\mathrm{H} 1$ & - \\
\hline 21 & $\begin{array}{r}\text { Biological, } \\
\text { physical }\end{array}$ & $\begin{array}{l}\text { Point Arena } \\
\text { Creek }\end{array}$ & Salt water intrusion & - & - \\
\hline 22 & $\begin{array}{l}\text { Biological, } \\
\text { recreational, } \\
\text { infrastructure }\end{array}$ & $\begin{array}{l}\text { Point Arena } \\
\text { Cove }\end{array}$ & Cliff erosion, road flooding & - & $\mathrm{H} 1$ \\
\hline 24 & Infrastructure & $\begin{array}{l}\text { Point Arena pier } \\
\text { lower parking } \\
\text { lot }\end{array}$ & Flood during storms & $\mathrm{H} 1$ & - \\
\hline 25 & Biological & $\begin{array}{l}\text { Miner Hole } \\
\text { Road }\end{array}$ & Mountain beaver habitat; floods and enpondment; floods roadway & - & - \\
\hline 26 & $\begin{array}{l}\text { Infrastructure, } \\
\text { biological }\end{array}$ & Port Road & Road floods; adjacent mountain beaver habitat & - & - \\
\hline 27 & $\begin{array}{l}\text { Biological, } \\
\text { physical }\end{array}$ & Tar seeps & Bluff erosion; tar seeps; sea star habitat below & - & - \\
\hline 31 & Infrastructure & $\begin{array}{l}\text { Wastewater } \\
\text { treatment } \\
\text { plant }\end{array}$ & Has potential to flood; likely will flood in the future & $\mathrm{L} 2$ & - \\
\hline 32 & Cultural & Obsidian site & Very old midden site & $\mathrm{H} 1$ & - \\
\hline 33 & Cultural & Milk barn & Lithic scatter, historic integrity & $\mathrm{H} 1$ & - \\
\hline 34 & Cultural & $\begin{array}{l}\text { Cattle grazing } \\
\text { site }\end{array}$ & $\begin{array}{l}\text { Better area for cattle to graze due to midden (plants more succulent); } \\
\text { freshwater flowing into ocean creates confluence of ecotones }\end{array}$ & M2 & - \\
\hline 35 & Biological & Freshwater area & Bird use & M1 & - \\
\hline 36 & Geological & $\begin{array}{l}\text { Bluff north of } \\
\text { Point Arena } \\
\text { Cove pier }\end{array}$ & $\begin{array}{l}\text { Intertidal; vulnerable to SLR; sea stars used to be present; most southern } \\
\text { section is the most protected with little erosion or nesting, northern } \\
\text { section has more erosion }\end{array}$ & M1 & - \\
\hline 37 & Recreational & $\begin{array}{l}\text { Fishing area } \\
\text { north of } \\
\text { lighthouse }\end{array}$ & - & - & - \\
\hline
\end{tabular}


Table 1.4. Key resources as identified and ranked by the small groups at the Point Arena-Stornetta workshop.-Continued

[H1, high importance, high perceived vulnerability; M2, medium importance, medium perceived vulnerability; —, not applicable; H2, high importance, medium perceived vulnerability; M1, medium importance, high perceived vulnerability; SLR, sea-level rise; PECO, pelagic cormorant; BLOY, black oystercatcher]

\begin{tabular}{|c|c|c|c|c|c|}
\hline $\begin{array}{c}\text { Map } \\
\text { number }\end{array}$ & Category & Location name & Resource of importance & $\begin{array}{c}\text { Ranking } \\
\text { group } 1\end{array}$ & $\begin{array}{l}\text { Ranking } \\
\text { group } 2 \\
\end{array}$ \\
\hline 38 & Recreational & $\begin{array}{l}\text { Garcia River- } \\
\text { fly fishing } \\
\text { area }\end{array}$ & - & - & - \\
\hline 39 & Biological & $\begin{array}{l}\text { Red-legged frog } \\
\text { habitat }\end{array}$ & Freshwater area north of Garcia River & M1 & - \\
\hline 41 & Biological & $\begin{array}{l}\text { Harbor seal haul } \\
\text { out }\end{array}$ & - & - & - \\
\hline 42 & Biological & PECO habitat & Nesting & - & - \\
\hline
\end{tabular}

\section{Results}

\section{Pre-workshop Survey Responses}

The pre-workshop survey, sent to participants before the workshop, included nine questions that covered participant affiliation, perceived climate change drivers affecting the area, effects of climate drivers, resource management priorities, locations of importance, and challenges to incorporating climate change information into decision making. A total of 28 responses were collected.

Responses to the survey questions specified 25 percent of respondents at both sites worked for federal or city agencies. At Point Arena-Stornetta, non-profits accounted for 44 percent of respondent affiliations. In Trinidad, private citizens accounted for 25 percent of respondents. All other categories composed less than 20 percent of respondents (fig. 1.3). At both sites, most respondents belonged to the local stakeholder partnership group, with 69 percent belonging to the Point Arena Gateway Group and 92 percent belonging to the Trinidad Gateway Partnership (fig. 1.4). Individual job descriptions included federal, state, and city agencies, local stakeholder groups, researchers and environmental consultants, resource and archaeology specialists, local business representatives, and private citizens. The anonymous survey respondents were not necessarily the same individuals who attended the workshop.

When asked about the effects of potential climate change drivers, respondents rated all drivers as having medium to medium-high effect (median rank=4.04, fig. 1.5). Survey respondents also rated their concerns regarding public recreation area loss, culturally/historically important area loss, beach erosion, tidal wetland loss, and cliff and rock erosion with medium to medium-high concern (median rank=3.41, fig. 1.6). Only rocky intertidal habitat loss was ranked as a medium-low concern; however, this topic was highlighted at both workshops, particularly in areas where it is important for traditional use (fig. 1.6). When asked to identify potential biological management priorities, including nesting seabirds, intertidal species, marine mammals (for example, pinnipeds and whales), migratory birds, culturally/historically important species, and commercial and recreational fisheries, all categories were considered important by 58 percent or more respondents (fig. 1.7). At both sites, nesting seabirds were considered important by more than 80 percent of respondents. At Point Arena-Stornetta, intertidal species and marine mammals also were identified by more than 80 percent of respondents (fig. 1.7). At Trinidad, commercial and recreational fisheries were identified by more than 80 percent of respondents (fig. 1.7). When asked if any important climate change concerns were not addressed in the survey, respondents at both sites identified infrastructure as well as ecologically important areas outside the CCNM unit boundaries that are vulnerable to sea-level rise and erosion (table 1.1). When asked to identify the greatest challenge to incorporating climate change information into decision making from policy/ leadership, available information, funding, expertise, and time, more than half of respondents at both sites chose policy/ leadership, 53 percent at Point Arena-Stornetta and 75 percent at Trinidad (fig. 1.8). 


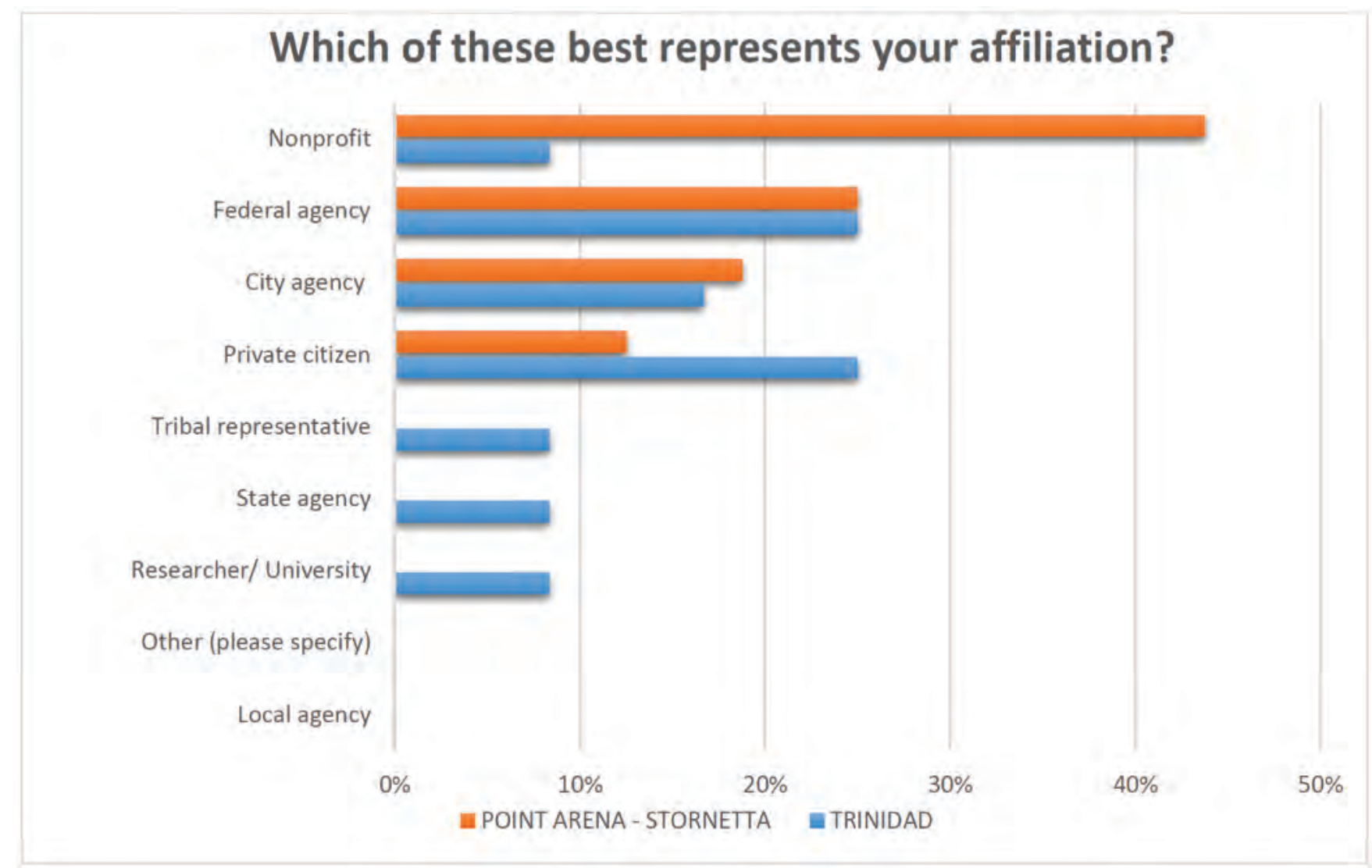

Figure 1.3. Selected categorical affiliations of respondents to the anonymous pre-workshop survey. Survey respondents were not necessarily the same individuals who attended the workshop.

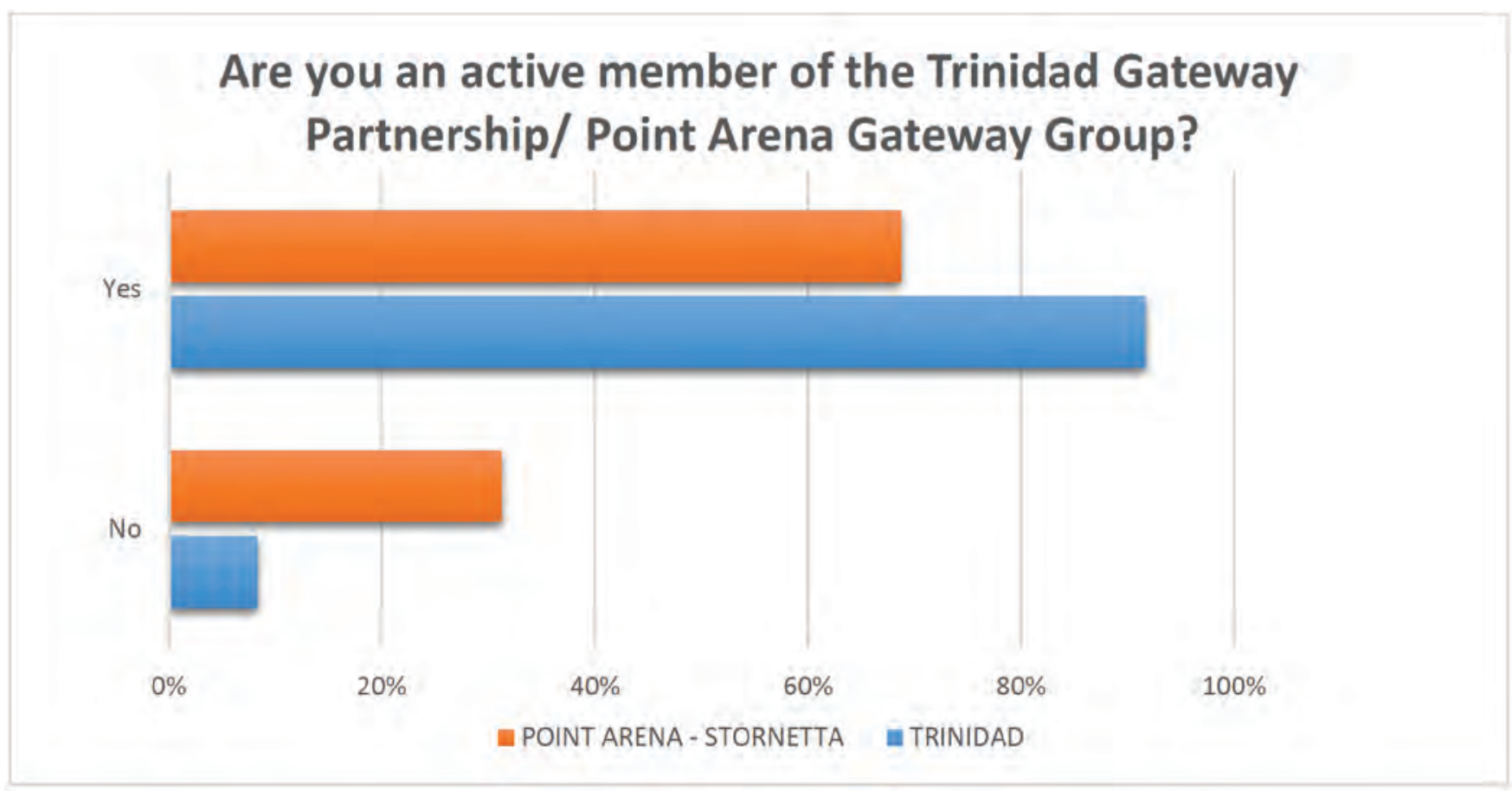

Figure 1.4. The Trinidad Gateway Partnership and Point Arena Gateway Group are the California Coastal National Monument local stakeholder organizations at each site. 


\section{Which of these climate change drivers do you think will have the greatest effect on the Trinidad Head / Point Arena - Stornetta area?}

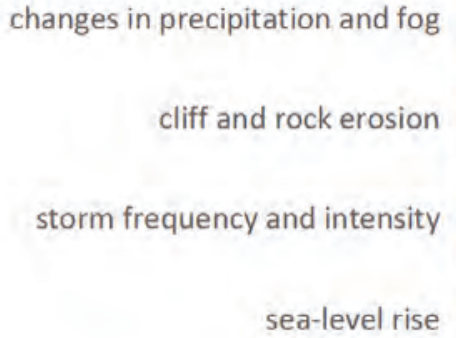

1

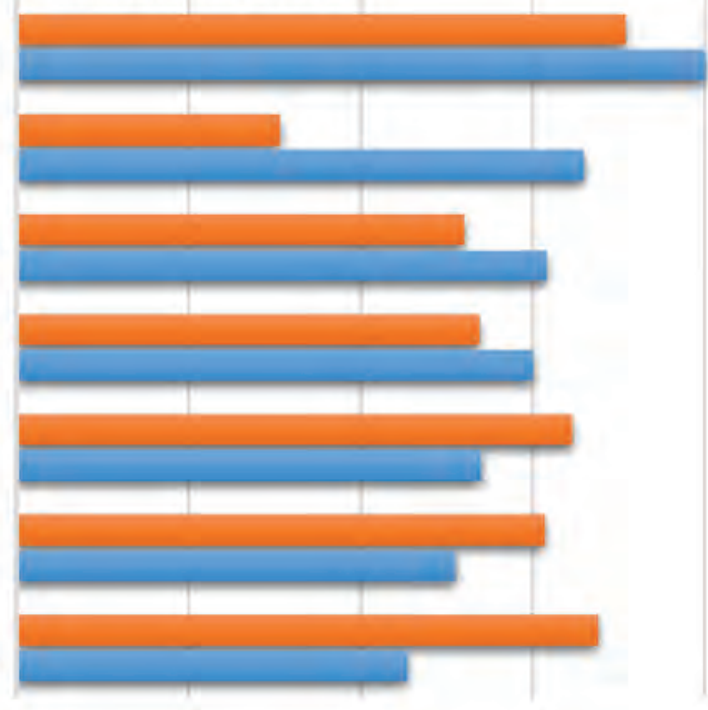
3

(No Effect) Respondent Rank

(Greatest Effect)

Figure 1.5. Respondents were asked to rank climate change drivers, from least effect (1) to greatest effect (7). 


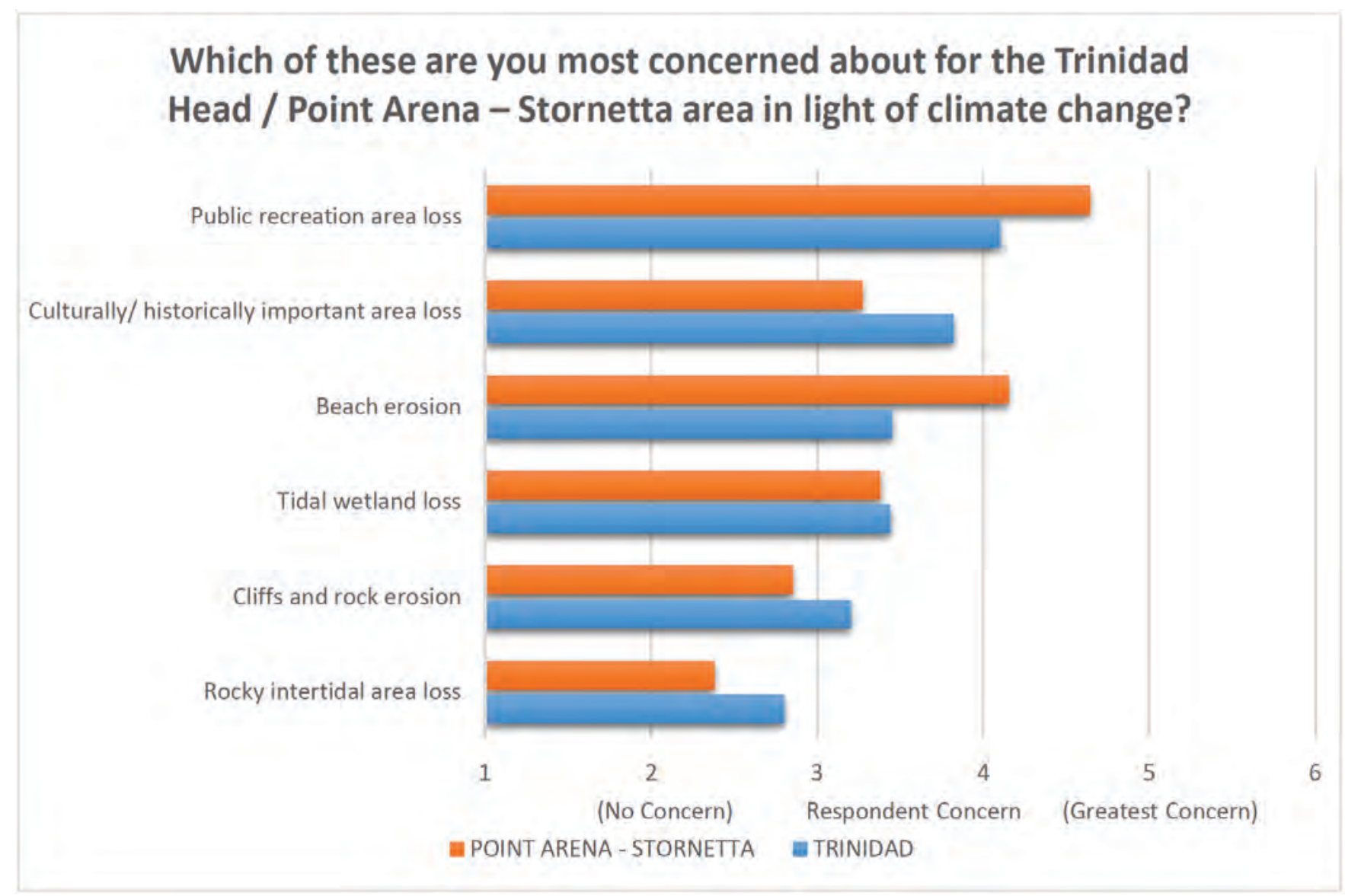

Figure 1.6. Respondents were asked to rank six features (public recreation area loss, culturally/historically important area loss, beach erosion, tidal wetland loss, cliffs and rock erosion, and rocky intertidal area loss) in terms of their concerns about climate change for Point Arena-Stornetta and Trinidad, from least concern (1) to greatest concern (6). 


\section{Which of these biological management priorities are you most concerned about for the Trinidad Head / Point Arena - Stornetta area?}

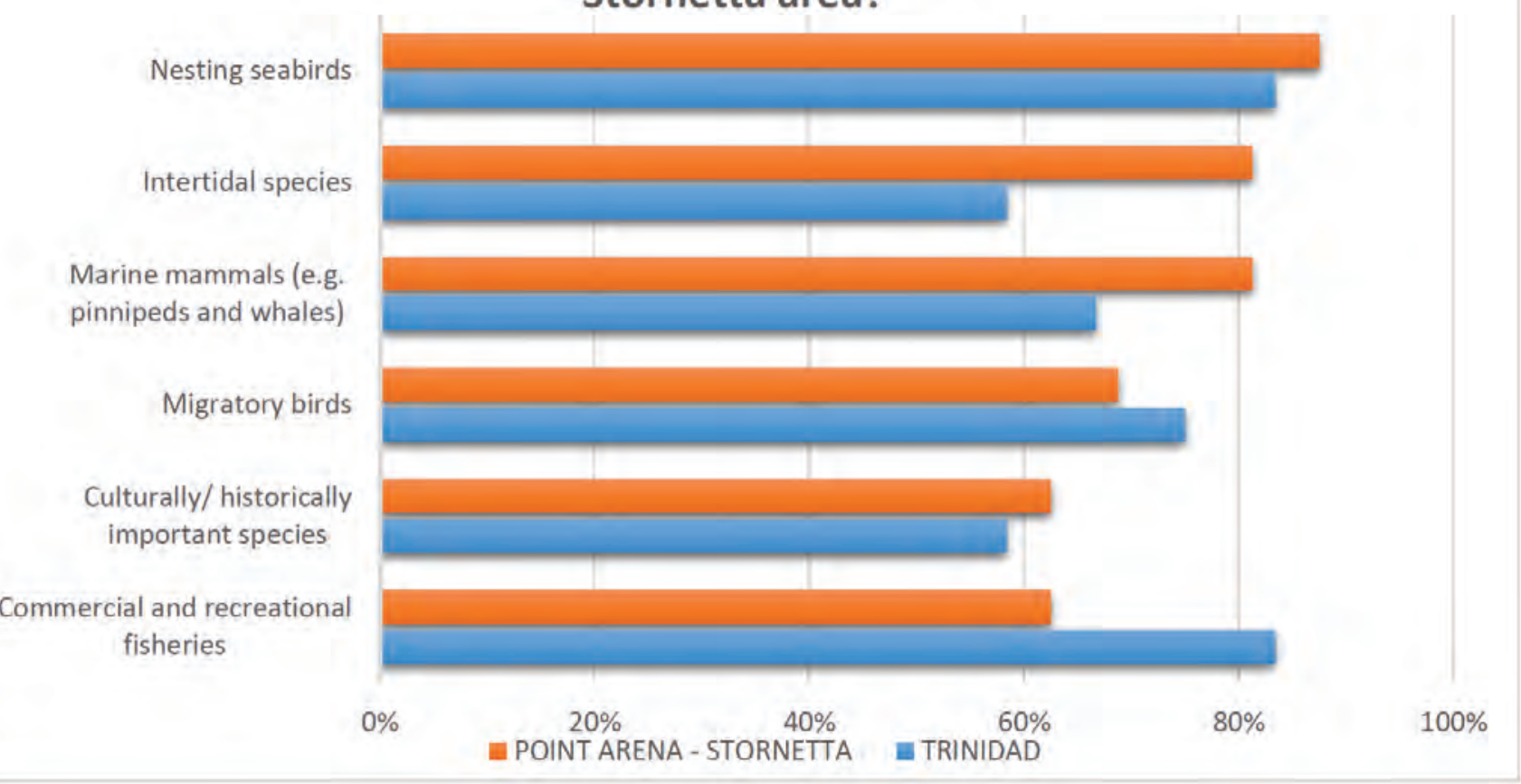

Figure 1.7. Respondents were asked to identify all important potential biological management priorities. Percentage indicates number of respondents at each site who identified a given category.

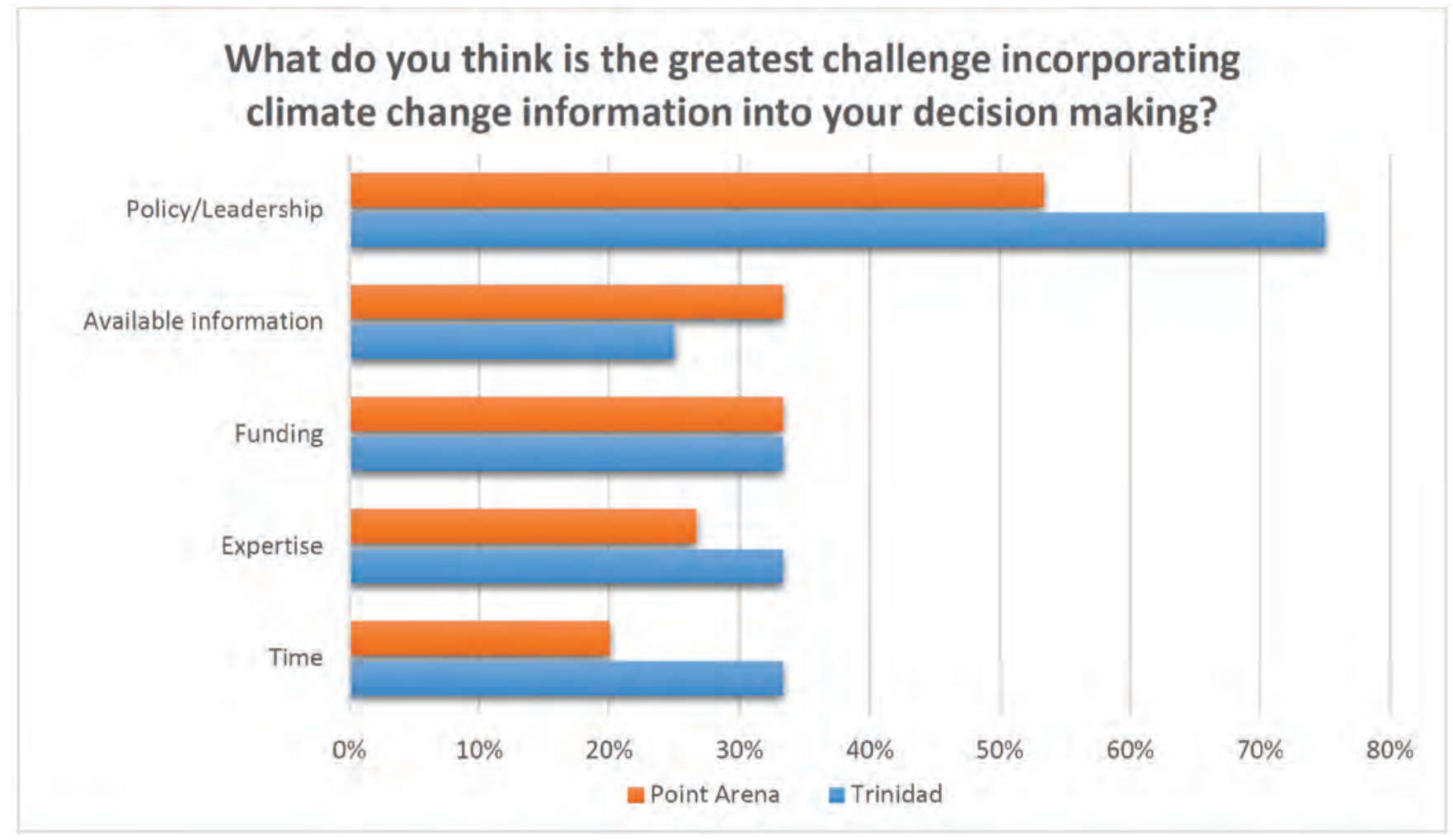

Figure 1.8. Respondents were asked to identify one of the five options representing the greatest challenge to incorporating climate change into their decision making. 


\section{Trinidad Workshop Pre-workshop Survey Responses}

The workshop was on June 06, 2017, from 1:00 to 3:00 p.m. at the Trinidad Town Hall in Trinidad, California. At the workshop, 12 participants took the pre-workshop survey and 16 people attended the workshop, representing 6 different agencies or groups (table 1.1). Ninety-two percent of participants self-identified as belonging to the Trinidad Gateway Partnership. Half of the survey respondents reported they were either private citizens or federal agency employees, 17 percent worked for a city agency, and the remainder worked for a state agency, nonprofit, or identified as a researcher or university affiliate (figs. 1.3, 1.4). The survey respondents are not necessarily the same individuals who attended the workshop. When asked about the effect of climate change drivers, respondents ranked "changes in precipitation and fog" as medium-high (ranked 5, on a scale from 1 to 7). All other drivers were ranked as medium effect (answers ranged between 3.3 and 4.3 on the same scale from 1 to 7), with atmospheric warming ranking the lowest (fig. 1.5). When asked to rank the resources they were concerned about in light of climate change, participants identified public recreation area loss, cultural and historically important area loss, beach erosion, tidal wetland loss, cliff and rock erosion, and rocky intertidal area loss, as a medium concern (2.8-4.1, on a scale from 1 to 6; fig. 1.6). When asked to identify potential biological management priorities, including nesting seabirds, intertidal species, marine mammals (for example, pinnipeds and whales), migratory birds, cultural and historically important species, and commercial and recreational fisheries, all categories were considered important by more than 58 percent of respondents. Commercial and recreational fisheries and nesting seabirds were identified by more than 80 percent of respondents (fig. 1.7). When asked if any important climate change concerns were not addressed in the survey, respondents identified Highway 101 infrastructure and Clam Beach, south of the unit boundary (table 1.2). When asked to choose the greatest challenge to incorporating climate change information into decision making among the categories policy and leadership, available information, funding, expertise, and time, 75 percent of respondents chose policy and leadership (fig. 1.8).

\section{Trinidad Workshop Exercises}

\section{Trinidad Group Mapping Exercise}

Workshop participants engaged in participatory mapping exercises to identify key resources (figs. 1.9-1.11). Participants, comprised of local managers, agency, community, and tribal representatives, identified areas of importance. They were asked to categorize these areas by resource type and rank them by perceived climate change vulnerability. Importance and perceived vulnerability were binned in three groups each, high, medium, and low (fig. 1.2).

In total, 34 resource sites were identified with 22 of those sites categorized as biological resources, 2 as cultural resources, and 10 as physical resources. Nine sites were ranked high importance and high perceived vulnerability, nine sites were ranked as high importance and medium perceived vulnerability, and four sites were ranked high importance and unranked vulnerability. No sites were ranked low importance or low perceived vulnerability (table 1.4). At the request of the BLM archaeologist, cultural sites have been removed from the maps for publication.

\section{Trinidad Workshop Discussion}

At the Trinidad workshop, BLM staff discussed the process of working with the community to incorporate the Trinidad Unit into the CCNM (fig. 1.12). Staff from BLM highlighted the importance of continuing to work with the community in the process of planning for the unit. Workshop participants identified 36 key resources, all of which were considered high importance and high perceived vulnerability (table 1.4). The Trinidad Head area was a focal point of discussion for all priority resource categories, cultural, historic, economic, recreational, and biological.

In the biological resource category, seabirds, marine mammals, and rocky intertidal habitats were considered high importance and high perceived vulnerability to climate change. The BLM conducts surveys of important nesting seabird sites, and several of these rocks house a large percentage of the California common murre nesting population. Specific rocks of importance to avian species were identified, including Pilot Rock, Blank Rock, Green Rock, White Rock, and Flat Iron Rock. Flat Iron Rock was considered potentially the most vulnerable, being flat and low relative to current sea level. Green, Blank, and Pilot rock were considered particularly important for common murres and California sea lions. North of the CCNM, a western snowy plover nesting area was recorded near Big Lagoon. Patrick's Point and Palmer's Point also were highlighted as nesting seabird and pinniped haul-out areas. Participants noted wintering species of importance that utilize habitat in the Trinidad Unit include brown pelicans and wandering tattlers. Harbor seals, California sea lions, Steller sea lions, and elephant seals haul out along the rocks, cliff edges, and pocket beaches. Rocky intertidal habitats of importance were noted at the Baker and Luffenholtz tidepools (figs. 1.9, 1.13) as well as the intertidal area near Patrick's and Palmer's Points. South of Trinidad Head, there is kelp habitat designated as an Area of Special Biological Significance (ASBS) that participants noted as important and vulnerable. 


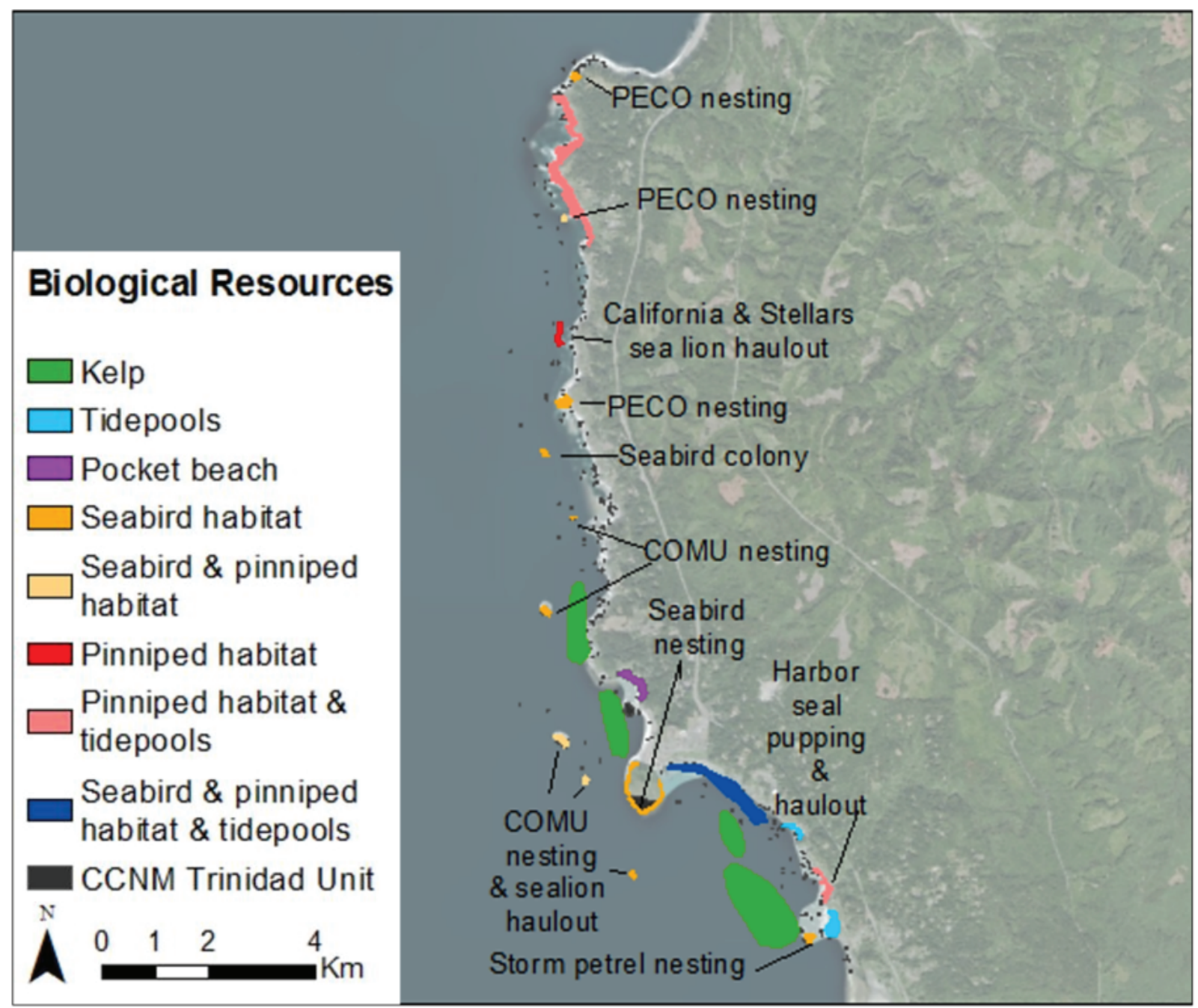

Map image is the intellectual property of Esri and is used herin under license. Copyright 2020 Esri and its licensors. All rights reserved.

Figure 1.9. Biological resources identified by workshop participants during interactive exercises. $\mathrm{COMU}=\mathrm{common}$ murre; $\mathrm{PECO}=$ pelagic cormorant.

A Cher-Ae Heights tribal representative and a BLM archaeologist were present at the workshop, though no local tribal members attended. Several cultural sites of importance were identified as vulnerable to sea-level rise, including Old Home Beach, south and adjacent to Trinidad Head. Several particular offshore rocks were identified as having significant cultural importance. The Big Lagoon community and school, north of the unit, also were identified as important and potentially vulnerable to sea-level rise impacts.

Infrastructure was a large concern in terms of access, recreation, and resource preservation. The community placed cultural value on the Trinidad Head Lighthouse. Where Highway 101 runs near the coast, there is high concern about cliff erosion for coastal communities and visitor access to areas. Areas that could have access affected by highway erosion were noted at Patrick's Point, where the road has already been observed experiencing cliff erosion, and Trinidad Head. The low-lying infrastructure around the Trinidad Pier, which includes the parking area, pier, and harbor, were ranked of high importance and high perceived sea-level rise vulnerability. Both lighthouses were perceived as highly vulnerable to cliff erosion. Additional erosion was reported north of Trinidad Head at the state park and at Agate Beach, north of the unit. Moonstone Beach, south of the unit, also was reported to be currently experiencing erosion in the access points. 

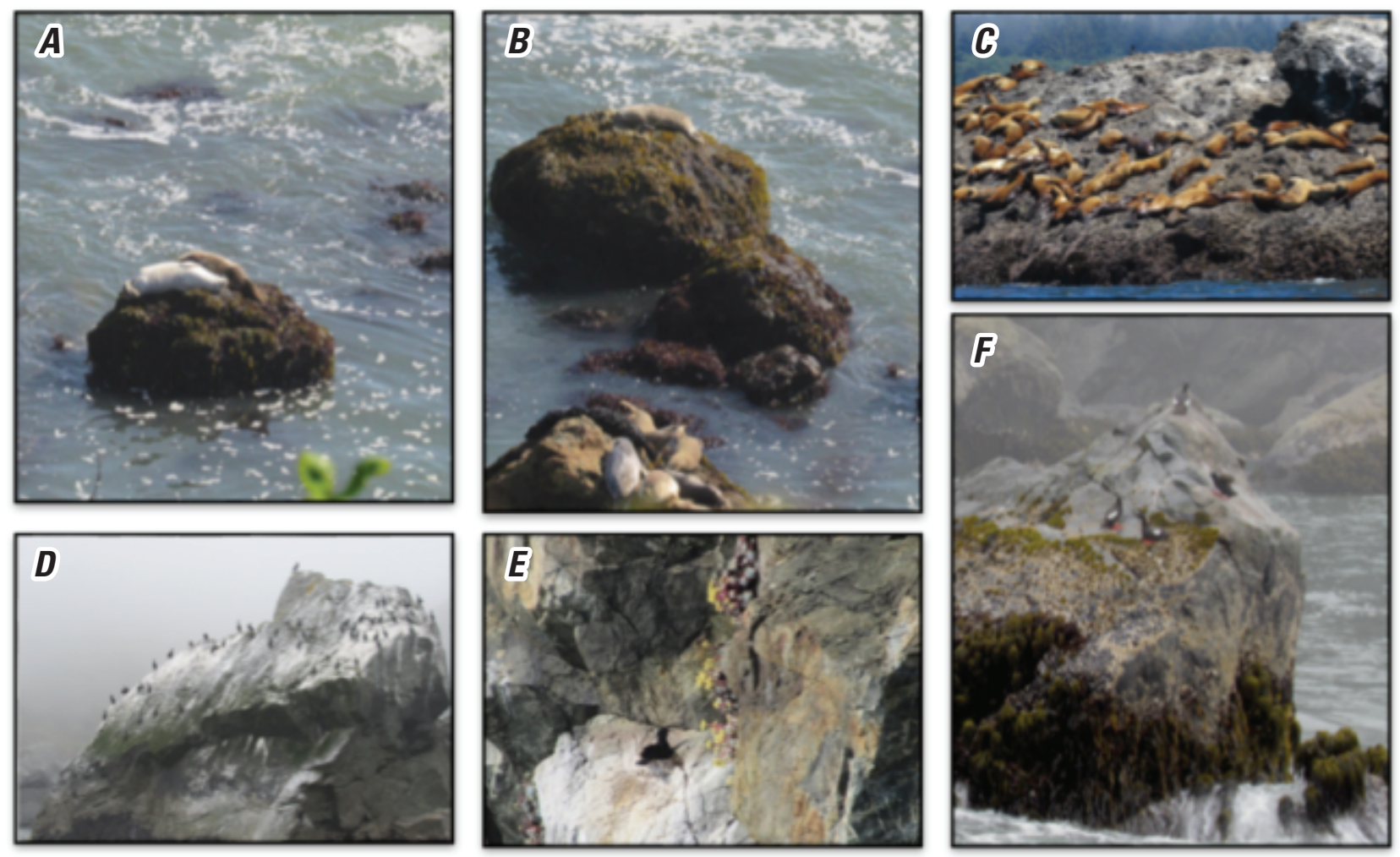

Figure 1.10. Examples of biological resources identified: $A$, harbor seals on small rocks near the shore below the cliff road; $B$, California sea lions on Turtle Rocks; $C$, California sea lions haul-out site; $D$, cormorants on Cormorant Rock; $E$, cormorant nesting on Wedding Rock; and $F$, pigeon guillemots roosting. 

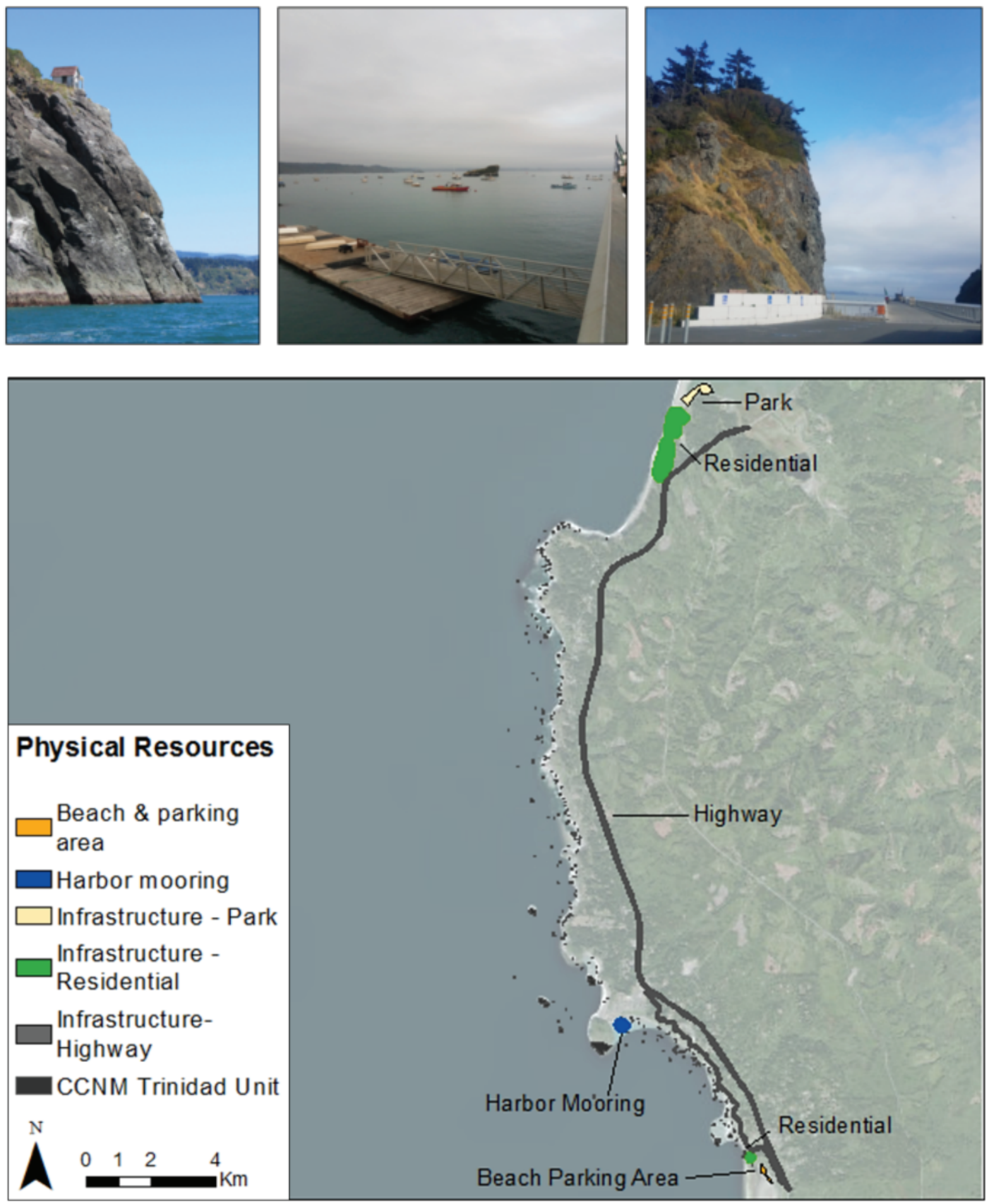

Map image is the intellectual property of Esri and is used herin under license. Copyright 2020 Esri and its licensors. All rights reserved.

Figure 1.11. Physical resources map and photographs of the Historic Bell House, Trinidad mooring harbor, and the Trinidad harbor parking lot access area. 

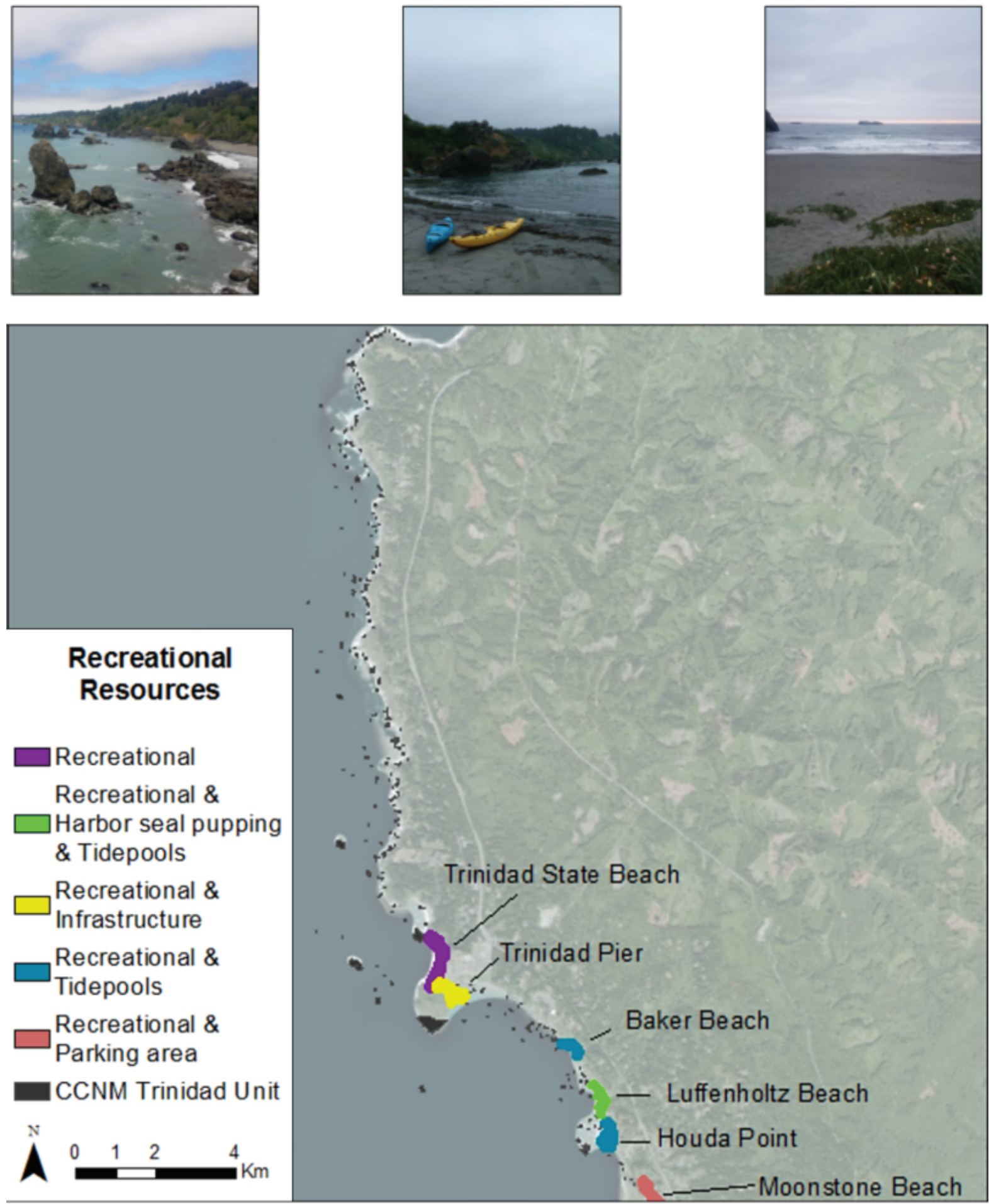

Map image is the intellectual property of Esri and is used herin under license. Copyright 2020 Esri and its licensors. All rights reserved.

Figure 1.12. Recreational resources map and photographs of Luffenholtz beach, Trinidad harbor kayak access, and sunset on Trinidad beach. Photograph by Karen Backe, June 2017. 


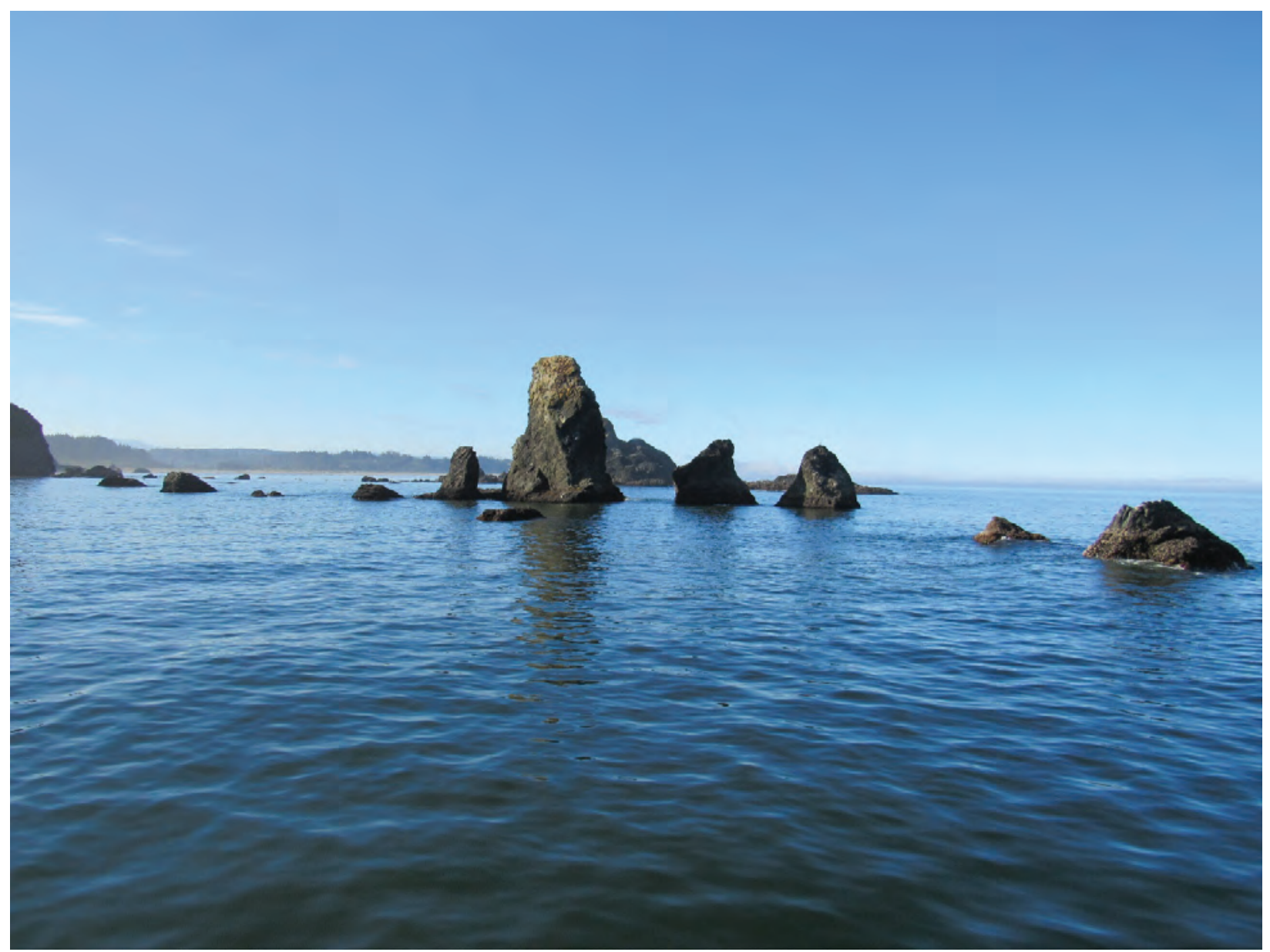

Figure 1.13. Photograph of Half Moon Rock within the Trinidad Unit, July 2017. Photograph by Karen Backe, June 2017. 


\section{Point Arena-Stornetta Workshop Pre-workshop Survey Responses}

The workshop was on October 19, 2017, from 3:00 to 5:00 p.m., at the Point Arena City Hall in Point Arena, California. At Point Arena-Stornetta, 16 participants took the pre-workshop survey and 22 people attended the workshop, representing 10 different agencies or groups (fig. 1.14; table 1.1). Sixty-nine percent self-identified as belonging to the Point Arena Gateway Group. When asked to identify their affiliation, 44 percent of respondents specified they work for a nonprofit, 25 percent for a federal agency, 19 percent for a city agency, and the rest were private citizens (figs. 1.3, 1.4). When asked to identify their job description, seven were representatives of a local stakeholder group, two were city employees, four were ecological scientists or resource specialists, and three were private citizens (table 1.1). It should be noted that the survey respondents were not necessarily the same individuals who attended the workshop.

When asked about the effect of climate change drivers, respondents ranked most concerns as medium concern (2.5-4.5, on a scale from 1 to 7). Like the responses in Trinidad, "changes in precipitation and fog" was ranked the highest concern (4.5, on a scale from 1 to 7 ), whereas cliff and rock erosion ranked the lowest (2.5, on a scale from 1 to 7; fig. 1.6). This low concern regarding erosion contrasts with the workshop discussion and exercise results, where cliff and rock erosion was the highest concern. When asked to rank their concerns in light of climate change, public recreation area loss and beach erosion were of greatest concern (4.6, on a scale from 1 to 6 ), whereas rocky intertidal area loss was rated as the least concerning (2.4, on a scale from 1 to 6 ; fig. 1.6). This also is in contrast to the workshop, where rocky intertidal habitats were a priority concern for attendees. When asked to identify biological management priorities, including nesting seabirds, intertidal species, marine mammals (for example, pinnipeds and whales), migratory birds, cultural and historically important species, and commercial and recreational fisheries, all categories were selected as important by 63 percent of respondents. Nesting seabirds, intertidal species, and marine mammals were identified as priorities by more than 80 percent of respondents (fig. 1.7). When asked if any important climate change concerns were not addressed in the survey, respondents identified changes in weather, water and climate patterns, drought and fire changes, increasing erosion, impacts on vegetation, and infrastructure (table 1.2). Lastly, when asked to identify the greatest challenge to incorporating climate change information into decision making, given the choice among policy and leadership, available information, funding, expertise, and time, 53 percent of respondents chose policy and leadership (fig. 1.8).

\section{Point Arena-Stornetta Workshop Exercises}

\section{Point Arena-Stornetta Group Mapping Exercises}

Workshop participants engaged in participatory mapping exercises to identify key resources (figs. 1.15, 1.16). Participants, comprised of local managers, agency, community, and tribal representatives, identified areas of importance. They were asked to categorize these areas by resource type and rank them by perceived climate change vulnerability. Importance and perceived vulnerability were binned in three groups each, high, medium, and low (fig. 1.2).

In total, 45 resource sites were identified with 10 sites classified in multiple resource categories (table 1.4). Overall, 25 sites were categorized as biological resources, 9 cultural resources, 16 physical resources (including geological and infrastructure), and 6 recreational resources. Of those sites, 18 were ranked high importance and high perceived vulnerability, 2 sites were ranked as high importance and medium perceived vulnerability, and one site was ranked high importance and unranked vulnerability. Five sites were ranked as medium importance and high perceived vulnerability, two sites were ranked medium importance and low perceived vulnerability, and one site was ranked low importance and medium perceived vulnerability (table 1.4).

\section{Point Arena-Stornetta Group Priorities, Resource Identification, Classification, and Ranking}

\section{Point Arena-Stornetta Workshop Discussion}

Bureau of Land Management staff discussed the process to incorporate the Point Arena-Stornetta Unit into the CNNM, and the Ukiah field office and the local community worked together to bring the Point Arena-Stornetta lands into the monument (fig. 1.17). The community expressed that coastal bluffs and estuaries, and local threatened and endangered species warranted a resource management plan for the national monument to protect and foster appreciation for the unique coastal resources. Bureau of Land Management staff highlighted the importance of working with the tribes and other local community members and stakeholders in the process of planning for the unit. Workshop participants identified 45 key resources, notably including the Point Arena Lighthouse and Sea Lion Rock in multiple resource categories (table 1.4; fig. 1.18). Both of these sites were perceived as highly vulnerability to sea level rise and erosion. 


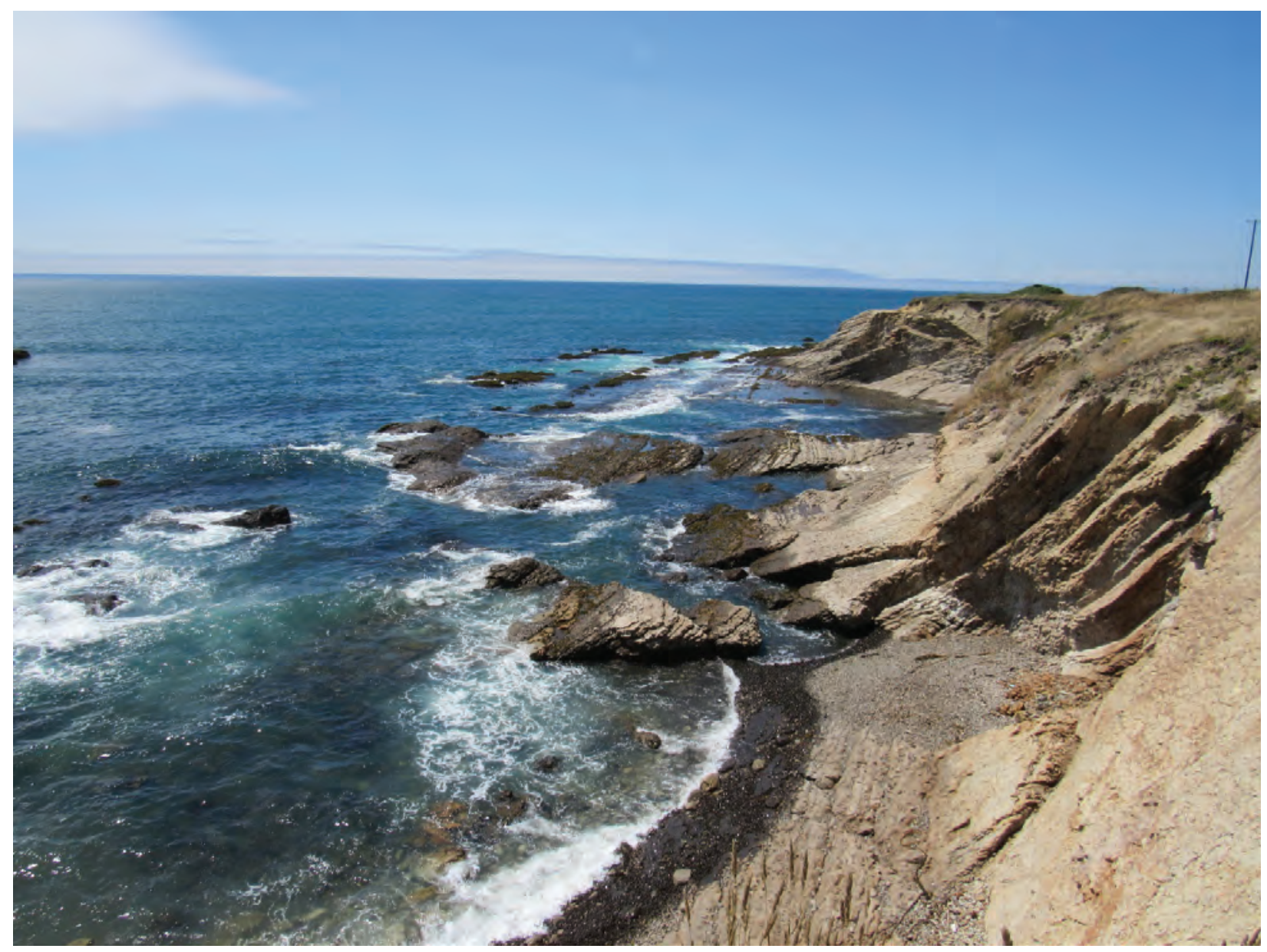

Figure 1.14. Cliff, beach, and rocky intertidal habitat on the Point Arena-Stornetta Unit coastline. Photograph by Karen Backe, June 2017.

In the biological category, seabird and pinniped habitat areas were considered important, along with the ecosystem around the Garcia River and estuary that provides habitat for salmonids, red-legged frogs, and the Point Arena mountain beaver. North of the estuary, snowy plover wintering habitat was noted on Manchester beach. Sensitive coastal vegetation was recorded along the length of the unit. The Point Arena lighthouse cliffs were described as a major habitat area for pelagic cormorants, black oystercatchers, pigeon guillemots, and American white and brown pelicans. The bases of these cliffs were noted as important haul-out areas for pinnipeds, including Pacific harbor seals and California sea lions. South of the unit, Haven's Neck and Fish Rocks also were noted as important haul-out areas for sea lions and juvenile elephant seals and important nesting areas for Brandt's cormorants, double crested cormorants, and common murres. Recreational fishing was noted as potentially threatened by climate change, particularly at Arena Cove, north of the lighthouse at the Garcia River, and around Sea Lion Rock.
A representative of the Pomo tribe attended the workshop and gave a presentation. He spoke about the value of giving a voice to the land, preserving cultural resources for future generations, and maintaining access to these resources with climate change. He also discussed the tribal understanding of connections to climate change and the importance of resource use reduction. To this end, the tribe is working with BLM and local agencies on stewardship projects. He highlighted several areas of importance to preserve, including ancestral and cultural sites that are susceptible to erosion and sea level rise. These sites included Sea Lion Rock, a cultural site that still offers access at low tide and for traditional use, which is particularly susceptible to reduced access with sea level rise. Other important and historic cultural sites noted by workshop attendees included the Milk Barn, an area of lithic scatter, a midden and cattle grazing site on the cliffs, the obsidian site, and a shellfish-heavy anthropogenic midden site at the mouth of the Garcia River. These sites were considered particularly susceptible to erosion. At the request of the BLM archaeologist, cultural sites have been removed from the maps for publication (figs. 1.15, 1.16). 

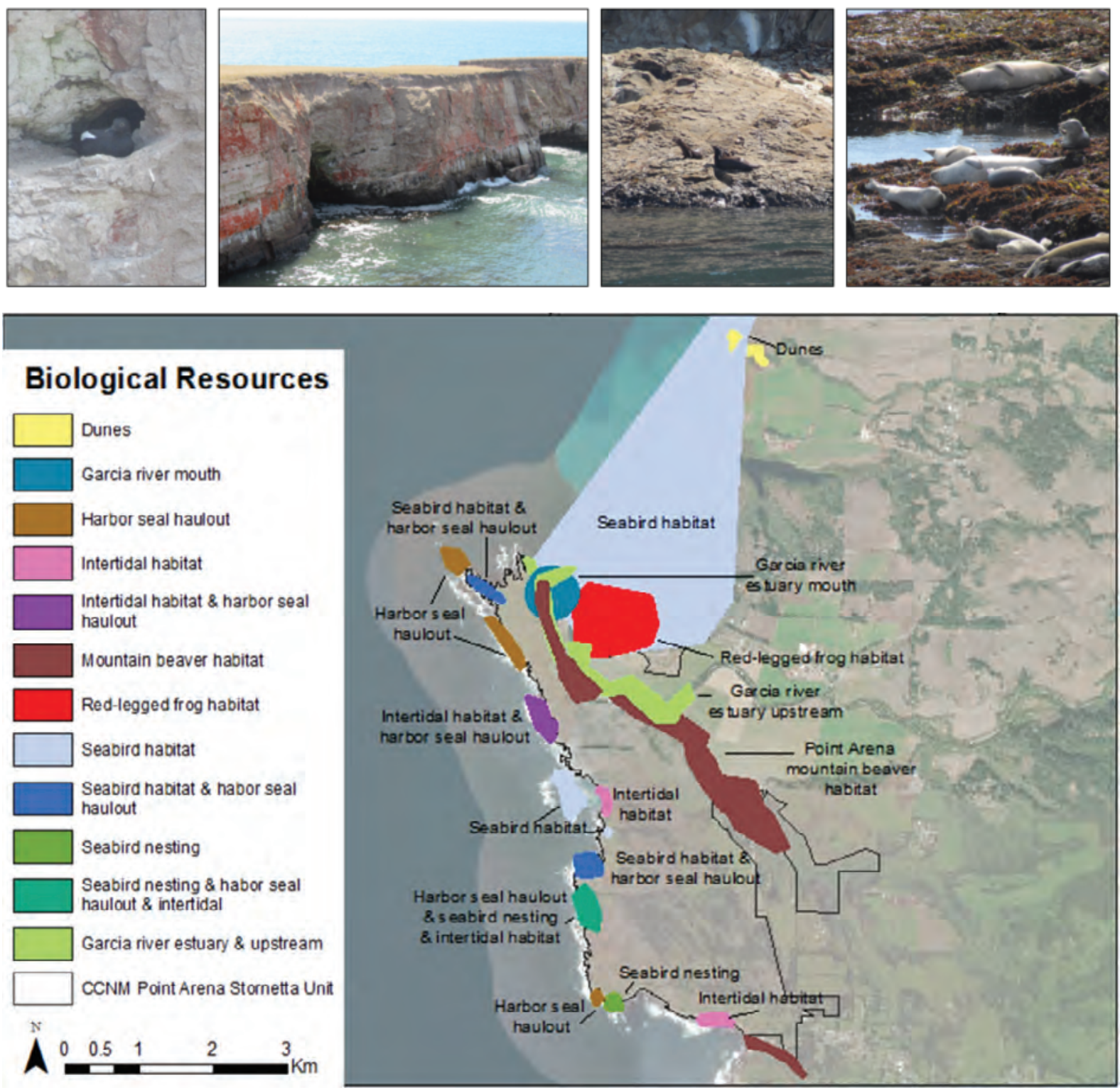

Map image is the intellectual property of Esri and is used herin under license. Copyright 2020 Esri and its licensors. All rights reserved.

Figure 1.15. Biological resources map and photographs of a nesting pigeon guillemot at Sea Lion Rock, pigeon guillemot habitat on Sea Lion Rock, a female harbor seal and two pups hauled out below the lighthouse road, and marine adapted river otters at the base of Sea Lion Rock. Photograph by Karen Backe, June 2017.

Due to the significant cliff erosion, coastal infrastructure was of concern, both for safety and community access. The road leading to the lighthouse, hiking trails on the coastal bluffs, the river bridge, pier parking lot, and water treatment plant were all ranked as high erosion risk. Workshop participants detailed erosion at the Point Arena Lighthouse cliff, where between 8 and 20 feet ( $\mathrm{ft}$ ) of cliff near the gazebo was lost during the 2016-17 winter. The bluff north of the
Arena Cove pier also has been observed eroding, though at a slower rate. Participants noted that those bluffs provide important intertidal habitat, which may be experiencing the effects of sea level rise already. These impacts were marked by the absence of sea stars that used to be present and consistently observed. More erosion has been observed in the northern areas than the southern areas. 

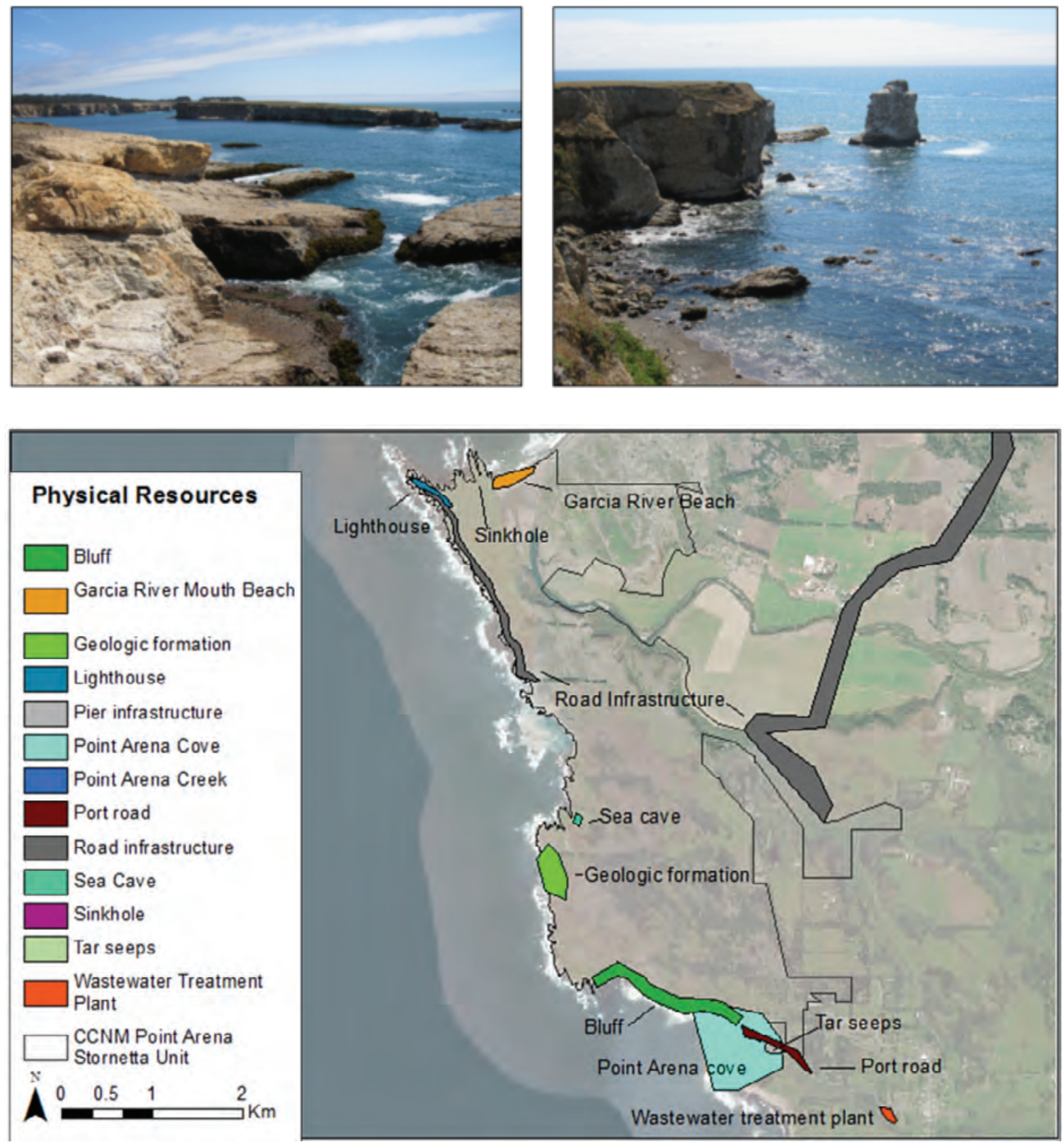

Map image is the intellectual property of Esri and is used herin under license. Copyright 2020 Esri and its licensors. All rights reserved.

Figure 1.16. Physical resources map and photographs of intertidal rocks (left) and sea stacks near Sea Lion Rock (right). Photograph by Karen Backe, June 2017. 

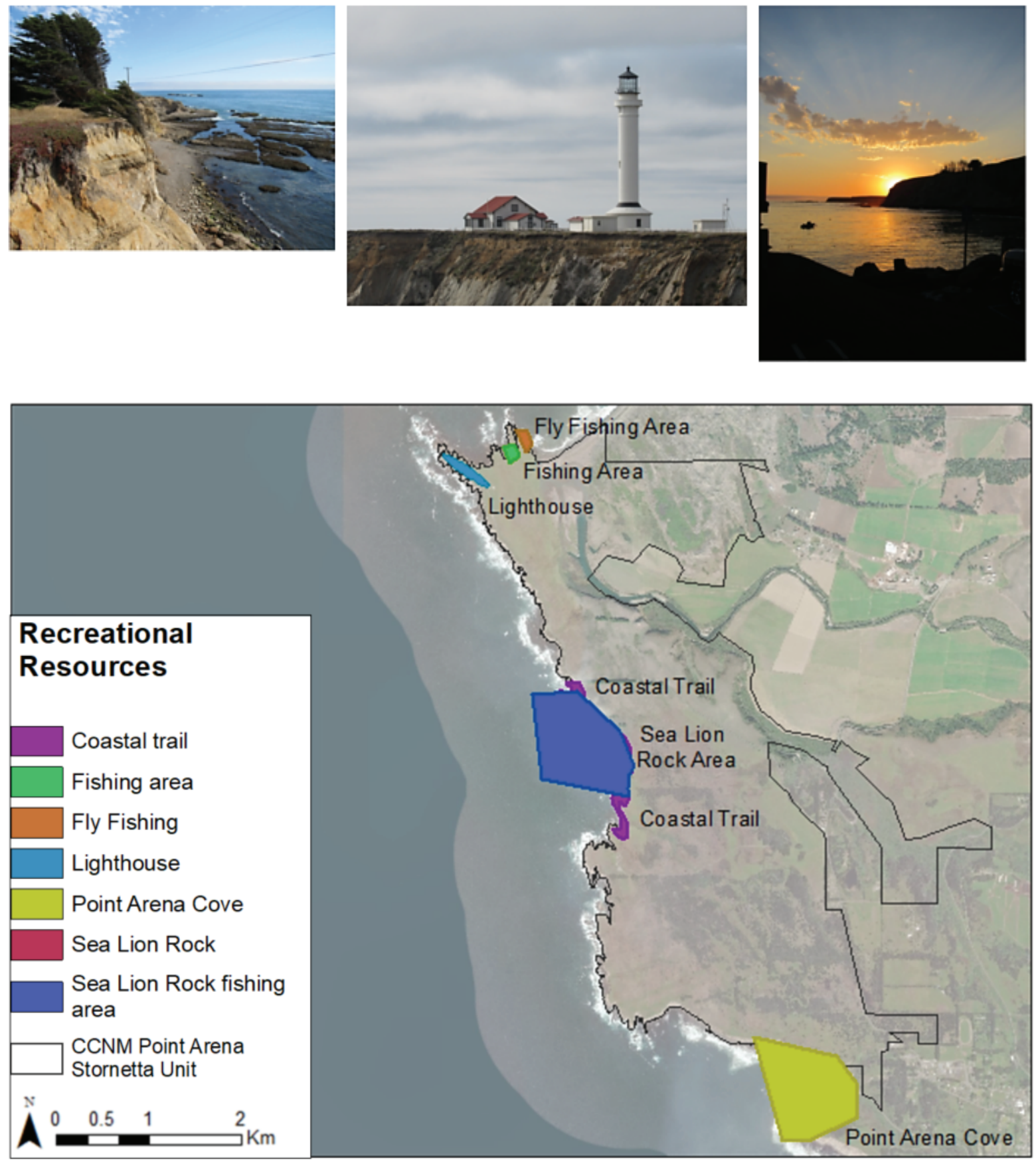

Map image is the intellectual property of Esri and is used herin under license. Copyright 2020 Esri and its licensors. All rights reserved.

Figure 1.17. Recreational resources and photographs of the lighthouse, cliff trail, and the Point Arena Cove. Photograph by Karen Backe, June 2017. 


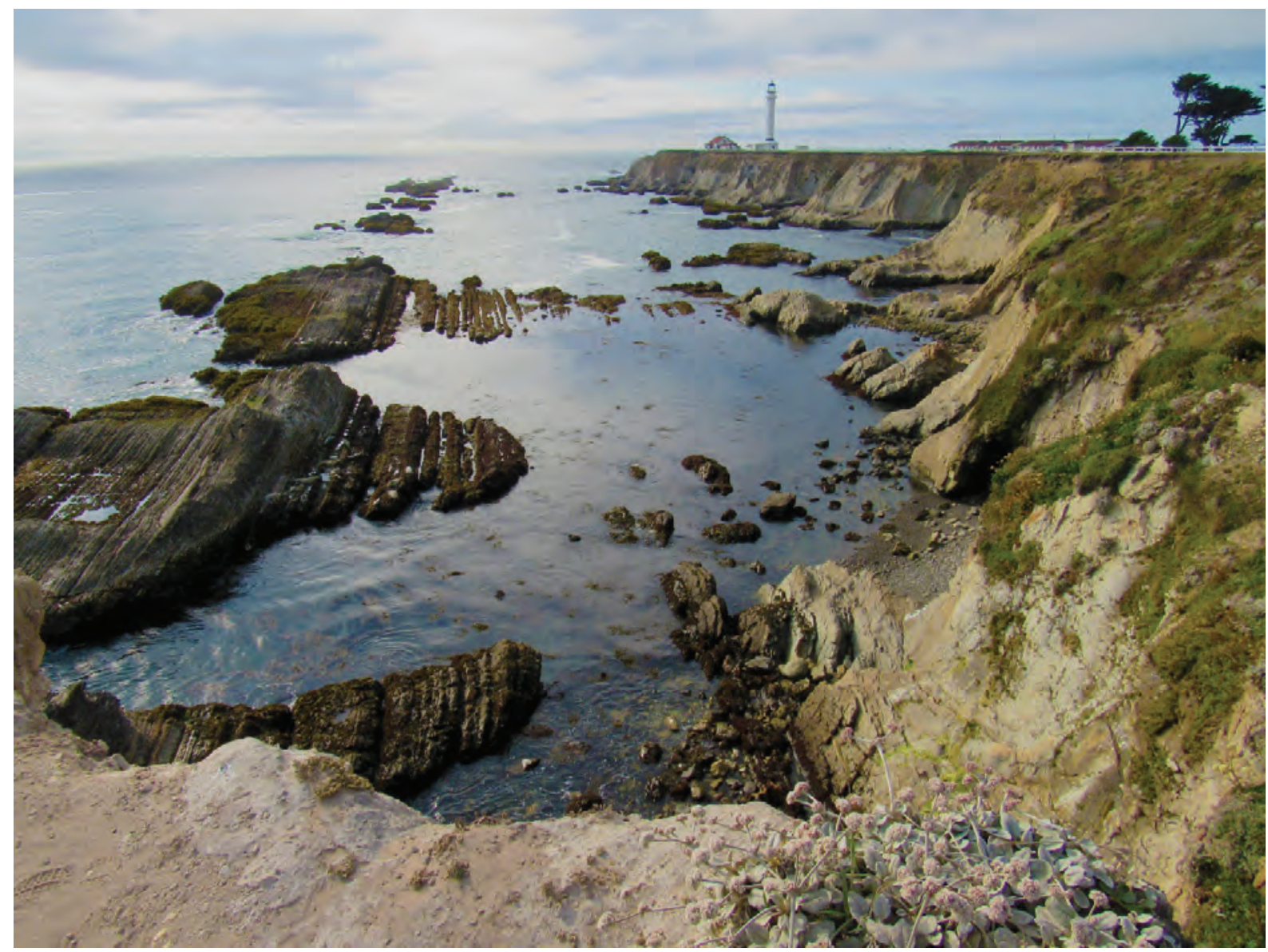

Figure 1.18. Cliff and rocky habitat by the Point Arena Lighthouse. Photograph by Karen Backe, June 2017.

\section{Summary Discussion}

There were marked similarities in the concerns and priorities resulting from the workshops at both sites, though the landscapes are noticeably different. These landscape differences were reflected in the main concerns at each workshop. Point Arena-Stornetta contains significantly more coastal bluff features, whereas Trinidad has a far greater number of small and large offshore rocks. There was significantly more discussion and concern in Point Arena-Stornetta about bluff erosion. In Trinidad, there was greater concern about offshore rocks, particularly those rocks providing important seabird habitat.

Workshop participants at both units highlighted the value of habitat for important and sensitive local species, including seabirds, marine mammals, and the rocky intertidal. Participants at both workshops noted ecologically contiguous areas of concern for these species to the north and south of the California Coastal National Monument (CCNM) unit boundaries. Preserving tribal, cultural, and historic sites and access to these sites was a key concern at both sites. Vulnerability was largely described as sea level rise impeding off-shore rock site access and cliff erosion affecting coastal sites. Cliff erosion was a large infrastructure concern, with its impact on coastal communities and coast road access. Sea level rise was a large concern with its impact on low-lying areas and habitats at both sites.

Although both sites have offshore rocks and coastal cliffs, Point Arena-Stornetta typifies coastal cliffs in the CCNM, and Trinidad typifies offshore rocks in the CCNM. These representative sites are vulnerable to the same drivers of climate change. Workshop participants at both sites shared a high level of concern about the effects of climate change on their coastal resources. These workshops advanced the goal of the Bureau of Land Management to include the community and their concerns and priorities in planning for climate change affecting the CCNM. 


\section{References Cited}

Asch, R.G., 2015, Climate change and decadal shifts in the phenology of larval fishes in the California current ecosystem: Proceedings of the National Academy of Sciences of the United States of America, 9 p., https://doi.org/10.1073/pnas.1421946112.

Cloern, J.E., Abreu, P.C., Carstensen, J., Chauvaud, L., Elmgren, R., Grall, J., Greening, H., Johansson, J.O.R., Kahru, M., Sherwood, E.T., Xu, J., and Yin, K., 2016, Human activities and climate variability drive fast-paced change across the world's estuarine-coastal ecosystems: Global Change Biology, v. 22, no. 2, p. 513-529, https://doi.org/10.1111/gcb.13059.

Griggs, G., Árvai, J., Cayan, D., DeConto, R., Fox, J., Fricker, H.A., Kopp, R.E., Tebaldi, C., and Whiteman, E.A., 2017, Rising seas in California-An update on sea-level rise science: California Ocean Protection Council Science Advisory Team Working Group, California Ocean Science Trust, April 2017.
Mitchell, S.B., Jennerjahn, T.C., Vizzini, S., and Zhang, W., 2015, Changes to processes in estuaries and coastal waters due to intense multiple pressures-An introduction and synthesis, in Mitchell, S.B., Jennerjahn, T.C., Vizzini, S., and Zhang, W., eds., Changes to processes in estuaries and coastal waters due to intense multiple pressures: Estuarine, Coastal and Shelf Science, v. 156, p. 1-6, https://doi.org/10.1016/j.ecss.2014.12.027.

National Marine Fisheries Service (NMFS), 1997, Investigation of scientific information on the impacts of California sea lions and Pacific harbor seals on salmonids and on the coastal ecosystems of Washington, Oregon, and California: U.S. Department of Commerce, National Oceanic and Atmospheric Administration Technical Memorandum NMFS-NWFSC-28, $172 \mathrm{p}$.

Proclamation 7264-Establishment of the California Coastal National Monument," January 11, 2000.

Proclamation 9089-Boundary Enlargement of the California Coastal National Monument, March 11, 2014.

Proclamation 9563-Boundary Enlargement of the California Coastal National Monument, January 12, 2017.

Vitousek, S., Barnard, P.L., Fletcher, C.H., Frazer, N., Erikson, L., and Storlazzi, C.D., 2017, Doubling of coastal flooding frequency within decades due to sea-level rise: Scientific Reports, v. 7, 9 p., https://doi.org/10.1038/s41598-017-01362-7. 
For more information concerning the research in this report, contact the

Karen M. Thorne, PhD

USGS Western Ecological Research Center

Davis Field Station

One Shields Avenue

University of California

Davis, CA 95616

(916) 502-2996

Email: Kthorne@usgs.gov

https://www.usgs.gov/centers/werc

Publishing support provided by the U.S. Geological Survey Science Publishing Network, Sacramento Publishing Service Center 
